\title{
DANI EJZENBERG
}

\begin{abstract}
Avaliação das concentrações das interleucinas 1-ß e 6 e da proteína amilóide $A$, no líquido peritoneal e no soro de pacientes com endometriose pélvica
\end{abstract}

Dissertação apresentada ao Departamento de Ginecologia e Obstetrícia da Faculdade de Medicina da Universidade de São Paulo para a obtenção do título de Mestre em Ciências

Área de concentração: Ginecologia e Obstetrícia

Orientador: Prof. Dr. Maurício Simões Abrão

São Paulo

2007 


\title{
DANI EJZENBERG
}

\begin{abstract}
Avaliação das concentrações das interleucinas 1-ß e 6 e da proteína amilóide $A$, no líquido peritoneal e no soro de pacientes com endometriose pélvica
\end{abstract}

Dissertação apresentada ao Departamento de Ginecologia e Obstetrícia da Faculdade de Medicina da Universidade de São Paulo para a obtenção do título de Mestre em Ciências

Área de concentração: Ginecologia e Obstetrícia

Orientador: Prof. Dr. Maurício Simões Abrão

São Paulo

2007 


\section{DEDICATÓRIA}

Dedico esta dissertação aos meus pais, Vânia e Bernardo, que foram nestes trinta anos incomparáveis mestres, tutores, parceiros e amigos. São exemplos como pais, profissionais e seres humanos e foram parte importante de todas as vitórias alcançadas. 


\section{AGRADECIMENTO ESPECIAL}

Ao Prof. Maurício Simões Abrão que estruturou o presente estudo dentro de sua área de investigação, e orientou com atenção, disponibilidade e didatismo. 


\section{AGRADECIMENTOS}

À Fundação de Amparo à Pesquisa do Estado de São Paulo pela contribuição financeira que viabilizou esta pesquisa.

À minha esposa Daniela pela compreensão, incentivo e colaboração na concretização deste trabalho.

Ao Dr. Ricardo de Oliveira pela orientação metodológica e experiência compartilhada.

À minha irmã Priscila e meu cunhado Fábio pelo apoio e estímulo.

Aos meus avós, Rosa Guinsburg, Helena e Izrael Ejzenberg (in memoriam) pelo carinho, apoio e estímulo ao longo de toda a vida.

À bióloga Anna Cristina pelo cuidado e dedicação no processamento das amostras.

Ao Dr. Cristóvão Pitangueira pela supervisão no processamento das amostras.

Às pacientes participantes que permitiram a realização deste estudo.

Aos Drs. Walter Pinheiro, Paulo Serafini, Elvio Tognotti, Carlos Izzo e Pedro Monteleone, Kaio Jia Bin, do Centro de Reprodução Humana, que apoiaram minha dedicação a este projeto. 
Ao Dr. Sérgio Podgaec pela colaboração na coleta das amostras e auxílio na revisão desta dissertação.

Aos Drs. Flávia Fairbanks, João Dias e Midgley Gonzalez, do grupo de Endometriose pelo auxílio na coleta das amostras.

À Dra Creusa Dal Bó pelo apoio estatístico na análise dos resultados.

Ao Prof. Edmund Chada Baracat pelo estímulo à pesquisa científica e revisão desta dissertação.

Ao Centro de Estudos da Ginecologia pelo apoio financeiro para a realização deste estudo.

À Prof. Ângela Maggio da Fonseca pelo estímulo e disponibilidade ilimitada para correção deste estudo.

À Cláudia Vieira pela colaboração na revisão de formato desta dissertação 


\section{Normatização adotada}

Esta dissertação está de acordo com as seguintes normas, em vigor no momento desta publicação:

Referências: adaptadas de International Commitee of Medical Journals Editors (Vancouver)

Universidade de São Paulo. Faculdade de Medicina. Serviço de Biblioteca e Documentação. Guia de Apresentação de dissertações, teses e monografias. Elaborado por Anneliese Carneiro da Cunha, Maria Julia de A. L. Freddi, Maria F. Crestana, Marinalva de Souza Aragão, Suely Campos Cardoso, Valéria Vilhena. São Paulo: Serviço de Biblioteca e Documentação; 2005

Abreviaturas dos títulos dos periódicos de acordo com List of Journal Indexed in Index Medicus 


\section{SUMÁRIO}

Lista de abreviaturas

Lista de tabelas

Lista das figuras

Resumo

Summary

1. INTRODUÇÃO.

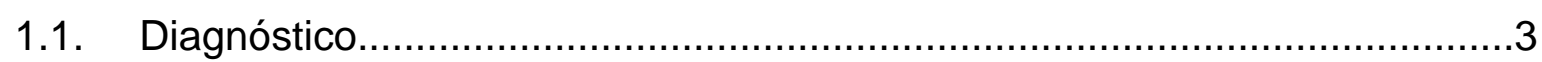

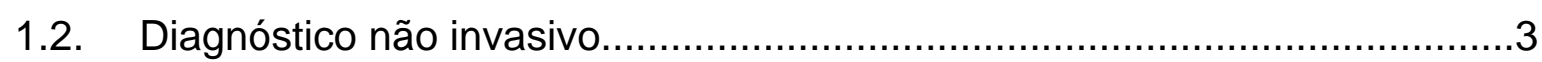

1.3. As citocinas e sua avaliação na endometriose pélvica...............................6

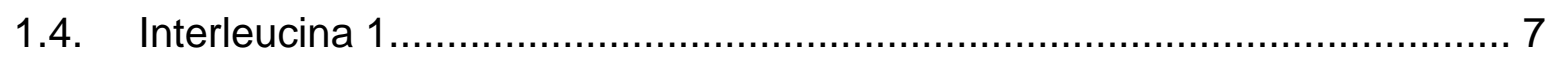

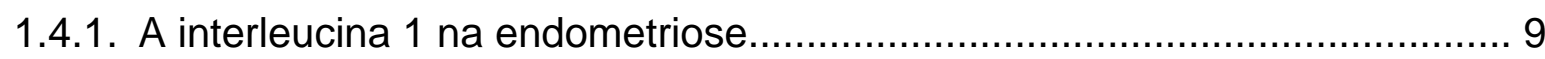

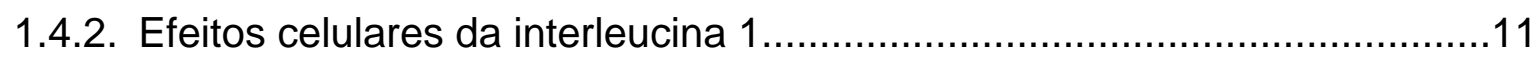

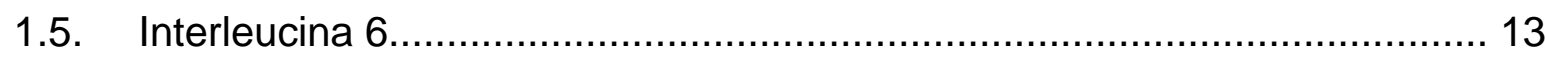

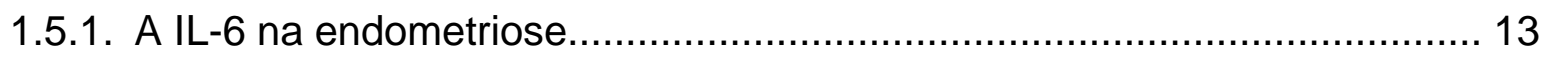

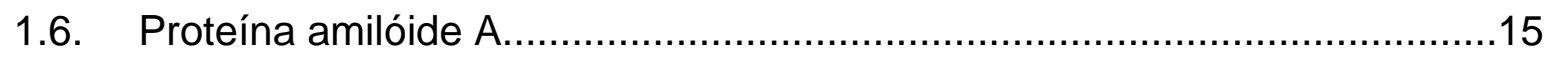

2. OBJETIVOS

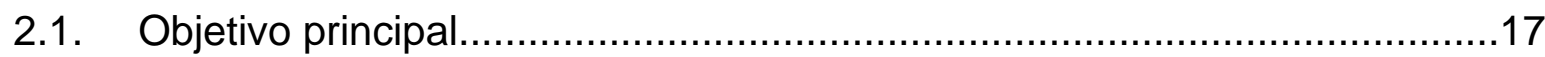

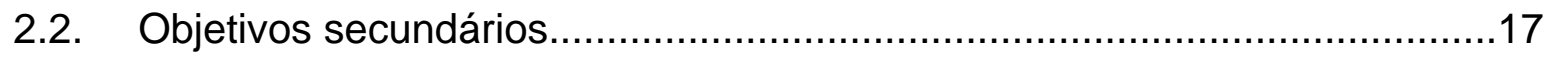

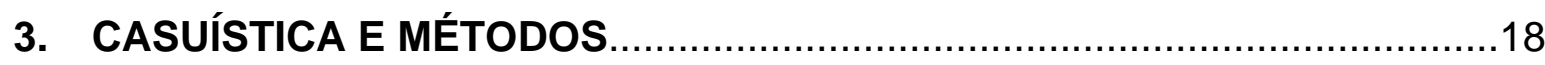

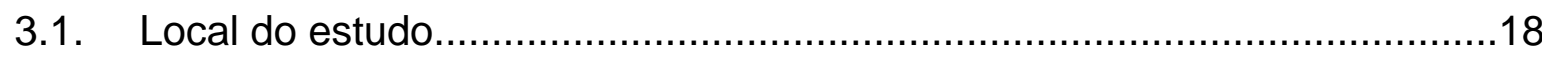

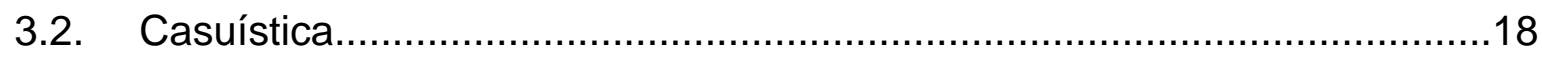

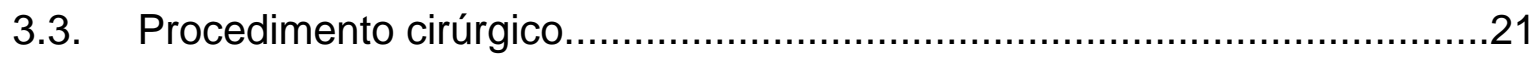

3.4. Localização e estadiamento da endometriose.........................................21

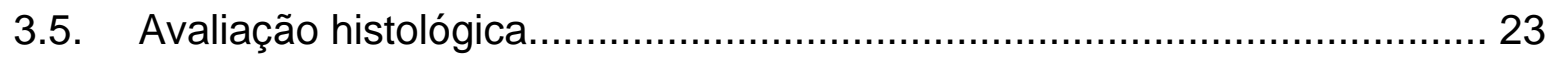

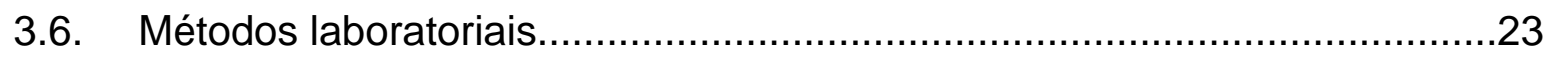

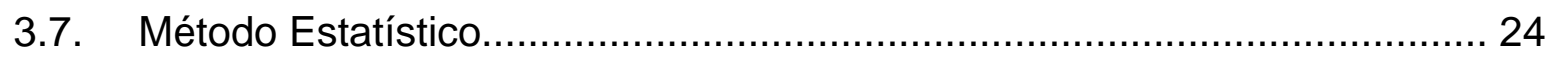

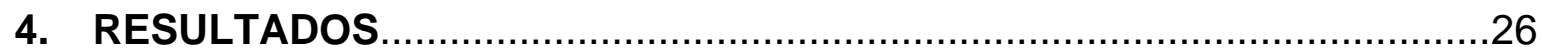

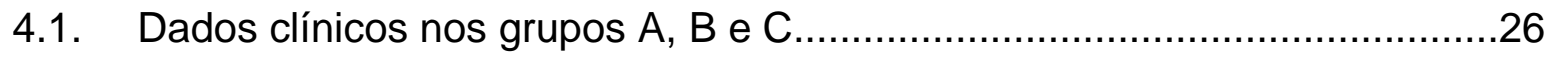

5. DISCUSSÃO

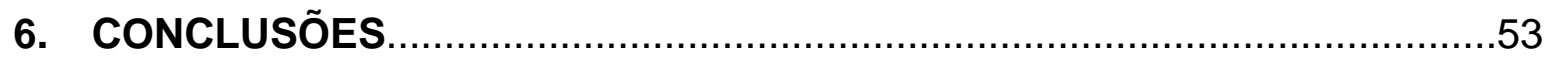

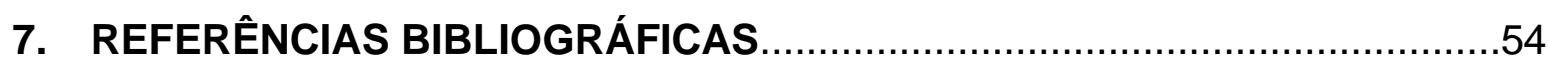

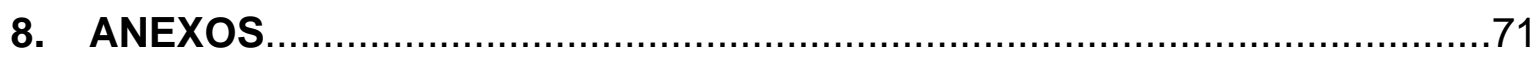




\title{
Lista de abreviaturas
}

\author{
AP-1 fator de ativação da proteína 1 \\ Ca-125- anidrase carbônica \\ COX2- ciclooxigenase 2 \\ GNRH- hormônio liberador de gonadotrofinas \\ ICAM-1s molécula de adesão intercelular 1 solúvel \\ ICE- enzima conversora de interleucina \\ IgG Imunoglobulina $G$ \\ IGM- Imunoglobulina $M$ \\ IL-1 $\alpha$-Interleucina 1-alfa \\ IL-1 $\beta$ - Interleucina 1-beta \\ IL-1RA- receptor antagonista da IL-1 \\ IL-3- Interleucina 3 \\ IL-6 Interleucina 6 \\ IL-7-interleucina 7 \\ IL-8 interleucina 8 \\ LPS- lipopolissacarides \\ MCP-1 proteína quimiotática de monócitos \\ $N F \kappa \beta$ - fator nuclear ?B \\ PCR- reação de polimerase em cadeia \\ SAA- PRoteína amilóide A \\ TNF- $\alpha$ - Fator de necrose tumoral alfa \\ VEGF- Fator de crescimento do endotélio vascular
}




\section{Lista de Tabelas}

Tabela 1. Fase do ciclo menstrual em que foram realizadas as cirurgias nos três grupos

Tabela 2. Sintomas das pacientes dos grupos A e B.......................................28

Tabela 3. Estadiamento da American Society for Reproductive Medicine (1997), local de apresentação e tipo histológico das pacientes do grupo A.

Tabela 4. Valores de média, desvio-padrão, mediana, limites mínimo e máximo dos marcadores no líquido peritoneal (LP) e no sangue nos três grupos estudados. .31

Tabela 5. Valores de média, desvio-padrão, mediana, limites mínimo e máximo dos marcadores no líquido peritoneal, nos três grupos estudados. 32

Tabela 6. Valores de média, desvio-padrão, mediana, limites mínimo e máximo dos marcadores no líquido peritoneal e no sangue, nos três grupos estudados...33

Tabela 7. Valores de média, desvio-padrão, mediana, limites mínimo e máximo dos marcadores no líquido peritoneal e no sangue no grupo $A$ 
Tabela 8. Valores de média, desvio-padrão, mediana, limites mínimo e máximo dos marcadores no líquido peritoneal e no sangue no grupo A...........................38

\section{Lista de figuras}

Figura 1. Classificação da endometriose proposta pela American Society for Reproductive Medicine. .22

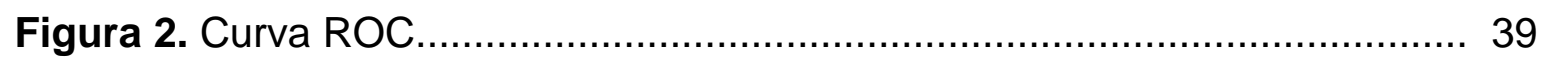

Gráfico 1. Concentração da IL-1 $\beta$ peritoneal em pacientes dos grupos $A$ e $B$ com dismenorréia severa / incapacitante. 35

Gráfico 2. Concentração de SAA sérica em pacientes dos grupos $A$ e $B$ com infertilidade. 35 


\section{Lista de anexos}

Anexo A. Aprovação pelo Comitê de Ética e Pesquisa........................................71

Anexo B. Termo de Consentimento Livre e Esclarecido.....................................72

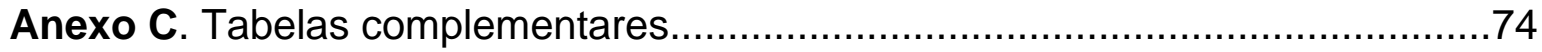

$\begin{array}{ll}\text { Anexo D } & 79\end{array}$

Tabela 1. Valores de média, desvio-padrão, mediana, limites mínimo e máximo dos marcadores no líquido peritoneal (LP), nos dois grupos estudados segundo a presença de dismenorréia severa..................................................................

Tabela 2. Valores de média, desvio-padrão, mediana, limites mínimo e máximo dos marcadores no sangue, nos dois grupos estudados segundo a presença de dismenorréia severa....... .74

Tabela 3. Valores de média, desvio-padrão, mediana, limites mínimo e máximo dos marcadores no líquido peritoneal, nos dois grupos estudados segundo a presença de infertilidade. .75

Tabela 4. Valores de média, desvio-padrão, mediana, limites mínimo e máximo dos marcadores no sangue, nos dois grupos estudados segundo a presença de infertilidade. .75

Tabela 5. Valores de média, desvio-padrão, mediana, limites mínimo e máximo dos marcadores no líquido peritoneal (LP), nos dois grupos estudados segundo a presença de dismenorréia moderada. .76

Tabela 6. Valores de média, desvio-padrão, mediana, limites mínimo e máximo dos marcadores no sangue (S), nos dois grupos estudados segundo a presença de dismenorréia moderada. 
Tabela 7. Valores de média, desvio-padrão, mediana, limites mínimo e máximo dos marcadores no líquido peritoneal (LP), nos dois grupos estudados segundo a

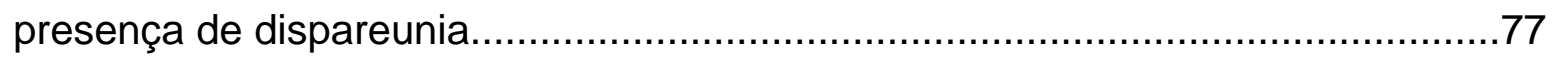

Tabela 8. Valores de média, desvio-padrão, mediana, limites mínimo e máximo dos marcadores no sangue, nos dois grupos estudados segundo a presença de dispareunia. 77

Tabela 9. Valores de média, desvio-padrão, mediana, limites mínimo e máximo dos marcadores no líquido peritoneal (LP), nos dois grupos estudados segundo a presença de dor acíclica. .78

Tabela 10. Valores de média, desvio-padrão, mediana, limites mínimo e máximo dos marcadores no sangue, nos dois grupos estudados segundo a presença de dor acíclica. .78 


\section{Resumo}

Ejzenberg, D. Avaliação das concentrações das interleucinas 1 e 6 e da proteína amilóide $A$ no líquido peritoneal e no soro de pacientes com endometriose pélvica. [Dissertação]. São Paulo: Faculdade de Medicina, Universidade de São Paulo;2007.

Objetivo: determinar as concentrações séricas e peritoneais das interleucinas $1 B$ (IL-1ß) e 6 (IL-6) e da proteína amilóide A (SAA) em pacientes com endometriose pélvica. Métodos: foram avaliadas 97 pacientes submetidas à videolaparoscopia, 57 com endometriose (A), 27 com sintomas sugestivos porém sem endometriose (B) e 13 sem sintomas e doenças (C). Foram coletados no ato cirúrgico líquido peritoneal e sangue. As concentrações dos mediadores foram determinadas em $\mathrm{pg} / \mathrm{ml}$ (IL-1 e 6) e ng/ml (SAA) por método imunoenzimático e leitura óptica. Resultados: (líquido peritoneal e sangue medianas) IL-1B: A- 11,22 and 1,83; B15,62 and 1,16; C- 1,92 and 0,80; IL-6: A- 6,80 and 3,70; B- 8,60 and 3,90; C- 3,40 and 2,0; SAA- A- 310,30 and 14,01; B- 306,20 and 10,39; C- 53,4 e 9,5 . Conclusão: as concentrações dos mediadores de inflamação avaliados estão elevadas no líquido peritoneal e no soro das mulheres com endometriose. Estas concentrações foram semelhantes às das pacientes com sintomas sugestivos porém sem a doença. A fase do ciclo menstrual, o tipo histológico envolvido e o local de acometimento da doença não influíram de forma significante nas concentrações séricas ou peritoneais de IL-1ß, IL-6 e SAA. 


\section{Summary}

Ejzenberg, D. Seric and peritoneal assessment of interleukin $1 B, 6$ and protein amyloid A concentrations in patients with pelvic endometriosis. [Dissertation]. São Paulo: “Faculdade de Medicina, Universidade de São Paulo”; 2007.

Objective: to assess peritoneal and seric interleukin-1ß (IL-1ß), 6 (IL-6), and protein amyloid A (SAA) concentrations in patients with pelvic endometriosis. Methods: 97 patients were submitted to video laparoscopic surgery, 57 with endometriosis (A), 27 with suggestive symptoms but no endometriosis (B), and 13 without symptoms and diseases (C). Peritoneal fluid and blood were collected during the procedure. Mediator's concentration was determined in $\mathrm{pg} / \mathrm{ml}(\mathrm{IL}-1 ß$ and IL-6) and $\mathrm{ng} / \mathrm{ml}(\mathrm{SAA})$ through immunoenzimatic test and optic measure. Results: (peritoneal fluid and blood -medians) IL-1B: A- 11,22 and 1,83; B- 15,62 and 1,16; C- 1,92 and 0,80; IL-6: A- 6,80 and 3,70; B- 8,60 and 3,90; C- 3,40 and 2,0; SAAA- 310,30 and 14,01 ; B- 306,20 and 10,39; C- 53,4 e 9,5. Conclusion: the inflammation mediators are increased in the peritoneal fluid and blood of women with pelvic endometriosis. The concentrations are similar to those found in patients with suggestive symptoms but no endometriosis. The place of the disease, the histological type and the day of the menstrual cycle didn't alter peritoneal or seric concentration of these cytokines. 


\section{INTRODUÇÃO}

A endometriose é definida pelo implante de glândula e/ou estroma endometriais em topografia extra-uterina, com localização mais freqüente nos ovários e ligamentos útero-sacros (D`Hooghe e Debrock, 2002). A prevalência desta doença situa-se entre 10 e $15 \%$ da população feminina em idade reprodutiva, acometendo até $50 \%$ das pacientes com infertilidade primária (D`Hooghe e Debrock, 2002). A moléstia apresenta grande morbidade para as pacientes e elevados custos para o sistema de saúde (Abbot et al, 2003). É a causa responsável por $15 \%$ das histerectomias e 25 a $35 \%$ das laparoscopias realizadas nos Estados unidos. O tratamento cirúrgico é estimado em US\$5805 e os medicamentos em US\$2418 por caso (Abbot et al, 2003).

A etiopatogenia da endometriose não está completamente esclarecida e várias teorias têm sido propostas nas últimas décadas. Uma das mais relevantes é a da menstruação retrógrada, formulada por Sampson em 1921, segundo a qual o tecido endometrial ectópico seria proveniente do fluxo menstrual, carreado pelas tubas uterinas para a cavidade abdominal. Evidências que reforçam esta teoria são a localização preferencial da endometriose nos ovários e ligamentos úterosacros, onde os resíduos menstruais ficam coletados em maior quantidade, a presença de tecido endometrial viável no fluxo menstrual e a caracterização de que 70 a $90 \%$ das mulheres em idade reprodutiva apresentam menstruação retrógrada (Sampson, 1921; Giudice e Kao, 2004). Entretanto, a teoria de Sampson é insuficiente para justificar casos em que ocorre a implantação do endométrio em órgãos e sítios distantes, como no cérebro, pulmão, diafragma, 
parênquima hepático e nervos periféricos; e os raros casos de endometriose em homens (Donnez e Langendonckt, 2004). Para estes casos outras hipóteses foram formuladas para elucidar todo o mecanismo etiopatogênico (D’Hooghe et al, 2004).

A disseminação do tecido endometrial pela via linfática, proposta por Halban, ou hematogênica, proposta por Sampson, explicariam a localização de implantes endometrióticos em órgãos ou sítios distantes do útero. Células endometriais podem ser encontradas nos linfonodos de um terço das pacientes com a doença (Antsiferova et al, 2005; Abrão et al, 2006).

Os raros casos de endometriose em homens e em mulheres com a Síndrome de Rokitansky-Kuster-Hauser podem ser justificados pela teoria de Meyer e Iwanoff, da metaplasia celômica, que propõe que os focos endometrióticos seriam originados de células do epitélio celômico, com diferenciação tardia em tecido endometrial (Meyer, 1919).

A combinação de possíveis mecanismos fisiopatogênicos busca explicar a discrepância entre a freqüente ocorrência de menstruação retrógrada nas mulheres e a prevalência seis vezes menor da doença. A explicação pode ser propiciada pela teoria imunológica, onde a ocorrência da endometriose seria resultado da incapacidade de erradicação do endométrio que atinge a cavidade abdominal pelo sistema imune (Giudice e Kao, 2004). Neste sentido, diversas alterações na imunidade foram descritas em pacientes com endometriose como: aumento do número de macrófagos peritoniais ativados com inflamação, menor atividade citotóxica das células Natural Killer e dos linfócitos sanguíneos, presença 
de auto-anticorpos séricos e produção alterada de citocinas e fatores de crescimento (Berkkanoglu e Arici, 2003, Antsiferova et al. 2005, Siristatidis et al. 2006; Podgaec et al, 2007). Nos dias correntes predominam na literatura especializada a teoria imunológica e a da menstruação retrógrada como causas principais da endometriose (Antsiferova et al, 2005; Siristatidis et al, 2006; Podgaec et al, 2007).

\subsection{Diagnóstico}

O diagnóstico definitivo da endometriose é realizado através de exame anatomopatológico das lesões suspeitas, obtidas em procedimento cirúrgico (Abrão et al 2003). Adicionalmente, durante o ato cirúrgico cada caso da doença deve ter o estadiamento avaliado, segundo os locais de acometimento, extensão das lesões e a presença de aderências, em quatro estádios determinados pela American Society for Reproductive Medicine (ASRM) em 1996. A análise histológica pode fornecer informações adicionais sobre o prognóstico de cada caso, segundo o grau de semelhança das lesões extirpadas com o endométrio tópico (Abrão et al, 2003). Contudo, apesar dos métodos diagnósticos não invasivos não estabelecerem diagnóstico definitivo, auxiliam na decisão quanto à necessidade de uma avaliação invasiva.

\subsection{Diagnóstico não invasivo}

A endometriose pode se manifestar com diferentes sintomas segundo a extensão da doença e os sítios acometidos. Nisolle e Donnez em 1997 propuseram um modelo em que a endometriose se manifestaria em três 
apresentações distintas: doença peritoneal, doença ovariana e doença de septo retovaginal.

Os sintomas mais freqüentemente relacionados à endometriose são dismenorréia, dispareunia de profundidade, infertilidade, algia pélvica e alterações urinárias e intestinais cíclicas. A presença de um destes seis sintomas apresenta sensibilidade de $76 \%$ e especificidade de $58 \%$ no diagnóstico da doença (Eskenazi et al 2001). A dismenorréia é a manifestação predominante, apresentando-se com intensidade variável (Eskenazi et al, 2001). A infertilidade pode ser secundária às alterações na gametogênese, à alteração no carreamento oocitário pelas tubas uterinas, aos efeitos embriotóxicos das citocinas, e à limitação da implantação embrionária (De Hondt et al, 2006; Siristatidis et al, 2006). As queixas urinárias predominantes são a disúria e a hematúria cíclicas decorrentes do implante vesical de tecido endometrial. As manifestações digestivas envolvem predominantemente o tenesmo e a enterorragia (Eskenazi et al, 2001). O quadro de algia pélvica é secundário às aderências, inflamação e infiltração de feixes nervosos (Wu et al, 2002). Com exceção da algia pélvica acíclica, os demais sintomas apresentam com freqüência intensidade maior em determinado período do ciclo menstrual (Wu et al, 2002).

Com o intuito de aumentar o acesso ao diagnóstico e diminuir a realização de procedimentos invasivos em um grande contingente de mulheres com suspeita clínica de endometriose, diversos grupos pesquisam métodos para o diagnóstico não invasivo desta moléstia. A ultra-sonografia pélvica transvaginal, e a ressonância nuclear magnética possibilitam o diagnóstico de endometriose com 
sensibilidade elevada, atingindo até 90\%, porém alguns estudos revelam especificidade limitada, principalmente nos casos de doença inicial, e naqueles com endometriomas pequenos e aderências (Okaro et al, 2006). Recentemente Abrão et al (2007) verificaram sensibilidade de 99\% e especificidade de $90 \%$ para o diagnóstico da endometriose profunda com comprometimento retal com a utilização do ultra-som transvaginal com preparo intestinal e da ressonância magnética. Nos casos de acometimento da região retrocervical a sensibilidade e especificidade dos exames foram de $97 \%$ e $71 \%$ respectivamente. O primeiro marcador sérico utilizado para o diagnóstico não invasivo foi o CA-125 por Niloff et al em 1984, que havia sido associado inicialmente aos tumores ovarianos por Bast et al, em 1983. Abrão et al em 1997 testaram o Ca-125II, a anticardiolipina (IgG e IgM) e as proteínas inflamatórias de fase aguda $C$ reativa $(P C R)$ e a proteína amilóide A (SAA). Neste estudo clínico com 50 pacientes encontraram aumento significativo dos níveis de CA-125 e de SAA nos casos avançados de endometriose frente aos controles (Abrão et al, 1997).

Diversos autores passaram a investigar a função de algumas citocinas no diagnóstico da doença, baseados no seu caráter inflamatório e nas alterações imunolológicas verificadas na sua gênese (Koyama et al, 1993; D`Hooghe et al, 2001; Pizzo et al, 2002). Estudo de Bedaiwy et al em 2002 envolvendo 130 pacientes e um painel de citocinas mostrou elevadas sensibilidade e especificidade apenas para a interleucina (IL)-6 sérica (90\% e $67 \%$ ) e para o fator de necrose tumoral alfa (TNF-a) peritoneal (100\% e 85\%) adotando como nível de corte $2 \mathrm{pg} / \mathrm{ml}$ e $15 \mathrm{pg} / \mathrm{ml}$, respectivamente (Bedaiwy et al, 2002). Em contrapartida, 
Somigliana et al em 2004 em trabalho prospectivo com 80 pacientes, $45 \mathrm{com}$ endometriose e 35 com outras doenças ginecológicas benignas, não observaram benefício na avaliação adicional da IL-6 aos valores do CA-125 para o diagnóstico da endometriose. Neste estudo o CA-125 apresentou sensibilidade de $27 \%$ e especificidade de 97\% (Somigliana et al, 2004). Martinez et al em 2007 em estudo caso-controle com 119 pacientes observaram aumento da IL-6 sérica principalmente nos estádios inciais da doença, com sensibilidade de $75 \%$ e especificidade de $83 \%$ para o diagnóstico quando o nível de corte foi de 25,75 $\mathrm{pg} / \mathrm{ml}$. Na mesma pesquisa, o CA-125 com nível de corte de $35 \mathrm{Ul} / \mathrm{ml}$ atingiu sensibilidade de $47 \%$ e especificidade de $97 \%$ (Martinez et al, 2007).

\subsection{As citocinas e sua avaliação na endometriose pélvica}

As citocinas são mediadores celulares, polipeptídeos e glicoproteínas, que possuem atividade autócrina, parácrina e por vezes endócrina. Têm como principal função a regulação da resposta imune em resposta a antígenos ou microorganismos. Atuam em receptores de membrana com alta afinidade nas células-alvo, que geram sinalização intracelular. Esta estimulação pode resultar em atividade celular proliferativa, citostática, quimiotáxica, ou induzir a diferenciação. As citocinas têm ação variada, e algumas, como a IL-3 e a IL-7, além da mediação do sistema imune têm ação reconhecida na hematopoiese (Berkkanoglu e Arici, 2003; Cao et al, 2004). Quanto às células-alvo, algumas

citocinas, como as interleucinas, apresentam pleiotropismo, ou seja, a mesma citocina atua sobre diferentes células. Este efeito pode ser observado quando ocorrem efeitos colaterais diversos nas experimentações terapêuticas (Gallinelli et 
al, 2004). As citocinas são produzidas por células pertencentes ao sistema imune, principalmente pelos macrófagos e por outras não específicas deste sistema, como as células endoteliais, plaquetas e fibroblastos.

Alguns autores têm buscado caracterizar perfis de elevações das diversas citocinas frente às doenças inflamatórias (Siristatidis et al., 2006). Como a endometriose envolve processo inflamatório pélvico, com alteração da resposta imune local, abordar-se-á a seguir duas das principais citocinas envolvidas na inflamação: as interleucinas 1 e 6 e sua proteína efetora, a proteína amilóide A.

\subsection{Interleucina 1}

A interleucina 1 (IL-1) é uma citocina presente na resposta imune inata, que se eleva nas inflamações de variada natureza. É produzida por macrófagos, neutrófilos, células epiteliais (queratinócitos) e células endoteliais frente a produtos bacterianos, como os lipopolissacárides (LPS), e a outras citocinas como o TNF-a. Existem duas formas desta citocina: a IL-1 a e B, que atuam nos receptores leucocitários com a mesma eficiência, embora tenham apenas 30\% de semelhança na composição. São produzidas com 33kD e secretadas com 17kD. A

IL-1 a pode ser ativa mesmo antes de sua clivagem, na forma de 33kD. A IL-1-ß é clivada pela enzima conversora (ICE) da família das caspases. A maior parte da interleucina encontrada na circulação sanguínea é do tipo B. O mecanismo de secreção desta interleucina permanece incerto por não possuir uma seqüência hidrofóbica, que habitualmente a direcionaria ao retículo endoplasmático (Rossi et al, 2005). 
Existem dois tipos de receptores onde a interleucina 1 atua, ambos da chamada superfamília das imunoglobulinas. O receptor do tipo I é o responsável pela resposta imune na defesa contra infecções microbianas, e o receptor tipo II é encontrado principalmente nos linfócitos tipo B, não gera atividade biológica e atua apenas como competidor para o receptor do tipo I. Esse está associado à proteína acessória IL-1R, presente em vários tipos de células. A porção intracitoplasmática do receptor IL-1 é homóloga à encontrada na espécie Drosophila conhecida como toll. A ligação da IL-1 com seu receptor leva à ativação de fatores de transcrição como fator nuclear ?ß (NF-?ß), e fator de ativação da proteína 1 (AP-1). Os efeitos da IL-1 são dependentes da concentração atingida e são semelhantes aos do TNF, apesar de serem substâncias diversas em relação à composição e ao receptor de atuação. Os efeitos similares destas citocinas decorrem dos mecanismos comuns de transcrição. Apesar destes efeitos similares, a IL-1 não induz à ocorrência da apoptose celular ou ao choque séptico, como faz o TNF (Kondera et al, 2005).

Em baixas concentrações, a IL-1 participa da inflamação local pela ação sobre células endoteliais, aumentando o número de moléculas de superfície para a adesão leucocitária. Em grandes concentrações, passa a ter efeito sistêmico, causando febre e produção de proteínas hepáticas de fase aguda, como o fibrinogênio e a proteína sérica amilóide A. Níveis elevados persistentes desta interleucina podem causar perda de células musculares e adiposas, até à caquexia (Cao et al, 2005). 
A IL-1 na infertilidade é avaliada desde os estudos que observaram alterações na função espermática com a adição de IL-1 (Fakih et al, 1987, Sueldo et al 1990). Uda (1992) propôs que a IL-1 inibiria a clivagem embrionária e o desenvolvimento do embrião após a nidação, pela diminuição do glicogênio intracelular na célula endometrial. Porém Sheth et al em 1991 correlacionaram altos níveis de IL-1a (>60 pg/ml) em cultura de embriões com altas taxas de gestação em ciclos de FIV.

Os macrófagos produzem o antagonista do receptor de IL-1 (IL-1 ra) que tem estrutura similar à desta citocina, e liga-se aos mesmos receptores, porém sem efeito biológico. Este inibidor competitivo é um regulador endógeno da ação da IL-1. Pela redundância de efeitos entre a IL-1 e o TNF, o bloqueio da ação da primeira através de antagonistas solúveis ou IL-1 ra, não mostrou benefício em ensaios experimentais de inflamação, como na artrite (Cao et al, 2005).

\subsubsection{A interleucina 1 na endometriose}

A IL-1 começou a ser investigada na endometriose através do estudo de Fakih et al de 1987 que encontraram níveis elevados de IL-1 no líquido peritoneal obtido através de punção de fórnice vaginal posterior em 10 de 11 pacientes com endometriose, frente a 7 outras que foram submetidas a laqueadura tubárea. Neste estudo a IL-1 também mostrou em caráter experimental toxicidade para o desenvolvimento embrionário de ratos.

A partir deste estudo, diversos autores buscaram verificar a importância das concentrações da IL-1 no líquido peritoneal e no soro. Mori et al encontraram em 1991 aumento da IL-1ß no líquido peritoneal nos casos de endometriose, como 
também em pacientes com aderências pélvicas, moléstia inflamatória pélvica, miomas e cistos ovarianos, em relação a mulheres sem alterações. No ano seguinte verificaram aumento dos níveis de IL-1 no líquido peritoneal nos estádios I/II da endometriose frente aos estádios III/IV, porém não tiveram diferenças estatísticas entre os estádios III/IV e pacientes sem alterações pélvicas. Dois anos após foi verificado que $36 \%$ das pacientes com endometriose apresentavam IL-1 acima de $20 \mathrm{pg} / \mathrm{ml}$ no líquido peritoneal enquanto nas pacientes sem endometriose esta porcentagem atingia 7\% (Ishimaru et al, 1994).

Keenan et al (1995) demonstraram aumento de macrófagos no líquido peritoneal e maior produção de IL-1 beta por estas células, frente aos controles. Contudo, o nível de IL-1-ß no fluido peritoneal não diferiu entre as pacientes com endometriose e outras doenças benignas. Outros autores observaram níveis mais elevados de IL-1-ß no líquido peritoneal frente aos controles (Ho et al, 1996). Skrzypczak et al em 2005 não encontraram no líquido peritoneal diferença significativa para IL-1ß em casos de endometriose inicial frente a pacientes inférteis ou normais. No mesmo ano, outros autores encontraram aumento da IL$1 ß$ no líquido peritoneal em 27 pacientes com endometriose frente a 12 pacientes normais (Sokolov et al, 2005).

Kharfi e Akoum, em 2001, não encontraram diferença entre os níveis séricos de IL-1 beta entre pacientes com e sem endometriose. Em outra pesquisa também não foi observada diferença entre pacientes com endometriose e pacientes inférteis quanto ao nível de IL-1 no líquido peritoneal (Calhaz et al, 2003). Wieser et al, no mesmo ano, em estudo com 92 mulheres com 
endometriose e 69 controles não encontraram diferença nos níveis séricos de IL1ß. Hudelist et al, em 2005 encontraram nos implantes endometrióticos aumento dos níveis de IL-1 alfa e da metaloproteinase 1 em relação ao endométrio tópico, quando compararam o material de biópsia das 37 pacientes com endometriose com 37 controles. Kondera et al em 2005 também encontraram aumento dos níveis séricos de IL-1 a em pacientes com endometriose frente a pacientes sem a moléstia.

Os níveis séricos e peritoneais de IL-1 também têm sido avaliados durante os tratamentos de pacientes com endometriose e nas simulações experimentais. Em 1990, Mori et al mostraram in vitro inibição da IL-1ß e do TNF-a pelo danazol. Koumantakis et al também encontraram diminuição dos níveis séricos de IL-1a e do IL-6 em 10 pacientes com endometriose após a administração de danazol (Koumantakis et al 1994). Ho et al mostraram diminuição dos níveis de IL-1 no líquido peritoneal em 14 pacientes com endometriose avançada após utilização por 6 meses de agonista de $\mathrm{GnRH}$, enquanto Meresman et al utilizando cultura celular mostraram que a utilização do acetato de leuprolida levou à diminuição dos níveis de IL-1ß e fator de crescimento endotelial vascular (VEGF) e aumento da ocorrência de apoptose (Ho et al, 1996; Meresman et al, 2003).

\subsubsection{Efeitos celulares da interleucina 1}

Em 1995 Akoum et al evidenciaram aumento da proteína quimiotática para monócitos (MCP-1), produzida pelas células endometriais em resposta à IL-1 e ao TNF-a. Após alguns anos, o mesmo grupo verificou que o estradiol promove aumento da responsividade da célula endometrial à IL-1 através da MCP-1 
(Akoum et al, 2000) e que a IL-1 promove o aumento da IL-8 (Akoum et al, 2001). No ano seguinte o mesmo autor mostrou ação sinérgica do estradiol com a IL-1 na produção de outra proteína quimiotática, a RANTES (Akoum et al, 2002). Em 1998 Vigano et al demonstraram em cultura de células a produção de molécula de adesão intercelular 1 solúvel (ICAM-1s), induzida pela IL-1 em tecidos de pacientes com endometriose e propuseram que este seria um mecanismo para evitar a fagocitose pelas células de defesa.

Em 2003 Mueller et al mostraram em estudo experimental aumento de 23 vezes na concentração do peptídeo ativador de neutrófilos (ENA), potente agente quimiotático, através da ação da IL-1ß. Sillem et al (1999) observaram em estudo experimental o aumento da capacidade de adesão celular endometrial à laminina e fibronectina após a ação da IL-1, o que reforça a teoria de Sampson. Lebovic et al (2000) concluíram que a neoangiogênese na endometriose seria derivada da ação da IL-1 beta no receptor tipo I, o que estimula a produção da IL-6 e do VEGF. Maas et al em 2001 atribuíram a angiogênese no foco endometriótico ao TNF-a, nos casos de endometriose estádio I/II, e não encontraram correlação com os níveis de IL-1-ß. Em dois estudos consecutivos, Lebovic et al (2001 e 2002) verificaram em cultura de tecido endometrial que a IL-1 também leva ao aumento da RANTES, proteína responsável pelo recrutamento de macrófagos e leucócitos, e à supressão do Tob-1, gene responsável pela inibição do ciclo celular; isto pode explicar a proliferação dos focos endometrióticos. Em 2002, Akoum et al propuseram que o estradiol exerce efeito sinérgico com a IL-1 sobre a produção de RANTES, em estudo experimental. Wu et al (2005) mostraram aumento da 
produção de ciclooxigenase tipo 2 (COX2) mediada pela IL-1 em pacientes com endometriose, por atuação desta citocina no promotor do gene. Neste mesmo ano Rossi et al através de estudos genéticos identificaram 29 genes que poderiam sofrer ação da IL-1ß. Em 2006 Braundmeier e Novak, em trabalho experimental mostraram ação da IL-1 sobre as metaloproteinases 1, 2 e 3.

\subsection{Interleucina 6}

A interleucina 6 (IL-6) é um homodímero, em que cada unidade forma um domínio globular de 4-a hélices. Atua sobre o receptor do tipo I da família de receptores das citocinas, e a subunidade transdutora de sinais é a gp130, com

peso molecular de 130 kD. A IL-6 ativa a via de sinalização JAK/STAT, porém, esta via pode ser acionada por outras interleucinas (Yamauchi et al, 2004).

A IL-6 faz parte dos processos da imunidade inata e da adquirida, produzida em resposta ao TNF, à IL-1, e a algumas células $T$ ativadas. Na resposta inata a IL-6 estimula a síntese de proteínas hepáticas, como a proteína amilóide A e o fibrinogênio, que constituem parte da resposta de fase aguda da inflamação sistêmica. Na imunidade adquirida, a IL-6 estimula o desenvolvimento dos linfócitos B produtores de anticorpos. Isto pode ser observado nos plasmócitos neoplásicos dos mielomas e nas células neoplásicas produtoras de anticorpos monoclonais, denominadas hibridomas (Khan et al, 2005; Hirota et al, 2005).

\subsubsection{A IL-6 na endometriose}

O papel da IL-6 na endometriose tem sido estudado desde 1992, quando Bouten et al verificaram em cultura de células que os macrófagos do líquido peritoneal das pacientes com endometriose produziam maiores concentrações de 
IL-6 frente a pacientes sem a doença. A contraprova foi verificada quando os níveis séricos de IL-6 se mostraram reduzidos após a remoção cirúrgica dos focos de endometriose (Imaizumi et al, 1993; Keenan et al, 1994). Keenan et al em 1994 mostraram concentrações de IL-6 elevadas em 4 vezes no líquido peritoneal nos estágios iniciais da endometriose, e em 8 vezes nos estádios avançados. Em 1996 Schroder et al encontraram níveis de IL-6 apenas discretamente elevados no fluido peritoneal nos estádios avançados frente aos estádios iniciais e controles; e, ao contrário, níveis séricos superiores nos estádios iniciais frente aos estádios avançados e controles.

Tseng et al, em 1996, mostraram em estudo in vitro grande aumento da produção de IL-6 pelas células estromais do endométrio após estimulação com IL1ß, e maior produção pelas células estromais dos implantes endometrióticos em relação ao endométrio tópico das mesmas pacientes. No ano de 1997 Harada et al encontraram níveis maiores e proporcionais de IL-6 no fluido peritoneal, conforme o número de lesões ativas (vermelhas), com predomínio na fase secretora. Também Khan et al em 2002 encontraram elevação da IL-6 no fluido peritoneal de pacientes com endometriose, principalmente com lesões ativas (vermelhas) e em estádios iniciais (I/II). Em contrapartida, Rapkin et al em 2000 não verificaram diferenças no nível peritoneal de IL-6 entre pacientes com endometriose, com aderências sequelares ou no grupo controle sem doença, através de laparoscopia para procedimento de laqueadura.

Em 2002, Khan et al evidenciaram correlação entre os níveis séricos e peritoniais de IL-6, e diminuição sérica após a remoção dos focos de doença por 
laparoscopia, sugerindo que esta citocina poderia ser utilizada como marcador de atividade da doença e medida de sucesso do tratamento cirúrgico. Darai et al (2003), situaram os níveis de IL-6 séricos dos casos de endometriose como inferiores aos de tumores malignos ovarianos, e superiores em relação aos tumores benignos. Iwabe et al, em 2003, mostraram que pacientes com endometriomas ovarianos apresentavam maiores níveis séricos de IL-6, e que os agonistas do GNRH e a cirurgia corretiva levaram à diminuição dos níveis desta citocina.

\subsection{A proteína amilóide $A$}

A proteína amilóide A (SAA) é uma apolipoproteína de 200 kD produzida principalmente no fígado, e que integra as proteínas intervenientes na fase aguda da inflamação sistêmica. Adicionalmente, também pode ser sintetizada nos macrófagos, monócitos, células endoteliais, células da musculatura lisa, tecido sinovial, tecido cerebral e eventualmente em outros tecidos. Os dois genes (SAA1 e 2) que codificam esta proteína se encontram no braço curto do cromossomo 11 (Malle e De Beer, 1996).

O mecanismo de ação da SAA não está completamente esclarecido, tendo atividades pró-inflamatória e antiinflamatória. Participa do metabolismo e transporte do colesterol, quimiotaxia dos leucócitos, depuração de endotoxinas, indução da produção de metaloproteinases, inibição da proliferação de células endoteliais e de linfócitos, e inibe a agregação plaquetária. Também parece proteger os tecidos normais contra a ação de neutrófilos ativados (Uhlar e Whitehead, 1999). 
Os níveis séricos de SAA estão elevados em até milhares de vezes, frente ao nível habitual, em resposta ao aumento do TNF-a e às interleucinas 1, 2 e 6, o que ocorre em casos de infecção ou inflamação. Esta resposta tende a ser rápida, atingindo seu pico em torno de 50 horas após a afecção aguda, sendo a fração predominante o SAA1. Em algumas doenças inflamatórias há aumento de SAA, como na doença de Crohn, artrite reumatóide, doença de Still, e a síndrome de Behcet. Em outras doenças, como nos casos de lupus e retocolite ulcerativa, não há aumento desta proteína, pelo padrão de citocinas presente. A SAA pode estar elevada também em casos de neoplasia, como na doença de Hodgkin e nos tumores renais, e nas injúrias tissulares químicas ou físicas (Urieli et al, 2000). Como a proteína $\mathrm{C}$ reativa, a proteína amilóide $\mathrm{A}$ constitui um marcador de atividade de doença, e é o melhor destes para indicar rejeição em casos de transplante heterólogo (Malle et al, 1996). Há um único estudo da SAA em relação à endometriose de Abrão et al.(1997), que encontraram níveis séricos elevados em pacientes nos estádios III/IV.

Considerando o caráter inflamatório da endometriose e os dados ainda controversos sobre o comportamento das interleucinas e de proteínas inflamatórias da fase aguda nesta afecção, o presente estudo se propõe a avaliar as concentrações de interleucina-1ß e 6 e da proteína amilóide A, mediadores inflamatórios, no líquido peritoneal e no soro de pacientes com endometriose pélvica. 


\section{OBJETIVOS}

\subsection{OBJETIVO PRINCIPAL}

Avaliar as concentrações no líquido peritoneal e no soro da IL-1B, IL-6 e SAA em pacientes com endometriose pélvica.

\subsection{OBJETIVOS SECUNDÁRIOS}

- Comparar as concentrações peritoneais e séricas da IL-1B, IL-6 e SAA nas pacientes com endometriose e sem a doença. Correlacionar as concentrações séricas e no líquido peritoneal de IL1B, IL-6 e SAA das pacientes com endometriose com:
a) os sintomas apresentados;
b) as fases do ciclo menstrual;
c) o tipo histológico da endometriose;
d) o estádio da doença (ASRM,1997);
e) os locais de acometimento da doença. 


\section{CASUÍSTICA E MÉTODOS}

\subsection{Local do estudo}

Foi desenvolvido estudo prospectivo no Setor de Endometriose da Clínica Ginecológica do Hospital das Clínicas da Faculdade de Medicina da Universidade de São Paulo (HC-FMUSP), de Janeiro de 2004 a Abril de 2007. O estudo foi aprovado pelo Comitê de Ética e Pesquisa do Hospital das Clínicas da Faculdade de Medicina da Universidade de São Paulo (Protocolo 769/2002-Anexo A). Todas as pacientes foram informadas sobre o estudo, leram e assinaram o termo de consentimento pós-informação (Anexo B). A Fundação de Amparo à Pesquisa do Estado de São Paulo patrocinou a realização do estudo, através do processo 05/01218-3.

\subsection{Casuística}

A partir de abril de 2004, foram avaliadas, consecutivamente, 92 pacientes com suspeita clínica de endometriose e com indicação de procedimento cirúrgico. Adotaram-se os seguintes critérios de inclusão: quadro clínico sugestivo de endometriose; idade entre 18 e 40 anos; ausência de doenças auto-imunes e neoplasias malignas; não utilização de terapêutica hormonal nos três meses precedentes à inclusão no estudo. As doenças auto-imunes e neoplásicas foram excluídas por meio de anamnese dirigida, exames radiológicos e exames laboratoriais, quando necessários.

A suspeita clínica de endometriose foi estabelecida pela anamnese, exame físico e exames complementares. O quadro clínico foi considerado sugestivo na presença de algum dos seis sintomas mais prevalentes nesta doença: 
dismenorréia, dispareunia de profundidade, dor pélvica crônica, infertilidade e alterações intestinais e urinárias cíclicas (Eskenazi et al, 2001). Quanto à dismenorréia selecionaram-se os casos de intensidade severa e incapacitante. Foram classificados como de intensidade severa aqueles em que a dor não tinha remissão completa com analgésicos, mas não limitava as atividades habituais da paciente, e incapacitante quando não melhorava com analgésicos (Eskenazi et al, 2001). Agrupamos os casos de dismenorréia leve e moderada e de dismenorréia severa e incapacitante para melhor avaliação dos casos. Na caracterização da dor pélvica crônica foi considerada a presença do sintoma, sem relação com o ciclo menstrual, ao menos por seis meses. Como critério de infertilidade utilizou-se a ausência de gestação em casal com vida sexual ativa sem uso de método contraceptivo, por ao menos um ano. Foram considerados, na anamnese, como sintomas intestinais sugestivos de endometriose, a alteração cíclica do trânsito intestinal como dor à evacuação, puxo, tenesmo e sangramento nas fezes durante o período menstrual. Entre as alterações urinárias, foram consideradas a disúria e a hematúria durante as menstruações. O exame físico foi considerado sugestivo de endometriose quando havia nódulos em fundo-de-saco vaginal, útero em retroversão fixa, espessamento de ligamentos útero-sacros ou aumento de volume anexial. A ultra-sonografia pélvica transvaginal foi realizada em todos os casos e, quando necessário, também a ressonância nuclear magnética para exclusão de doenças não-ginecológicas e/ou para o planejamento cirúrgico.

O número de casos elegíveis foi previamente avaliado por meio de cálculo amostral, que utilizou como base os resultados de estudos anteriores que 
avaliaram a IL-6, mediador considerado relevante (Bedaiwy et al, 2002), com um teste de $80 \%$ de poder e nível de significância de $5 \%$. Aplicou-se a fórmula a seguir, que resultou em um mínimo de 27 casos tanto para o grupo endometriose como para o grupo controle sem a doença.

FÓRMULA:

$$
N=\frac{2^{*}\left\{[Z(? / 2)+Z(1-?)]^{*} \text { DESVIO-PADRÃO }\right\}^{2}}{(\text { MÉDIA1 - MÉDIA2 })^{2}}
$$

NA QUAL: $N$ = TAMANHO DA AMOSTRA; $Z(a / 2)$ e $Z(B)=$ valores obtidos na tabela da distribuição $\mathrm{N}(0,1)$

desvio-padrão $=0,45$

média 1 - média2 $=0,3$

Todas as pacientes avaliadas e dentro dos critérios seletivos, foram convidadas a participar da pesquisa. Foram triadas até alcançar o número mínimo de casos e de controles calculados para a amostra. Todas as pacientes concordaram e assinaram o termo de consentimento pós-informação. Foi realizada, a seguir, videolaparoscopia para avaliar e confirmar a doença através de biópsia de todas as lesões cavitárias suspeitas de endometriose e de outras entidades nosológicas. Excluíram-se os casos onde não havia líquido peritoneal. O resultado histológico das lesões separou as pacientes em dois grupos: grupo A com endometriose $(n=57)$ e grupo $B(n=27)$ sem a doença, mas com sintomas sugestivos da mesma.

Foi avaliado também um terceiro grupo - denominado grupo C, composto por 15 pacientes que seriam submetidas à esterilização tubária eletiva por videolaparoscopia, com idade entre 18 e 40 anos, do Setor de Planejamento Familiar da Disciplina de Ginecologia da FMUSP. Neste grupo foram considerados, como critérios de exclusão, a presença de dismenorréia severa ou 
incapacitante, dispareunia de profundidade, infertilidade, dor pélvica acíclica e as alterações intestinais e urinárias cíclicas, doenças auto-imunes e neoplasias malignas, e utilização de terapêutica hormonal no mês precedente à inclusão no estudo. Foram excluídos os casos nos quais não havia líquido peritoneal. Estabeleceu-se o número de 15 casos para este grupo, baseado em estudo prévio de Bedaiwy em 2002.

\subsection{Procedimento cirúrgico}

Foi anotado o dia do ciclo menstrual em que a paciente se encontrava no momento do procedimento cirúrgico. Antes da anestesia geral para a videolaparoscopia, foram colhidos $5 \mathrm{ml}$ de sangue periférico em tubo seco, de veia do membro superior. No início do procedimento não foi realizada a injeção de soro fisiológico na cavidade abdominal, para não alterar o líquido peritoneal. Pela punção secundária foi feita a coleta de todo o líquido peritoneal depositado em fundo de saco anterior e/ou posterior, que foi armazenado em tubo seco. $\mathrm{O}$ material foi imediatamente colocado sob refrigeração, encaminhado ao laboratório para ser centrifugado, separado em alíquotas, e congelado em freezer à $-20^{\circ} \mathrm{C}$.

\subsection{Localização e estadiamento da endometriose}

Após a coleta do líquido peritoneal, as pacientes com lesões suspeitas de endometriose foram avaliadas quanto à presença de focos de doença em peritônio, ovário e/ou em localização profunda - regiões retro-cervical, paracervical, septo reto-vaginal, reto-sigmóide, ureteres e bexiga. Os casos também foram classificados pelos critérios da American Society for Reproductive Medicine (1996), em estádios de I a IV (Figura 1). 
FIGURA 1 - Classificação da endometriose proposta pela American Society for Reproductive Medicine (revisada em 1996).
ESTÁDIO I (MÍNIMA):
$1-5$
ESTÁDIO II (LEVE):
6-15
ESTÁDIO III (MODERADA):
$16-40$
ESTÁDIO IV (SEVERA): > 40

\begin{tabular}{|c|c|c|c|c|}
\hline \multirow{3}{*}{ PERITÔNIO } & ENDOMETRIOSE & $<1 \mathrm{~cm}$ & $1-3 \mathrm{~cm}$ & $>3 \mathrm{~cm}$ \\
\hline & Superficial & 1 & 2 & 4 \\
\hline & Profunda & 2 & 4 & 6 \\
\hline \multirow{4}{*}{ OVÁRIO } & D superficial & 1 & 2 & 4 \\
\hline & Profunda & 4 & 16 & 20 \\
\hline & E superficial & 1 & 2 & 4 \\
\hline & Profunda & 4 & 16 & 20 \\
\hline \multirow{2}{*}{\multicolumn{2}{|c|}{$\begin{array}{l}\text { OBLITERAÇÃO DO FUNDO } \\
\text { DE SACO POSTERIOR }\end{array}$}} & \multicolumn{2}{|l|}{ Parcial } & Completa \\
\hline & & \multicolumn{2}{|l|}{4} & 40 \\
\hline \multirow{5}{*}{ OVÁRIO } & ADERÊNCIAS & $<$ 1/3 Envolvido & 1/3 - 2/3 Envolvidos & > 2/3 Envolvidos \\
\hline & D Velamentosa & 1 & 2 & 4 \\
\hline & Densa & 4 & 8 & 16 \\
\hline & E Velamentosa & 1 & 2 & 4 \\
\hline & Densa & 4 & 8 & 16 \\
\hline \multirow{4}{*}{ ГROMPA } & D Velamentosa & 1 & 2 & 4 \\
\hline & Densa & $4 *$ & $8^{*}$ & 16 \\
\hline & E Velamentosa & 1 & 2 & 4 \\
\hline & Densa & $4^{*}$ & $8^{*}$ & 16 \\
\hline
\end{tabular}

* Se as fímbrias tubárias estiverem totalmente envolvidas por aderências, mude 0 escore para 16.
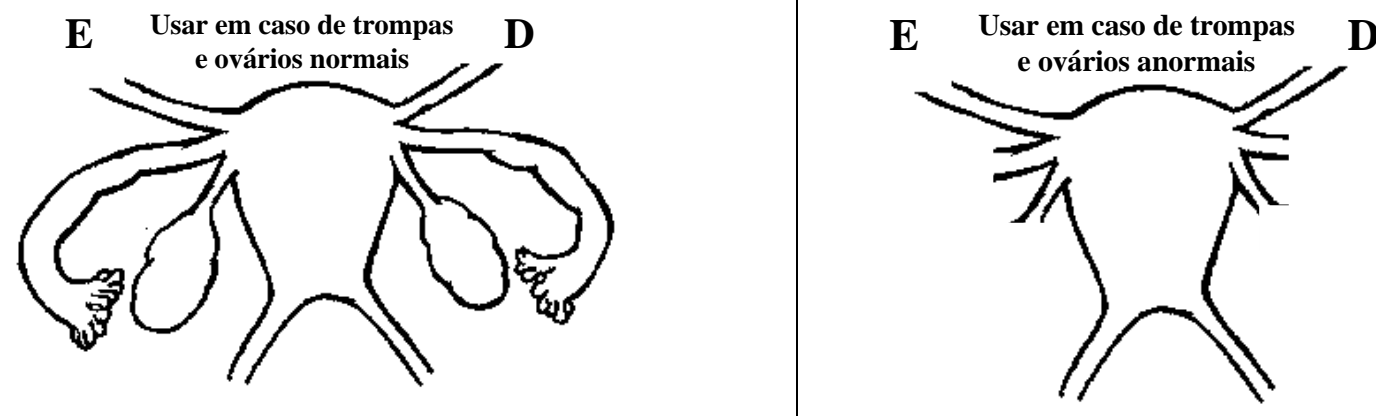


\subsection{Avaliação histológica}

A avaliação histológica das lesões retiradas seguiu os padrões da classificação proposta por Abrão et al. (2003), que classificaram a doença em padrões estromal, glandular bem diferenciado, glandular indiferenciado e glandular misto de diferenciação.

Os padrões histológicos observados foram:

- padrão estromal: presença de estroma morfologicamente similar ao do endométrio tópico em qualquer fase do ciclo;

- padrão glandular bem diferenciado: composto por células epiteliais com morfologia indistinguível dos endométrios tópicos nas diferentes fases do ciclo menstrual. Estas se apresentam em arranjos superficiais ou constituindo espaços glandulares ou císticos;

- padrão glandular indiferenciado: presença de epitélio em diferentes arranjos sem as características morfológicas vistas no epitélio endometrial tópico;

- padrão glandular misto de diferenciação: presença na mesma localização de epitélios de padrão bem diferenciado e indiferenciado.

Para melhor avaliação dos casos, agrupamos os casos de padrão bem diferenciado e estromal (sem doença indiferenciada) assim como os casos de padrão indiferenciado ou misto (com doença indiferenciada).

\subsection{Métodos laboratoriais}

As amostras de líquido peritoneal e de sangue estocadas foram descongeladas para realização das dosagens de IL-1-B, IL-6 e SAA. 
O método laboratorial utilizado para as dosagens das interleucinas $1-\beta$ e 6 e do SAA foi o ELISA, técnica de ensaio imunoenzimático quantitativo tipo sanduíche: anticorpo-antígeno-anticorpo conjugado (Buyalos et al, 1992). Anticorpos monoclonais específicos para as referidas citocinas foram pré-fixados em uma placa de ELISA. Nesta foram colocadas soluções com concentração préestabelecida (padrões), as amostras clínicas e a seguir os conjugados (anticorpos policlonais contra IL-1ß,IL-6 e SAA ligados à enzima peroxidase), que foram pipetados dentro dos poços. Nos poços onde havia IL-1-B, IL-6 ou SAA presentes nas amostras, essas se ligavam ao respectivo anticorpo imobilizado e ao conjugado, formando um complexo. A seguir foi feita lavagem para remover substâncias não ligadas, e adicionada solução contendo o substrato para a peroxidase (tetrametilbenzidina + peróxido de hidrogênio), observando-se 0 aparecimento de cor, proporcional à quantidade do mediador ligado. A seguir a reação era suspensa através da adição de solução de ácido sulfúrico $2 \mathrm{~N}$, e a intensidade da cor medida por leitor de densidade óptica. Como padrões foram utilizados seis soluções de concentrações diferentes e conhecidas de IL-1-B, IL-6 e SAA recombinantes. Para o cálculo dos resultados foram criadas curvas-padrão com base nos resultados da leitura óptica dos padrões. Foram utilizados os kits Human 1L-B ELISA Kit (BD Biosciences ${ }^{\circledR}$, EUA) e Human IL-6 e SAA (Biosource ${ }^{\circledR}$,Bélgica).

\subsection{Método Estatístico}

Foram analisados pelo teste do qui-quadrado os resultados relativos às variáveis categóricas, na forma de proporções. Foram comparados três grupos, o grupo A com endometriose, o B (pacientes com sintoma e sem endometriose) e o 
C de pacientes sem sintomas. Para as variáveis quantitativas contínuas, os resultados foram avaliados quanto à normalidade da distribuição. Para as distribuições não-normais, foi utilizado o teste não-paramétrico de Mann-Whitney e o teste de Dunn, para comparar as médias, medianas e desvio padrão das concentrações séricas e do fluido peritoneal, dos três grupos do estudo A, B e C.

As pacientes com endometriose foram categorizadas de acordo com o estádio (ASRM, 1997), os locais de acometimento e a classificação histológica. Estes subgrupos foram comparados em análise uni e multivariada quanto aos níveis médios das interleucinas 1 e 6 e da proteína amilóide $A$, no fluido peritoneal e no soro. Para a análise univariada, foi utilizado o teste não paramétrico de Mann-Whitney. Os cálculos estatísticos foram realizados com o software Instat 3 (SPSS ${ }^{\circledR}$ Inc., USA), adotando-se o nível de significância de $5 \%(p<0,05)$. 


\section{RESULTADOS}

\subsection{Dados clínicos nos grupos A, B e C}

Foram avaliadas 97 pacientes consecutivas, com idade entre 18 e 40 anos, com idade média de 32,7 anos, desvio-padrão de 5,2 anos e mediana de 33 anos. Constatou-se que não houve diferença significante quanto à média de idade dos três grupos.

Cinqüenta e sete pacientes (58,7\%) apresentavam endometriose e formaram o grupo A; vinte e sete pacientes $(27,8 \%)$ possuíam queixas clínicas porém sem endometriose e compuseram o grupo B e as treze $(13,4 \%)$ que não apresentavam queixas clínicas nem endometriose e constituíram o grupo C. As alterações diagnosticadas nas pacientes do grupo B foram: 4 casos de cisto ovariano, 4 casos de leiomioma, 11 casos de dor pélvica sem alteração à videolaparoscopia e 8 casos de aderências pélvicas. Por falta de líquido peritoneal, foram excluídos 8 casos das pacientes com suspeita de endometriose (grupos A e B) e 2 do grupo C. 
Nas Tabela 1 estão descritos os resultados relativos à fase do ciclo menstrual no momento da realização da videolaparoscopia nos três grupos. Constatou-se que não havia diferença em relação aos grupos $A$ e $B(p>0,05)$, havendo predomínio dos casos na primeira fase do ciclo menstrual. As pacientes do grupo C, por sua vez, apresentaram distribuição eqüitativa em relação às fases folicular e lútea.

TABELA 1: Fase do ciclo menstrual em que foram realizadas as cirurgias nos três grupos (A: com sintoma e com endometriose, B: com sintoma e sem endometriose e C:sem sintoma e sem endometriose

\begin{tabular}{lcccccc}
\hline & \multicolumn{7}{c}{ GRUPO } \\
\hline & \multicolumn{2}{c}{ A $(\mathrm{N}=58)$} & \multicolumn{2}{c}{$\mathbf{B}(\mathrm{N}=27)$} & \multicolumn{2}{c}{$\mathbf{C}(\mathrm{N}=13)$} \\
FASE DO CICLO & $\mathbf{N}$ & $\%$ & $\mathbf{N}$ & $\%$ & $\mathbf{N}$ & $\%$ \\
FOLICULAR & 47 & 82,8 & 19 & 70,4 & 6 & 46,2 \\
LÚTEA & 10 & 17,2 & 8 & 29,6 & 7 & 53,8 \\
TOTAL & 57 & 100 & 27 & 100 & 13 & 100 \\
\hline AxB p>0,05 (nível descritivo de probabilidade do teste qui-quadrado)
\end{tabular}


Na Tabela 2 estão contidos os sintomas apresentados pelos grupos $A$ e $B$, destacando-se que as mulheres do grupo $C$ não possuíam queixas pelo critério seletivo. Houve diferença estatística entre estes grupos em relação à dismenorréia incapacitante $(p<0,01)$, dispareunia $(p<0,01)$, dor acíclica $(p<0,01)$, infertilidade $(p=0,02)$ e alteração intestinal $(p=0,01)$.

TABELA 2: Sintomas das pacientes dos grupos A e B (A: com sintoma e com endometriose, $B$ : com sintoma e sem endometriose)

\begin{tabular}{|c|c|c|c|c|c|}
\hline \multirow[b]{2}{*}{ SINTOMA } & \multicolumn{2}{|c|}{$\begin{array}{c}\text { GRUPOS } \\
\text { A }\end{array}$} & \multicolumn{2}{|r|}{ B } & \multirow[b]{2}{*}{$\mathbf{p}^{\star}$} \\
\hline & $\mathbf{N}$ & $\%$ & $\mathbf{N}$ & $\%$ & \\
\hline DISMENORRÉIA LEVE/MODERADA & 17 & 29,3 & 6 & 22,2 & 0,08 \\
\hline DISMENORRÉIA SEVERA/INCAPACITANTE & 38 & 65,5 & 6 & 22,2 & $<0,01$ \\
\hline DISPAREUNIA DE PROFUNDIDADE & 31 & 53,5 & 9 & 33,3 & $<0,01$ \\
\hline DOR ACÍCLICA & 34 & 58,6 & 10 & 37,0 & $<0,01$ \\
\hline INFERTILIDADE & 21 & 36,2 & 6 & 22,2 & 0,02 \\
\hline ALTERAÇÃO INTESTINAL & 30 & 51,7 & 2 & 7,4 & 0,01 \\
\hline ALTERAÇÃO URINÁRIA & 2 & 3,5 & 0 & 0,0 & $1,00^{* *}$ \\
\hline
\end{tabular}


As características das pacientes com endometriose (grupo A) quanto ao estadiamento (ASRM, 97), local de acometimento e tipo histológico estão contidos na Tabela 3. Verifica-se que os estádios III e IV predominaram sobre os estádios I e II. Na maior parte dos casos havia mais de um local de doença na cavidade abdominal (94 focos, média de 1,6 sítios/caso) e o padrão histológico era composto por mais de um tipo (91\% das pacientes).

TABELA 3: Estadiamento da American Society for Reproductive Medicine (1997), local de apresentação e tipo histológico das pacientes do grupo A (pacientes com sintoma e com endometriose)

\begin{tabular}{llrr}
\hline \multicolumn{1}{c}{ VARIÁVEL } & CATEGORIA & N & \multicolumn{1}{c}{$\%$} \\
\hline \multirow{2}{*}{ ESTÁDIO } & I & 8 & 13,8 \\
& II & 16 & 27,6 \\
& III & 4 & 6,9 \\
& IV & 30 & 51,7 \\
& & & \\
LOCAL & Peritônio & 27 & 46,6 \\
& Ovário & 36 & 62,1 \\
& Profunda & 31 & 53,4 \\
& & & \\
& BD & 1 & 1,7 \\
& E & 4 & 6,9 \\
TIPO & E+BD & 18 & 31,1 \\
HISTOLÓGICO* & E+I & 3 & 5,2 \\
& E+M & 32 & 55,1 \\
\hline (*) E (estromal), BD (bem diferenciado), \\
M (misto), I (indiferenciado). &
\end{tabular}


Os resultados referentes às concentrações de IL-1B, IL-6 e SAA no líquido peritoneal e no sangue se encontram na Tabela 4. Observa-se, em relação ao líquido peritoneal, que as concentrações de IL-1B dos grupos $A$ e $B$ não diferiram entre si $(p>0,05)$, e foram significativamente maiores que as do grupo $C(p=0,03)$. Quanto à IL-6 como na IL-1, as concentrações dos grupos $A$ e $B$ não diferiram entre si $(p>0,05)$ e foram significativamente maiores que as do grupo $C(p=0,02)$. Em relação à SAA as concentrações dos grupos $A$ e $B$ não diferiram entre si e foram superiores que as do grupo C. Observa-se dos resultados no soro em relação à IL-1ß, que as concentrações dos grupos $A$ e $B$ não diferiram entre si ( $p>0,05)$, as concentrações do grupo $A$ foram significativamente maiores que as do grupo $C(p=0,02)$ e não houve diferença entre as concentrações dos grupos $B$ e C ( $p>0,05)$. Quanto à IL-6, as concentrações dos grupos A e B não diferiram entre si $(p>0,05)$ e foram significativamente maiores que as do grupo $C(p=0,01)$. Em relação às concentrações séricas de SAA os grupos $A, B$ e $C$ não diferiram entre si $(p>0,05)$. 
TABELA 4: Valores de média, desvio-padrão, mediana, limites mínimo e máximo dos marcadores no líquido peritoneal (LP) e no sangue nos três grupos estudados (A: com sintoma e com endometriose, B: com sintoma e sem endometriose e C: sem sintoma e sem endometriose).

\begin{tabular}{cll|ccc|ccc}
\hline & & & \multicolumn{3}{c}{ LP } & \multicolumn{3}{c}{ SANGUE } \\
\hline & GRUPO & N & MEDIANA & DP & $\mathbf{p}^{*}$ & MEDIANA & DP & $\mathbf{p}^{*}$ \\
\hline & $A$ & 57 & 11,22 & 25,36 & & 1,83 & 3,68 & \\
IL-1 & $B$ & 27 & 15,62 & 19,07 & $<0,01$ & 1,16 & 2,10 & 0,02 \\
& $C$ & 13 & 1,91 & 2,49 & & 0,80 & 0,23 & \\
& & & & & & & & \\
& $A$ & 57 & 6,80 & 46,31 & & 3,70 & 1,70 & \\
IL-6 & $B$ & 27 & 8,60 & 8,74 & 0,02 & 3,90 & 1,41 & $<0,01$ \\
& $C$ & 13 & 3,40 & 1,90 & & 2,00 & 0,80 & \\
& & & & & & & & \\
& $A$ & 57 & 310,30 & 97,79 & & 14,01 & 32,30 & \\
SAA & $B$ & 27 & 306,20 & 88,18 & 0,01 & 10,39 & 8,73 & 0,35 \\
& $C$ & 13 & 53,4 & 58,16 & & 9,5 & 15,90 & \\
\hline
\end{tabular}

$\left.{ }^{*}\right)$ nível descritivo de probabilidade do teste não-paramétrico de Kruskal-Wallis IL-1ß e IL-6 pg/ml, SAA $\mathrm{ng} / \mathrm{ml}$

Na Tabela 5 apresentam-se as concentrações dos mediadores no líquido peritoneal e no sangue dos três grupos, subdividindo os resultados do grupo A segundo estádio inicial (I-II) ou avançado (III-IV). No líquido peritoneal quanto à IL$1 B$, as concentrações dos grupos A I-II, A III-IV e B não diferiram entre si $(p>0,05)$, mas diferiram significativamente do grupo $C(p=0,02)$. Quanto à IL-6 os grupos não diferiram entre si, com exceção do grupo $A$ I-II frente ao grupo $C(p=0,02)$. Em relação à SAA os grupos $A$ e $B$ não diferiram entre si; e tiveram concentrações superiores às do grupo $C(p>0,05)$. No sangue quanto à IL-1B, as concentrações dos grupos A I-II, A III-IV e B não diferiram entre si ( $p>0,05)$, porém as concentrações do grupo A III-IV diferiram significativamente das do grupo C $(p=0,02)$. 
Quanto à IL-6, os grupos A I-II, A III-IV e B não diferiram entre si ( $p>0,05)$, porém, foram significativamente diferentes do grupo $C(p=0,02)$. Em relação a SAA, os grupos não diferiram entre si $(p>0,05)$.

TABELA 5: Valores de média, desvio-padrão, mediana, limites mínimo e máximo dos marcadores no líquido peritoneal, nos três grupos estudados ( $A$ : com sintoma e com endometriose, B: com sintoma e sem endometriose e C: sem sintoma e sem endometriose), conforme o estadiamento da ASRM (1997)

\begin{tabular}{|c|c|c|c|c|c|c|c|c|}
\hline & & & & LP & & & ANGUE & \\
\hline & GRUPO & $\mathbf{N}$ & MEDIANA & DP & $\mathbf{p}^{*}$ & MEDIANA & DP & $\mathbf{p}^{*}$ \\
\hline & A I-II & 22 & 11,02 & 34,67 & & 1,72 & 1,41 & \\
\hline & $A I I I-I V$ & 35 & 11,22 & 18,22 & & 1,94 & 4,64 & \\
\hline IL-1 & $B$ & 27 & 15,62 & 19,07 & $<0,01$ & 1,16 & 2,10 & 0,03 \\
\hline & $C$ & 13 & 1,91 & 2,49 & & 0,80 & 0,23 & \\
\hline & A I-II & 22 & 5,05 & 48,48 & & 3,10 & 1,65 & \\
\hline & $A I I I-I V$ & 35 & 7,60 & 45,48 & & 3,90 & 1,69 & \\
\hline IL-6 & $B$ & 27 & 8,60 & 8,74 & 0,02 & 3,90 & 1,41 & $<0,01$ \\
\hline & C & 13 & 3,40 & 1,90 & & 2,00 & 0,00 & \\
\hline & A I-II & 22 & 323,70 & 91,29 & & 14,74 & 13,73 & \\
\hline & $A$ III-IV & 35 & 294,10 & 97,40 & 0,02 & 13,29 & 41,19 & 0,27 \\
\hline SAA & $B$ & 27 & 306,20 & 88,18 & & 10,39 & 8,73 & \\
\hline & C & 13 & 53,4 & 58,16 & & 9,5 & 15,90 & \\
\hline
\end{tabular}

$\left(^{\star}\right)$ nível descritivo de probabilidade do teste não-paramétrico de Kruskal-Wallis IL-1ß e IL-6 pg/ml, SAA $\mathrm{ng} / \mathrm{ml}$ 
$\mathrm{Na}$ Tabela 6 estão contidos os resultados das concentrações dos marcadores segundo a fase do ciclo menstrual no líquido peritoneal e no sangue. Pode-se observar que, ao subdividirmos as concentrações dos mediadores segundo a fase do ciclo, não foram verificadas diferenças entre os grupos $\mathrm{A}$ e $\mathrm{B}$ e intra-grupos $(p>0,05)$.

TABELA 6: Valores de média, desvio-padrão, mediana, limites mínimo e máximo dos marcadores no líquido peritoneal e no sangue, nos três grupos estudados ( $A$ : com sintoma e com endometriose, B: com sintoma e sem endometriose), conforme a fase do ciclo menstrual

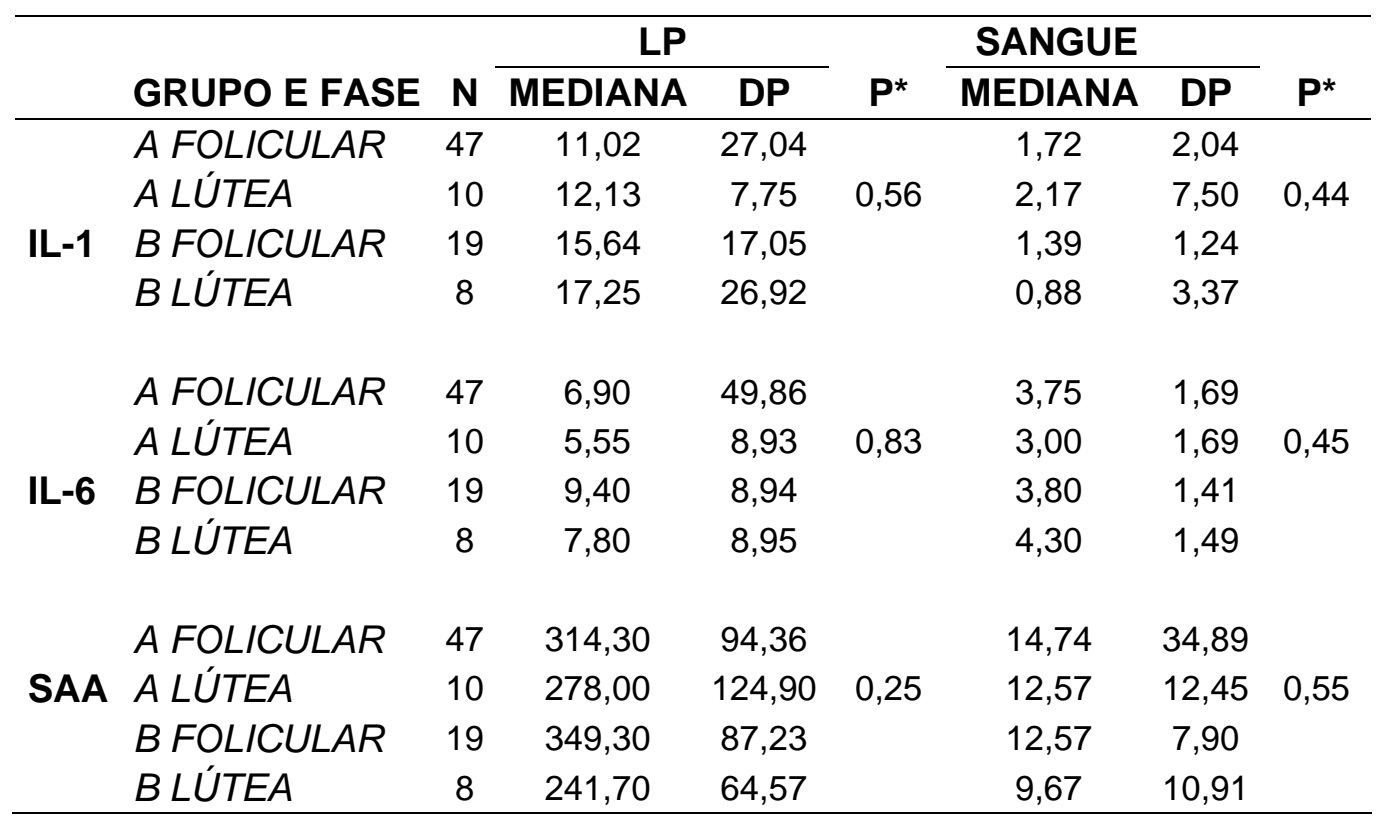

(*) nível descritivo de probabilidade do teste não-paramétrico de Kruskal-Wallis IL-1ß e IL- $6 \mathrm{pg} / \mathrm{ml}$, SAA $\mathrm{ng} / \mathrm{ml}$ 
As concentrações dos mediadores nos grupos A e B no sangue e no líquido peritoneal, considerando as queixas clínicas das pacientes, estão contidas nas tabelas no Anexo C. Observamos que:

-em relação à dismenorréia severa/incapacitante, houve aumento da IL-1ß no líquido peritoneal das pacientes do grupo $B$ frente às do grupo $A$ sem esta queixa $(p=0,03)$, porém esta correlação não foi observada no sangue (Gráfico 1);

- em relação à infertilidade, houve aumento de SAA no sangue das pacientes com endometriose e com a queixa, frente aos demais grupos $(p=0,02)$, porém este aumento não foi verificado no líquido peritoneal (Gráfico 2);

-em relação à dismenorréia moderada, dor acíclica e dispareunia, não houve diferença significativa no líquido peritoneal ou no sangue entre os grupos A e B .

As queixas de alteração intestinal ocorreram em apenas 2 pacientes e as de alteração urinária não ocorreram no grupo $B$, não permitindo a comparação estatística das concentrações de marcadores frente a estes sintomas nos grupos A e B. 
GRÁFICO 1

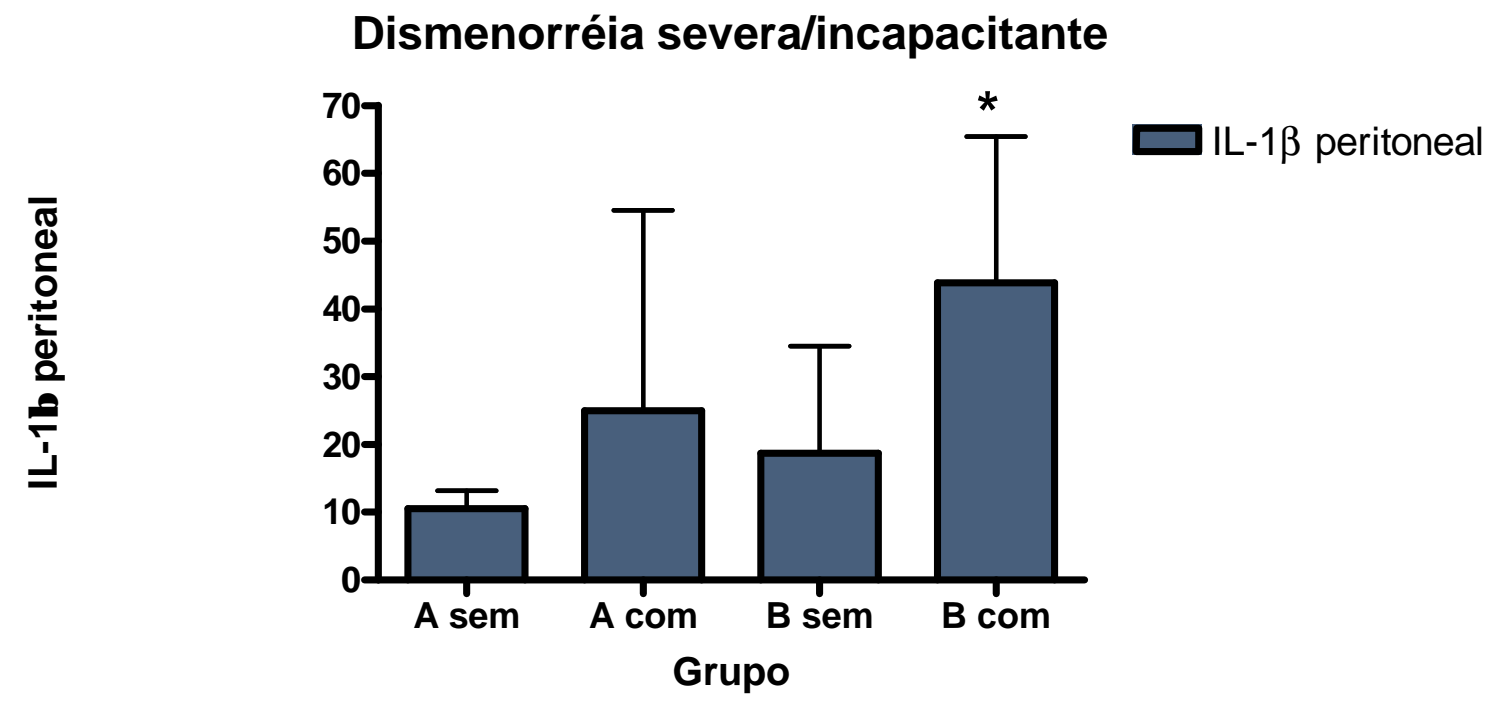

IL- $1 \beta \mathrm{pg} / \mathrm{ml}$

\section{GRÁFICO 2}

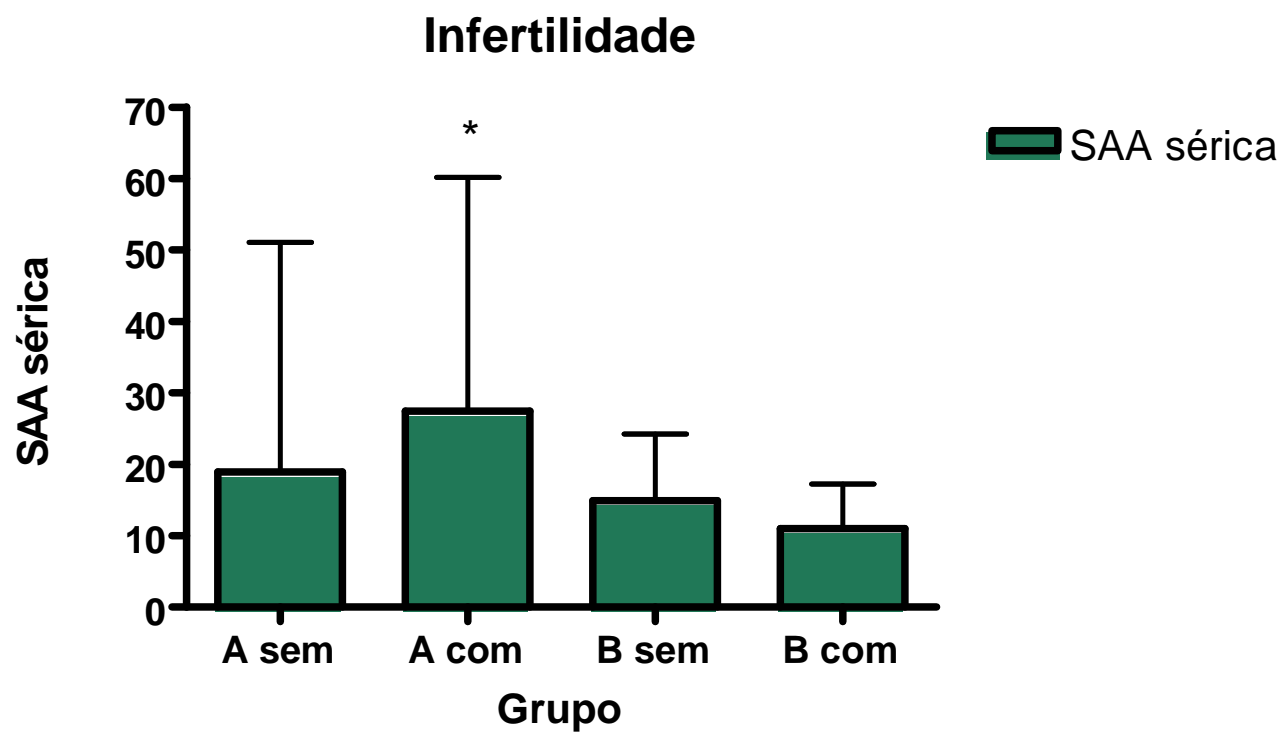


Ao analisarmos as concentrações dos mediadores no grupo $A$ segundo 0 local de acometimento da doença, verificamos que a IL-6 sérica apresentou níveis superiores nos casos de doença exclusivamente no peritônio, em relação às pacientes com a doença em outros sítios. Esta diferença não foi verificada no líquido peritoneal. Não existiram diferenças nas concentrações dos mediadores séricos ou peritoneais nos casos em que a doença se manifesta no ovário ou em outros locais, como também não verificamos diferenças nos casos de doença profunda frente aos demais casos (Tabela 7).

As concentrações séricas e peritoneais dos mediadores no grupo A não mostraram diferenças significativas comparando-se os casos com tipo histológico indiferenciado frente aos demais (Tabela 8). 
TABELA 7: Valores de média, desvio-padrão, mediana, limites mínimo e máximo dos marcadores no líquido peritoneal e no sangue no grupo A (com sintoma e com endometriose), segundo o principal local de doença (peritônio, ovário ou doença profunda)

\begin{tabular}{|c|c|c|c|c|c|c|c|c|}
\hline \multirow[b]{2}{*}{ LOCALIZAÇÃO } & & \multicolumn{4}{|c|}{ LP } & \multicolumn{3}{|c|}{ SANGUE } \\
\hline & & $\overline{\text { DOENÇA }}$ & MEDIANA & DP & $\mathbf{P}^{*}$ & MEDIANA & DP & $\mathbf{P}^{*}$ \\
\hline & IL-1 & SEM & 11,22 & 34,76 & 0,79 & 2,17 & 4,18 & 0,44 \\
\hline \multirow[t]{5}{*}{ PERITÔNIO } & & COM & 11,42 & 18,15 & & 1,50 & 3,36 & \\
\hline & IL-6 & SEM & 5,65 & 48,42 & 0,31 & 3,10 & 1,48 & 0,01 \\
\hline & & COM & 7,60 & 45,53 & & 4,00 & 1,73 & \\
\hline & SAA & SEM & 310,30 & 104,90 & 0,71 & 13,65 & 14,38 & 0,87 \\
\hline & & COM & 310,30 & 94,37 & & 14,01 & 40,30 & \\
\hline & IL-1 & SEM & 11,22 & 16,77 & 0,98 & 1,94 & 4,11 & 0,69 \\
\hline \multirow[t]{5}{*}{ OVÁRIO } & & COM & 10,62 & 42,46 & & 1,28 & 1,59 & \\
\hline & IL-6 & SEM & 6,90 & 41,48 & 0,46 & 3,80 & 1,55 & 0,15 \\
\hline & & COM & 5,15 & 62,21 & & 3,00 & 2,17 & \\
\hline & SAA & SEM & 296,80 & 106,00 & 0,51 & 14,01 & 23,42 & 0,54 \\
\hline & & COM & 311,60 & 70,43 & & 14,74 & 51,40 & \\
\hline & IL-1 & SEM & 10,42 & 33,76 & 0,34 & 1,28 & 2,51 & 0,64 \\
\hline \multirow{6}{*}{$\begin{array}{l}\text { DOENÇA } \\
\text { PROFUNDA }\end{array}$} & & COM & 11,22 & 18,44 & & 2,17 & 4,28 & \\
\hline & & & & & & & & \\
\hline & IL-6 & SEM & 5,60 & 69,95 & 0,33 & 3,45 & 2,27 & 0,53 \\
\hline & & COM & 8,30 & 25,65 & & 3,70 & 1,25 & \\
\hline & SAA & SEM & 313,00 & 96,58 & 0,85 & 14,74 & 49,62 & 0,77 \\
\hline & & COM & 296,80 & 100,60 & & 14,01 & 10,00 & \\
\hline
\end{tabular}

${ }^{*}$ ) nível descritivo de probabilidade do teste não-paramétrico de Man-Whitney IL-1ß e IL-6 pg/ml, SAA ng/ml 
TABELA 8: Valores de média, desvio-padrão, mediana, limites mínimo e máximo dos marcadores no líquido peritoneal e no sangue no grupo A (com sintoma e com endometriose), segundo a presença de tipo histológico indiferenciado na forma pura ou mista (sem e com)

\begin{tabular}{|c|c|c|c|c|c|c|c|}
\hline & \multirow[b]{2}{*}{$\begin{array}{l}\text { PADRÃO DE } \\
\text { DIFERENCIACÃO }\end{array}$} & \multicolumn{2}{|r|}{ LP } & \multirow[b]{2}{*}{$\mathbf{P}^{*}$} & \multicolumn{3}{|c|}{ SANGUE } \\
\hline & & MEDIANA & DP & & MEDIANA & DP & $\mathbf{P}^{*}$ \\
\hline \multirow[t]{2}{*}{ IL-1 } & $B D E / O U E$ & 11,62 & 36,81 & 0,56 & 1,94 & 3,26 & 0,82 \\
\hline & I E/OU M & 11,12 & 9,00 & & 1,83 & 4,08 & \\
\hline \multirow[t]{2}{*}{ IL-6 } & $B D E / O U E$ & 5,40 & 49,11 & 0,27 & 3,40 & 1,72 & 0,26 \\
\hline & I E/OU M & 7,25 & 44,53 & & 3,85 & 1,69 & \\
\hline \multirow[t]{2}{*}{ SAA } & $B D E / O U E$ & 314,30 & 91,11 & 0,24 & 14,01 & 13,72 & 0,89 \\
\hline & I E/OU M & 296,80 & 101,70 & & 24,01 & 42,90 & \\
\hline
\end{tabular}

BD: Bem diferenciada; E:Estromal, I:Indiferenciada, M:Mista

$\left({ }^{*}\right)$ nível descritivo de probabilidade do teste não-paramétrico de Man-Whitney

IL-1ß e IL-6 pg/ml, SAA $\mathrm{ng} / \mathrm{ml}$

Através dos testes de correlação de Spearman, verificou-se que não é possível predizer o nível peritoneal dos mediadores por meio de sua avaliação no soro. Foi detectado, no entanto, que as pacientes dos grupos A e B que apresentavam níveis mais elevados de IL-1 no peritônio também revelaram níveis mais elevados de IL-6. Não foi comprovada correlação entre estas interleucinas e o SAA.

Através das dosagens dos mediadores foi construída uma curva ROC para se estabelecer qual seria o melhor preditor de endometriose. Foram avaliados a IL-1 no soro e líquido peritoneal e a IL-6 nos mesmos locais. Segundo a área sob a curva ROC podemos observar que o melhor preditor entre os mediadores estudados para a endometriose foi o IL-6 sérico. O ponto de corte $3,45 \mathrm{pg} / \mathrm{ml}$ 
desta interleucina teve sensibilidade de 52,6\%, especificidade de $61,5 \%$ acurácia $52,1 \%$, valor preditivo positivo $61,7 \%$ e valor preditivo negativo $42,9 \%$.para 0 diagnóstico de endometriose na amostra avaliada.

FIGURA 2- Curva ROC avaliando a IL-1, IL-6 e SAA no sangue e fluido peritoneal como preditores da presença de endometriose

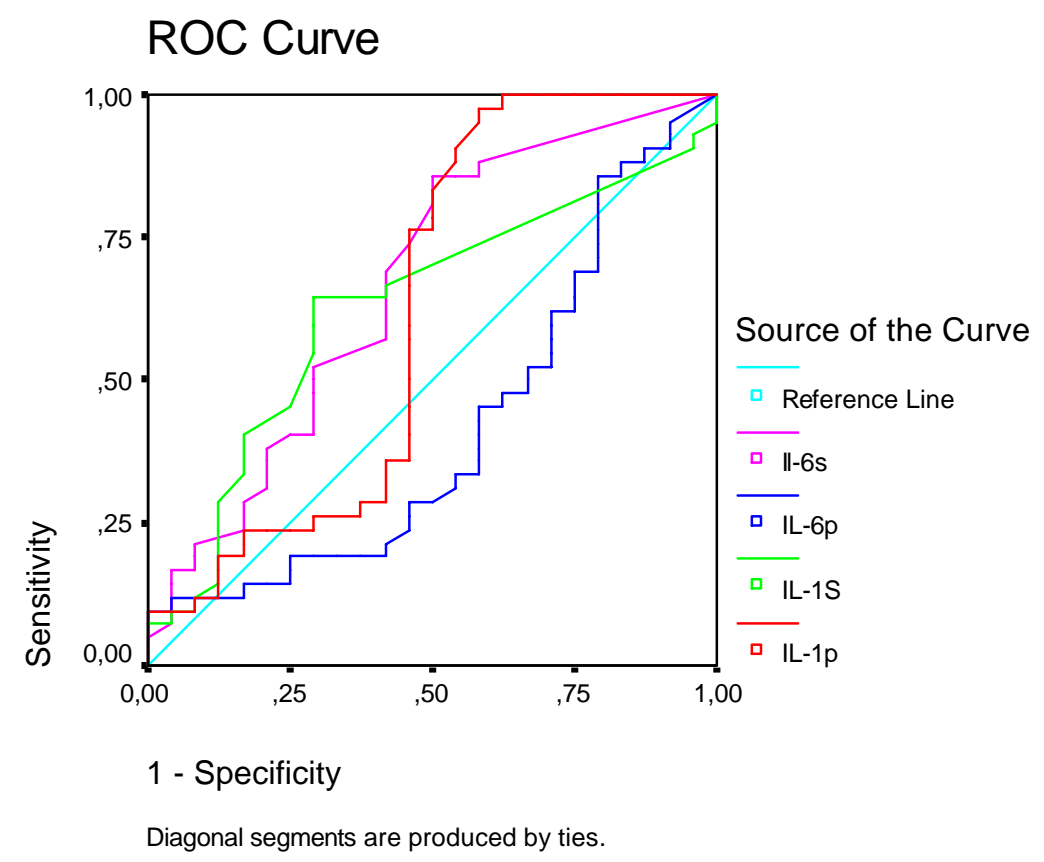

$\begin{array}{cc}\text { AREA UNDER THE CURVE } \\ \text { TEST } & \text { AREA } \\ \text { RESULT } & \\ \text { VARIABLE } & \\ \text { (S) } & \\ \text { IL-1P } & , 621 \\ \text { IL-1S } & , 627 \\ \text { IL-6P } & , 417 \\ \text { IL-6S } & , 668\end{array}$




\section{DISCUSSÃO}

O estudo de citocinas e de marcadores inflamatórios em portadoras de endometriose vem crescendo nos últimos anos, com a finalidade de esclarecer pontos obscuros sobre a etiopatogenia da endometriose e também para colaborar no diagnóstico desta doença. Procuramos neste estudo desenhar criteriosamente o método utilizado, selecionando-se 3 grupos de pacientes: com sintomas e com doença, com sintomas e sem doença e sem sintomas e sem doença. Esta subdivisão visou ampliar a análise das pacientes com suspeita de endometriose melhorando a interpretação dos resultados, de forma pioneira. Além disto, escolhemos citocinas relacionadas à inflamação, assim como a SAA, pela característica inflamatória da doença.

Discutiremos a seguir os resultados encontrados na seqüência analisada:

5.1 As concentrações peritoneais dos mediadores inflamatórios IL-1 $\beta$, IL-6 e SAA em pacientes com endometriose e seu significado

A concentração da IL-1ß no líquido peritoneal apresentou mediana de $11,22 \mathrm{pg} / \mathrm{ml}$ com média de 20,56 $\pm 25,36 \mathrm{pg} / \mathrm{ml}$. Estes resultados também indicam uma grande dispersão dos resultados -mínimo 7,80 e máximo 144,90 (Tabela 4). Estas concentrações foram semelhantes às pacientes do grupo B e foram superiores com significância estatística ao encontrado para o grupo C. $\mathrm{O}$ valor de mediana para IL-1ß no líquido peritoneal foi semelhante ao de Sokolov et al (2005) que encontraram o valor de $24,3 \mathrm{pg} / \mathrm{ml}$ para o grupo de 27 pacientes com endometriose, avaliados com método semelhante, e de Ishimaru et al em 1994 
com 34 casos de pacientes com endometriose com valores até $20 \mathrm{pg} / \mathrm{ml}$ e 19 casos com concentrações superiores a este valor. Outros autores verificaram concentrações menores que as apresentadas, como Ho em 1996, mas este incluiu na sua casuística pacientes medicadas, e de Calhaz et al em 2003 (máximo 8,7 $\mathrm{pg} / \mathrm{ml}$ ), mas este englobou 67 pacientes com endometriose e infertilidade, sem outras queixas clínicas.

A avaliação das concentrações de IL-6 no líquido peritoneal no grupo A resultou em média de $22,16 \mathrm{pg} / \mathrm{ml} \pm 46,31$ e mediana de $6,8 \mathrm{pg} / \mathrm{ml}$. Este valor é

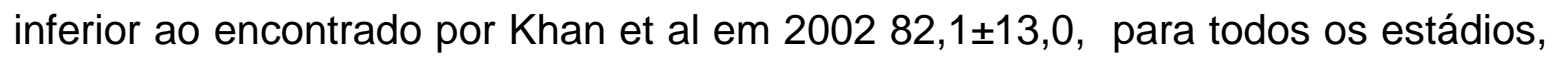

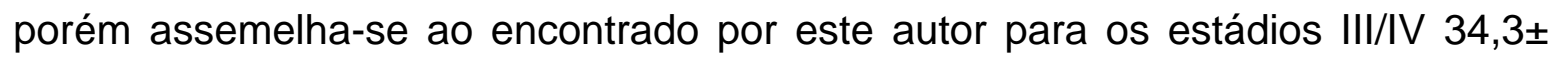
4,8;. O resultado é compatível com o encontrado por Rapkin et al em 2000 de $15,34 \pm 50,56$. Não houve diferença estatística em nosso estudo em relação ao grupo B e os valores foram superiores com significância estatística frente ao grupo C. Khan em 2002 não verificaram diferença estatística entre 20 pacientes com endometriose e 30 pacientes do grupo controle que apresentavam dor pélvica, infertilidade ou dismenorréia como em nosso estudo. No trabalho verificamos um DP muito elevado 45,31, indicando a grande dispersão dos resultados. Isto também foi observado por Skrzypczak em 2005, quando as medianas de vários subgrupos clínicos com endometriose situaram-se entre 0 a $110 \mathrm{pg} / \mathrm{ml}$ e o desvio padrão de 49 a 290,3; sendo os valores mais elevados verificados nas pacientes férteis com endometriose.

No líquido peritoneal o valor encontrado para a SAA foi $309,40 \pm 97,79$ $\mathrm{ng} / \mathrm{ml}$ com mediana de $310,30 \mathrm{ng} / \mathrm{ml}$. Não foram encontrados outros trabalhos na literatura que tenham avaliado este mediador de fase aguda no líquido peritoneal 
em casos de endometriose apesar da SAA ter sido descoberta em 1973 nos casos de amiloidose e ter sido encontrada posteriormente em outras doenças inflamatórias como descrito previamente. É produzida em resposta a citocinas entre elas a IL-1 e a IL-6. Apenas Abrão et al em 1997 avaliaram sua possível correlação com a endometriose em análise sérica. O elevado desvio padrão comprova a grande dispersão dos resultados para esta proteína. Não foi encontrada diferença entre os grupos A e B e houve diferença estatística para 0 grupo C. Isto pode se justificar pois a SAA é um marcador de inflamação e na comparação com o grupo $\mathrm{C}$, sem sintomas, houve diferença significante.

$\mathrm{Na}$ análise dos mediadores IL-1ß,IL-6 e SAA no líquido peritoneal observamos grande dispersão dos resultados, a ausência de diferença entre os casos de endometriose e outras afecções ginecológicas benignas e a diferença significativa frente a pacientes normais evidenciado novamente 0 caráter inflamatório da doença, porém não discriminatório frente a outras moléstias com componente inflamatório.

5.2-As concentrações séricas dos mediadores inflamatórios IL-1 $\beta$, IL-6 e SAA em pacientes com endometriose e seu significado

Os valores encontrados para IL-1B no soro (Tabela 4) para o grupo A foram: mediana 1,83pg/ml, média de $2,75 \mathrm{pg} / \mathrm{ml} \pm 3,68$ dentro de uma faixa de 0 a 20,62. Este valor foi similar ao encontrado por Koumantakis et al em 1994, 2,97 $\pm 2,83 \mathrm{pg} / \mathrm{ml}$. Estes resultados não foram significantemente diferentes dos encontrados no grupo B e foram superiores aos encontrados para o grupo C, evidenciando o aspecto inflamatório da doença. Também Pellicer et al em 1998, 
Kharfi e Akoum em 2001 e Wieser et al dois anos após, não encontraram diferenças entre a IL-1 sérica de pacientes com endometriose frente a pacientes com afecções benignas.

A concentração sérica de IL-6 para o grupo A teve mediana de 3,70pg/ml e média de 4,04 $\pm 1,70 \mathrm{pg} / \mathrm{ml}$ (Tabela 5). Estas concentrações também não diferiram daquelas encontradas no grupo B e foram estatisticamente maiores frente ao grupo C. As concentrações são superiores às encontradas por Somigliana et al em 2004 (máximo de 1,4pg/ml) e inferiores às verificadas por Bedaiwy et al em 2002$21,58 \mathrm{pg} / \mathrm{ml}(8,22-60,36)$ também utilizando a técnica de ELISA, e às observadas por Darai et al em 2003 que encontraram mediana de 18,4 pg/ml $\pm 13,5$ através da técnica de radioimunoensaio. Bedaiwy et al compararam 20 pacientes com endometriose, 8 casos de infertilidade sem causa aparente e 11 pacientes sem doença. As concentrações de IL-6 encontradas nas pacientes com endometriose não diferiram do grupo com infertilidade e foram superiores ao grupo controle, como no presente estudo. Somigliana et al (2004) avaliou 80 pacientes submetidas à videolaparoscopia, sendo $45 \mathrm{com}$ endometriose e $35 \mathrm{com}$ outras afecções benignas, e também não observou diferença significante entre os níveis de IL-6 (nas afecções benignas máximo de 1,9pg/ml). Darai estudou 34 pacientes com endometriomas, 30 com cistos ovarianos benignos e 13 com neoplasias malignas de ovário. Encontrou diferença significante entre os grupos, sendo que os endometriomas apresentaram valores intermediários e as neoplasias malignas as maiores concentrações, apesar da grande dispersão dos valores encontrados para os casos de endometriose, assim como em nosso estudo. 
A concentração de SAA sérica média (tabela 5) encontrada foi 21,93 \pm $32,30 \mathrm{ng} / \mathrm{ml}$ com mediana de $14,01 \mathrm{ng} / \mathrm{ml}$. As medianas foram assemelhadas para os grupos A e B porém houve diferença com o grupo $C$ (menor). No único estudo envolvendo esta proteína e pacientes com endometriose de Abrão et al (1997) os valores de concentração média variaram de 4,1 $\pm 0,8$ (estádio I/II) a 38,8 \pm 17 (estádio III/IV).

Em conjunto a análise das concentrações séricas dos mediadores avaliados mostrou novamente grande dispersão dos valores nos casos de endometriose, diferença significante frente a pacientes normais (grupo C), e não mostraram diferença frente a outras afecções benignas, como previamente observado por Kharfi et al 2001 e Bedaiwy et al 2002.

\subsection{As concentrações séricas e peritoneais dos mediadores inflamatórios IL-1 $\beta$, IL-6 e SAA nos pacientes segundo as características da endometriose}

Ao subdividirmos os resultados séricos do grupo A segundo o estádio da doença ou fase do ciclo menstrual, e compará-los aos mesmos grupos B e C observamos que persiste a ausência de diferença entre os grupos A e B, e se mantêm as diferenças frente ao grupo C. estádio (Tabela 5 e 6). Ao abordarmos o estadiamento frente às concentrações dos mediadores estudados observamos no líquido peritoneal níveis semelhantes para IL-1ß nos 4 estádios, para IL-6 uma tendência para níveis mais elevados nos estádios III/IV e para SAA os níveis tenderam a serem maiores nos estádios I/II. Na literatura para IL-1ß os estudos apresentados salientam não haver diferenças nas concentrações entre os estádios 
ou esta seria discretamente superior nos estádios iniciais (I/II) (Mori et al, 1992; Sokolov et al, 2005). Para a IL-6 nossos resultados são semelhantes aos de Schroder et al (1996) com aumento discreto nos estádios avançados. Por outro lado, Keenan et al em 1995 encontrou níveis quatro vezes maiores nos estádios avançados frente aos iniciais. Quanto às concentrações dos mediadores encontradas no grupo $\mathrm{A}$ frente à fase do ciclo menstrual, ao avaliarmos as fases folicular e secretora do ciclo menstrual, houve uma tendência de maiores concentrações no sangue e líquido peritoneal de IL-1 na fase lútea e de IL-6 e SAA na fase folicular. A maior parte dos estudos observa valores superiores para IL-1 na fase lútea, não encontra diferenças entre as concentrações de IL-6 frente às duas fases do ciclo e a SAA não foi avaliada previamente.

Frente às queixas clínicas apresentadas pelos grupos A e B em relação aos mediadores analisados no sangue e no líquido peritoneal pudemos observar uma diferença significativa com IL-1ß nas pacientes com dismenorréia severa no grupo B frente às pacientes do grupo A sem a queixa (Gráfico 1). Quanto à infertilidade ocorreu aumento de SAA no sangue das pacientes com endometriose com esta queixa frente aos demais grupos (Gráfico 2). Não ocorreu diferença em relação à dismenorréia moderada, dor acíclica e dispareunia (Tabelas no Anexo C). Não foi encontrado na literatura estudo que correlacione estas interleucinas com os sintomas apresentados pelas pacientes. O que parte dos trabalhos descreve é a diminuição dos níveis de IL-1 e IL-6 após procedimentos cirúrgicos, que são acompanhados muitas vezes de melhora dos sintomas. 
Quanto ao tipo histológico envolvido, ao avaliarmos a presença de tecido indiferenciado observamos que quando este se encontra presente de forma isolada ou associado a tecido diferenciado as concentrações no líquido peritoneal de IL-1B e SAA tendem a ser menores e de IL-6 tendem a ser maiores que nos casos de tecido diferenciado, porém sem significância estatística. Quanto à avaliação sérica na mesma situação a única diferença frente ao líquido peritoneal consiste em maiores níveis de SAA nos casos indiferenciados. Não há relatos prévios do estudo destes mediadores frente ao tipo histológico.

Frente às concentrações dos mediadores avaliados no grupo $\mathrm{A}$ em relação ao local de acometimento apenas foi observado o aumento da IL-6 sérica nos casos de endometriose com acometimento exclusivo de peritônio. Não foram verificados maiores níveis das interleucinas ou do SAA nos casos de acometimento ovariano ou doença profunda. Os demais trabalhos na literatura não avaliaram a concentração destes mediadores frente à localização da doença proposta por Nisolle e Donnez em 1997. Este resultado poderia indicar que estas citocinas não estariam relacionadas ao local de acometimento da doença.

5.4 Correlações entre o nível sérico e peritoneal de cada mediador IL$1 \beta$, IL-6 e SAA nos pacientes com endometriose

Ao avaliarmos as medianas dos mediadores estudados no peritônio frente aos níveis séricos encontramos valores 8 a 13 vezes superiores no peritônio frente aos níveis séricos nos grupos A e B e 2 a 3 vezes superiores em pacientes normais (grupo C) para a IL-1B; 2 vezes maiores para IL-6 nos grupos A e B e 1,7 vezes maior para o grupo C; e 22-30X maior para SAA nos grupos A e B. Não 
chega a ocorrer diferenças significativas entre os grupos A e B pois temos uma grande faixa de distribuição de resultados e estas se sobrepõem e esta grande diferença entre os níveis reflete o aumento dos mediadores no sítio de inflamação independente de sua natureza.

Foram avaliadas as correlações entre os níveis séricos e peritoneais do mesmo marcador, e a possibilidade destes mediadores servirem como teste diagnóstico não invasivo para a doença.

O teste de correlação de Spearman não encontrou uma relação direta neste estudo entre os níveis séricos e peritoneais de cada mediador, o que possibilitaria a inferência dos níveis peritoneais a partir dos níveis séricos. O único autor que encontrou uma correlação direta foi Harada et al em 1997 com a IL-6.

Ao analisarmos as relações entre concentrações dos três mediadores no sangue e no líquido peritoneal através do mesmo teste observamos uma correlação positiva entre a IL-1ß e a IL-6 no líquido peritoneal para os grupos A e B, conforme classicamente é descrito nas reações de imunidade inata. Esta correlação direta entre IL-1 e IL-6 não foi observada no sangue.

\section{5 - O significado dos resultados}

O estudo avaliou 84 pacientes com queixas compatíveis com endometriose pélvica (grupos A e B) e 13 pacientes sem doença alguma. A mediana de idade de 33 anos corresponde à media do setor de endometriose já avaliada previamente

em estudo de 2005 (Neme, 2005). É uma doença relacionada fundamentalmente à menacme com declínio da incidência após os 44 anos de idade (Signorello et al, 
1997). Os grupos A e B não apresentaram diferenças em relação à média de idade.

Os grupos A e B foram operados predominantemente na primeira fase do ciclo, mas isto ocorreu de forma aleatória. O grupo $\mathrm{C}$ foi operado nas duas fases, uniformemente, conforme seria previsível.

O percentual de casos com endometriose entre os 84 casos com queixas compatíveis foi elevado - 67,8\% (57/84) porém compatível como encontrado para pacientes sintomáticas. Na literatura o percentual de prevalência da endometriose varia segundo o perfil das pacientes dependendo da amostra avaliada- cerca de $70 \%$ entre as que apresentam algia pévica crônica, 50 a $68 \%$ dos casos quando a queixa é de infertilidade e apenas $5 \%$ em pacientes assintomáticas. No presente estudo a maior parte das queixas era de dismenorréia, considerado o sintoma mais prevalente da doença. No grupo A também houve maior incidência de infertilidade, dispareunia, dor acíclica e sintomas intestinais. O número de queixas por paciente também foi significativamente superior no grupo A frente ao grupo B $(p<0,05)$. O grupo A apresentou 173 sintomas para os 57 casos, com média de 2,9 sintomas/caso enquanto foram 39 entre os outros 27 casos sem endometriose, 1,4/caso. Em nosso meio desde o início dos sintomas até o diagnóstico da doença transcorrem em média sete anos.(Arruda et al, 2003). Isto pode explicar o predomínio dos casos dos estádios avançados(III e IV-58,6\%) frente aos estádios iniciais(I/II-41,4\%) em nossa amostra $O$ fato deste estudo ter sido realizado em hospital de refência aumenta a probabilidade de uma doença de base para justificar a sintomatologia da paciente, pelo tempo de duração do quadro até a avaliação cirúrgica. No entanto parte das pacientes do grupo B apresentaram 
apenas queixas clínicas sem achados à videolaparoscopia. A avaliação dos três mediadores de inflamação neste subgrupo são semelhantes ao dos outros pacientes com doenças de base do grupo B e do próprio grupo A com endometriose ( $p$ das medianas $>0,05$ ). Isto nos leva à suspeita de que havia nestas pacientes uma doença inflamatória em atividade, de causa não identificada no momento. Isto fica mais evidente quando os resultados dos grupos $A$ e $B$ foram comparados com as 13 pacientes submetidas à laqueadura tubárea, sem queixas clínicas e sem alterações à videolaparoscopia (grupo C). Ainda com estas ressalvas, o tamanho da amostra foi adequado à avaliação dos mediadores (Somigliana et al, 2004). Em 60,3\% dos casos estava presente tecido endometrial indiferenciado de forma isolada ou associado a outros tipos histológicos, o que vai de acordo com a maior predominância de casos nos estádios III e IV como já descrito por Abrão et al em 2003.

\subsubsection{Importância diagnóstica dos mediadores séricos IL-1 $\beta$, IL-6 e}

\section{SAA para a endometriose}

A avaliação destes marcadores para o diagnóstico da endometriose, evidenciou que o melhor a ser utilizado seria a IL-6 sérica. O ponto de corte 3,45 $\mathrm{pg} / \mathrm{ml}$ desta interleucina apresentou sensibilidade de $52,6 \%$ e especificidade de $61,5 \%$ sendo superior às descritas para o Ca-125 por Somigliana et al em 2004 e Martinez et al em 2007. Porém estes índices não foram tão elevados quanto os

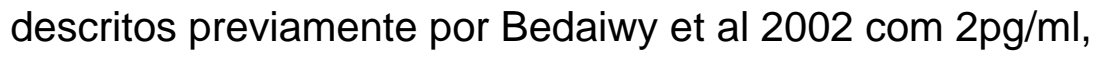




\subsubsection{Importância diagnóstica dos mediadores peritoneais IL-1 $\beta$, IL-6 e}

\section{SAA para a endometriose}

As teorias mais aceitas em torno da etiopatogenia da endometriose abordam 0 advento da menstruação retrógrada associada à alterações imunológicas que permitem o estabelecimento e desenvolvimento de focos ectópicos de endométrio. Entre as alterações imunológicas principais temos o aumento do número de macrófagos peritoniais ativados com inflamação, menor atividade citotóxica das células Natural Killer (células NK) e dos linfócitos sanguíneos a presença de autoanticorpos séricos e produção alterada de citocinas e fatores de crescimento (Berkkanoglu e Arici 2003, Antsiferova et al. 2005, Siristatidis et al. 2006). Este estudo se propôs a analisar as concentrações das principais citocinas envolvidas na resposta imune inata a IL-1ß e a IL-6, e uma de suas proteínas efetoras a SAA. A ação destas citocinas fazem parte das alterações imunológicas envolvidas na gênese e perpetuação da doença

Ao se analisar o caráter inflamatório da endometriose juntamente com os resultados de estudos experimentais que evidenciavam aumento dos níveis de IL1 nas culturas de tecido endometriótico esperava-se encontrar maiores concentrações da IL-1 no líquido peritoneal, local da doença, frente aos níveis séricos. Porém para se determinar a ação desta interleucina não bastam somente seus níveis mas a concomitante avaliação das concentrações do receptor do tipo II e do antagonista da IL-1. 
Em 1993 Simon et al caracterizaram a presença de receptor do tipo I no endométrio durante todo o ciclo menstrual principalmente na fase lútea inicial $\left(15^{\circ}\right.$ $19^{\circ}$ dias $)$ e fase lútea tardia $\left(25^{\circ}-28^{\circ}\right.$ dias $)$.

O receptor do tipo II da IL-1 tem como única função inibir (inibidor competitivo) o receptor do tipo I (Akoum et al, 2000). Em 2001, Akoum et al mostraram uma diminuição do receptor tipo II da IL1 em pacientes com endometriose, principalmente nos estádios I e II. Kharfi et al, no mesmo ano, mostraram que, ao longo de todo o ciclo menstrual, existiria nas pacientes com endometriose uma diminuição do receptor celular do tipo 2 da IL-1 (Kharfi et al, 2001; Kharfi e Akoum, 2002). Em 2007 Akoum et al encontraram uma diminuição do receptor do tipo II e um aumento do receptor do tipo I no foco endometriótico o que potencializaria a ação da IL-1 (Akoum et al 2007).

Mori et al em 1992 mostraram um aumento da produção do antagonista do receptor da interleucina 1 (IL-1RA) nos estádios avançados de endometriose (Mori et al, 1992). Sahakian et al, em 1993, mostraram que a expressão do antagonista do receptor da IL-1 ocorre preferencialmente no endométrio tópico frente ao foco endometriótico das mesmas pacientes. Isto possibilitaria o crescimento e a diferenciação dos focos endometrióticos, além de uma reação inflamatória exacerbada com aderências (Sahakian et al, 1993). Zhang et al em 2007 detectaram em estudo com 74 pacientes com endometriose e 44 controles uma diminuição significativa do IL-1RA nos casos de endometriose e esta se mostrou mais acentuada nos estádios mais avançados (Zhang et al, 2007). Portanto a concentração da IL-1 isolada não determina a real extensão do papel desta 
interleucina na gênese e manutenção da doença devendo ser considerada a concentração do receptor do tipo II e do antagonista da IL-1 de forma conjunta.

Este estudo foi pioneiro por agrupar a análise de 3 substâncias afins, relacionadas à inflamação, no sangue e no fluido peritoneal relacionadas a importantes aspectos da doença. Isto permitiu que obtivéssemos subsídios adicionais para a compreensão da etiopatogenia da doença e também que pudéssemos progredir no sentido de encontrarmos um marcador para 0 diagnóstico laboratorial da endometriose. 


\section{CONCLUSÕES}

6.1-As concentrações séricas e peritoneais da IL-1B, IL-6 e SAA mostraram-se elevadas em pacientes com endometriose pélvica.

6.2 -As concentrações no líquido peritoneal e no soro da IL-1ß, IL-6 e SAA em pacientes com endometriose pélvica foram semelhantes às de pacientes sem endometriose mas com sintomas, e maiores do que nas que as pacientes sem endometriose e sem sintomas.

6.3 Pacientes com endometriose e queixa de infertilidade apresentaram níveis mais elevados de SAA sérica nas pacientes com endometriose.

6.4 A fase do ciclo menstrual, o tipo histológico envolvido e o local de acometimento da doença não influíram de forma significante nas concentrações séricas ou peritoneais de IL-1ß, IL-6 e SAA.

6.5 A IL-1ß, IL6 e SAA apresentam limitada sensibilidade e especificidade para o diagnóstico da endometriose. O melhor parâmetro foi a concentração de IL-6 sérica que no ponto de corte $3,45 \mathrm{pg} / \mathrm{ml}$ teve sensibilidade de 52,6\% e especificidade de $61,5 \%$ superiores ao que é descrito para o CA-125, o marcador sérico mais empregado atualmente. 


\section{REFERÊNCIAS BIBLIOGRÁFICAS}

D`Hooghe TM, Debrock S. Endometriosis, retrograde menstruation and peritoneal inflammation in women and in baboons. Hum Reprod Update. 2002; 8(1):84-8.

Abbott JA, Hawe J, Clayton RD, Garry R. The effects and effectiveness of laparoscopic excision of endometriosis: a prospective study with 2-5 year followup. Hum Reprod. 2003; 18(9):1922-27.

Sampson JA. Perforating hemorrhagic cysts of the ovary, their importance and especially their relation to pelvic adenomas of endometrial type. Arch Surg. 1921; 3:245-7.

Giudice LC, Kao LC. Endometriosis. Lancet. 2004; 364:1789-99.

Donnez J, Van Langendonckt A. Typical and subtle atypical presentations of endometriosis. Curr Opin Obstet Gynecol. 2004; 16(5):431-7.

D'Hooghe TM, Kyama C, Debrock S, Meuleman C, Mwenda JM. Future directions in endometriosis research. Ann N Y Acad Sci. 2004; 1034:316-25.

Antsiferova YS, Sotnikova NY, Posiseeva LV, Shor AL. Changes in the T-helper cytokine profile and in lymphocyte activation at the systemic and local levels in women with endometriosis. Fertil Steril. 2005; 84(6):1705-11. 
Abrao MS, Podgaec S, Dias JA, Averbach M, Garry R, Ferraz Silva LF, Carvalho FM. Deeply infiltrating endometriosis affecting the rectum and lymph nodes. Fertil Steril. 2006; 86(3):543-7.

Meyer R. Uber den Staude der Frage der Adenomyosites Adenomyoma in Allgemeinen und Adenomyonetitis Sarcomatosa. Zentralbl Gynakol. 1919; 36:74559.

Berkkanoglu M, Arici A. Immunology and endometriosis. AJRI. 2003; 50:48-59.

Siristatidis C, Nissotakis C, Chrelias C, lacovidou H, Salamalekis E. Immunological factors and their role in the genesis and development of endometriosis. J Obstet Gynaecol Res. 2006; 32(2):162-70.

Podgaec S, Abrao MS, Dias JA, Rizzo LV, de Oliveira RM, Baracat EC. Endometriosis: an inflammatory disease with a Th2 immune response component. Hum Reprod. 2007; 22(5):1373-9.

Abrao MS, Neme RM, Carvalho FM, Aldrighi JM, Pinotti JA. Histological classification of endometriosis as a predictor of response to treatment. Int $\mathrm{J}$ Gynaecol Obstet. 2003; 82:31-40. 
Revised American Society for Reproductive Medicine classification of endometriosis: 1996. Fertil Steril. 1997;67:817-21.

Nisolle M, Donnez J. Peritoneal endometriosis, ovarian endometriosis and adenomyotic nodules of the rectovaginal septum are three different entities. Fertil Steril. 1997; 68:585-96.

Eskenazi B, Warner M, Bonsignore L, Olive D, Samuels S, Vercellini P. Validation study of nonsurgical diagnosis of endometriosis. Fertil Steril. 2001; 76(5):929-35.

De Hondt A, Meuleman C, Tomassetti C, Perraer K, D`Hooghe TM. Endometriosis and assisted reproduction: the role for reproductive surgery? Curr Opin Obstet Gynecol. 2006; 18(4):374-9.

Wu MH, Sun HS, Lin CC, Hsiao KY, Chuang PC, Pan HA, Tsai SJ. Distinct mechanisms regulate cyclooxygenase- 1 and -2 in peritoneal macrophages of women with and without endometriosis. Mol Hum Reprod. 2002; 8(12):1103-10.

Okaro E, Condous G, Khalid A, Timmerman D, Ameye L, Huffel SV. Bourne T. The use of ultrasound-based 'soft markers' for the prediction of pelvic pathology in women with chronic pelvic pain--can we reduce the need for laparoscopy? BJOG. 2006; 113(3):251-6. 
Abrão MS, Gonçalves MOC, Dias JA, Podgaec S, Chamie LP, Blasbalg R. Comparison between clinical examination, transvaginal sonography and magnetic resonance imaging for the diagnosis of deep endometriosis Human Reprod 2007 in press.

Niloff JM, Knapp RC, Schaetzl E, Reynolds C, Bast RC. CA125 antigen levels in obstetric and gynecologic patients. Obstet Gynecol. 1984; 64(5):703-7.

Bast RC Jr, Klug TL, St John E, Jenison E, Niloff JM, Lazarus H, Berkowitz RS, Leavitt T, Griffiths CT, Parker L, Zurawski VR Jr, Knapp RC. A radioimmunoassay using a monoclonal antibody to monitor the course of epithelial ovarian cancer. $\mathrm{N}$ Engl J Med. 1983; 309(15):883-7.

Abrao MS, Podgaec S, Filho BM, Ramos LO, Pinotti JA, de Oliveira RM. The use of biochemical markers in the diagnosis of pelvic endometriosis. Hum Reprod. 1997; 12(11):2523-7.

Koyama N, Matsuura K, Okamura H. Cytokines in the peritoneal fluid of patients with endometriosis. Int J Gynaecol Obstet. 1993; 43(1):45-50.

D'Hooghe TM, Xiao L, Hill JA. Cytokine profiles in autologous peritoneal fluid and peripheral blood of women with deep and superficial endometriosis. Arch Gynecol Obstet. 2001; 265(1):40-4. 
Pizzo A, Salmeri FM, Ardita FV, Sofo V, Tripepi M, Marsico S. Behaviour of cytokine levels in serum and peritoneal fluid of women with endometriosis. Gynecol Obstet Invest. 2002; 54(2):82-7.

Bedaiwy MA, Falcone T, Sharma RK, Goldberg JM, Attaran M, Nelson DR, Agarwal A. Prediction of endometriosis with serum and peritoneal fluid markers: a prospective controlled trial. Hum Reprod. 2002; 17(2):426-31.

Somigliana E, Vigano P, Tirelli AS, Felicetta I, Torresani E, Vignali M, Di Blasio AM. Use of the concomitant serum dosage of CA 125, CA 19-9 and interleukin-6 to detect the presence of endometriosis- results from a series of reproductive age women undergoing laparoscopic surgery for benign gynaecological conditions. Hum Reprod. 2004; 19(8):1871-6.

Martinez S, Garrido N, Coperias JL, Pardo F, Desco J, Garcia-Velasco JA, Simon C, Pellicer A. Serum interleukin-6 levels are elevated in women with minimal-mild endometriosis. Hum Reprod. 2007; 22(3):836-842.

Cao X, Yang D, Song M, Murphy A, Parthasarathy S. The presence of endometrial cells in the peritoneal cavity enhances monocyte recruitment and induces inflammatory cytokines in mice: implications for endometriosis. Fertil Steril. 2004; 82 Suppl 3:999-1007. 
Gallinelli A, Chiossi G, Giannella L, Marsella T, Genazzani AD, Volpe A. Different concentrations of interleukins in the peritoneal fluid of women with endometriosis: relationships with lymphocyte subsets. Gynecol Endocrinol. 2004;18(3):144-51.

Rossi M, Sharkey AM, Vigano P, Fiore G, Furlong R, Florio P, Ambrosini G, Smith SK, Petraglia F. Identification of genes regulated by interleukin-1beta in human endometrial stromal cells. Reproduction. 2005; 130(5):721-9.

Kondera-Anasz Z, Sikora J, Mielczarek-Palacz A, Jonca M. Concentrations of interleukin (IL)-1alpha, IL-1 soluble receptor type II (IL-1sRII) and IL-1 receptor antagonist (IL-1 Ra) in the peritoneal fluid and serum of infertile women with endometriosis. Eur J Obstet Gynecol Reprod Biol. 2005; 123(2):198-203.

Cao WG, Morin M, Metz C, Maheux R, Akoum A. Stimulation of macrophage migration inhibitory factor expression in endometrial stromal cells by interleukin 1beta involving the nuclear transcription factor NF kappa B. Biol Reprod. 2005; 73(3):565-70 .

Fakih H, Baggett B, Holtz G, Tsang KY, Lee JC, Williamson HO. Interleukin-1: a possible role in the infertility associated with endometriosis. Fertil Steril. $1987 ; 47(2): 213-7$.

Sueldo CE, Kelly E, Montoro L, Subias E, Baccaro M, Swanson JA,Steinleitner A, Lambert $\mathrm{H}$. Effect of interleukin-1 on gamete interaction and mouse embryo development. J Reprod Med. 1990; 35(9):868-72. 
Uda $S$. The role of the peritoneal macrophage on the infertility associated with endometriosis. Osaka City Med J. 1992; 38(1):11-26.

Sheth KV, Roca GL, al-Sedairy ST, Parhar RS, Hamilton CJ, al-Abdul Jabbar F. Prediction of successful embryo implantation by measuring interleukin-1-alpha and immunosuppressive factor(s) in preimplantation embryo culture fluid. Fertil Steril. $1991 ; 55(5): 952-7$.

Mori H, Sawairi M, Nakagawa M, Itoh N, Wada K, Tamaya T. Peritoneal fluid interleukin-1 beta and tumor necrosis factor in patients with benign gynecologic disease. Am J Reprod Immunol. 1991; 26(2):62-7.

Mori H, Sawairi M, Nakagawa M, Itoh N, Wada K, Tamaya T. Expression of interleukin-1 (IL-1) beta messenger ribonucleic acid (mRNA) andIL-1 receptor antagonist mRNA in peritoneal macrophages from patients with endometriosis. Fertil Steril. 1992; 57(3):535-42.

Ishimaru, T; Masuzaki, H; Samejima, T; Fujishita, A; Nakamura, K; Yamabe, T Influence of Ovarian Endometrioma on Fertility. Am J of Obstet \& Gyneco 1994; 171(2): 541-545.

Keenan JA, Chen TT, Chadwell NL, Torry DS, Caudle MR. IL-1 beta, TNF-alpha, and IL-2 in peritoneal fluid and macrophage-conditioned media of women with endometriosis. Am J Reprod Immunol. 1995; 34(6):381-5. 
Ho HN, Wu M, Chao K, Chen C, Chen, S, Chen H, Yang, Y. Decrease in interferon gamma production and impairment of T-lymphocyte proliferation in peritoneal fluid of women with endometriosis. Am J Obstet \& Gynecol. 1996; 175(5):1236-1241.

Skrzypczak J, Szczepanska M, Puk E, Kamieniczna M, Kurpisz M. Peritoneal fluid cytokines and SICAM-1 in minimal endometriosis: search for discriminating factors between infertility and/or endometriosis. Eur J Obstet Gynecol Reprod Biol. 2005; 122(1):95-103.

Sokolov DI, Solodovnikova NG, Pavlov OV, Niauri DA, Volkov NN, Sel'kov SA. Study of cytokine profile and angiogenic potential of peritoneal fluid inpatients with external genital endometriosis. Bull Exp Biol Med. 2005; 140(5):541-4.

Kharfi A, Akoum A. Correlation between decreased type-II interleukin-1 receptor and increased monocyte chemotactic protein-1 expression in the endometrium of women with endometriosis. Am J Reprod Immunol. 2001; 45(4):193-9.

Calhaz CJ, Costa AP, Santos MC, Palma MLC. Soluble intercellular adhesion molecule 1 in the peritoneal fluid of patients with endometriosis correlates with the extension of peritoneal implants. Eur J Obstet Gynecol Reprod Biol. 2003; 106 $170-4$. 
Wieser F, Hefler L, Tempfer C, Vlach U, Schneeberger C, Huber J, Wenzl R. Polymorphism of the interleukin-1beta gene and endometriosis. J Soc Gynecol Investig. 2003; 10(3):172-5.

Hudelist G, Lass H, Keckstein J, Walter I, Wieser F, Wenzl R, Mueller R, Czerwenka K, Kubista E, Singer CF. Interleukin 1alpha and tissue-lytic matrix metalloproteinase-1 are elevated in ectopic endometrium of patients with endometriosis. Hum Reprod. 2005; 20(6):1695-701.

Mori H, Nakagawa M, Itoh N, Wada K, Tamaya T. Danazol suppresses the production of interleukin-1 beta and tumor necrosis factor by human monocytes. Am J Reprod Immunol. 1990; 24(2):45-50.

Koumantakis E., Matalliotakis I., Neonaki M., Froudarakis G., Georgoulias V. Soluble serum interleukin-2 receptor,interleukin-6 and interleukin-1a in patients with endometriosis and controls. Arch Gynecol Obstet. 1994; 255:107-12.

Meresman GF, Bilotas MA, Lombardi E, Tesone M, Sueldo C, Baranao RI. Effects of $\mathrm{GnRH}$ analogues on apoptosis and release of interleukin-1beta and vascular endothelial growth factor in endometrial cell cultures from patients with endometriosis. Hum Reprod. 2003; 18(9):1767-71. 
Akoum A, Lemay A, Brunet C, Herbert J. Secretion of monocyte chemotactic protein -1 by cytokine-stimulated endometrial cells of women with endometriosis. Fertil Steril. 1995; 63(2):322-28.

Akoum A, Jolicoeur C, Boucher A. Estradiol amplifies interleukin-1-induced monocyte chemotactic protein-1 expression by ectopic endometrial cells of women with endometriosis. J Clin Endocrinol Metab. 2000; 85(2):896-904.

Akoum A, Lawson C, McColl S, Villeneuve M. Ectopic endometrial cells express high concentrations of interleukin (IL)-8 in vivo regardless of the menstrual cycle phase and respond to oestradiol by up-regulating IL-1-induced IL-8 expression in vitro Mol Hum Reprod. 2001 7(9): 859-66.

Akoum A, Lemay A, Maheux R. Estradiol and interleukin-1 exert a synergistic stimulatory effect on the expression of the chemokine regulated upon activation, normal T cell expressed, and secreted in endometriotic cells. J Clin Endocrinol Metab. 2002; 87(12):5785-92.

Vigano $\mathrm{P}$, Gaffuri B, Somigliana E, Busacca M, Di Blasio AM, Vignali M. Expression of intercellular adhesion molecule (ICAM)-1 mRNA and protein is enhanced in endometriosis versus endometrial stromal cells in culture. Mol Hum Reprod. 1998; 4(12):1150-6. 
Mueller MD, Mazzucchelli L, Buri C, Lebovic DI, Dreher E, Taylor RN. Epithelial neutrophil-activating peptide 78 concentrations are elevated in the peritoneal fluid of women with endometriosis. Fertil Steril. 2003; 79 Suppl 1:815-20.

Sillem M, Prifti S, Monga B, Arslic T, Runnebaum B. Integrin-mediated adhesion of uterine endometrial cells from endometriosis patients to extracellular matrix proteins is enhanced by tumor necrosis factor alpha (TNF alpha) and interleukin-1 (IL-1). Eur J Obstet Gynecol Reprod Biol. 1999; 87(2):123-7.

Lebovic DI, Bentzien F, Chao VA, Garrett EN, Meng YG, Taylor RN. Induction of an angiogenic phenotype in endometriotic stromal cell cultures by interleukin1beta. Mol Hum Reprod. 2000; 6(3):269-75.

Maas JW, Calhaz-Jorge C, ter Riet G, Dunselman GA, de Goeij AF, StruijkerBoudier HA. Tumor necrosis factor-alpha but not interleukin-1 beta or interleukin-8 concentrations correlate with angiogenic activity of peritoneal fluid from patients with minimal to mild endometriosis. Fertil Steril. 2001; 75(1):180-5.

Lebovic DI, Chao VA, Martini JF, Taylor RN. IL-1beta induction of RANTES (regulated upon activation, normal T cell expressed and secreted) chemokine gene expression in endometriotic stromal cells depends on a nuclear factor-kappaB site in the proximal promoter. J Clin Endocrinol Metab. 2001; 86(10):4759-64. 
Lebovic D, ,Baldocchi R, Mueller M, Taylor R. Altered expression of a cell-cycle suppressor gene, Tob-1, in endometriotic cells by cDNA array analyses. Fertil Steril. 2002; 78 (4) 849-54.

Wu MH, Wang CA, Lin CC, Chen LC, Chang WC, Tsai SJ. Distinct regulation of cyclooxygenase-2 by interleukin-1beta in normal and endometriotic stromal cells.J Clin Endocrinol Metab. 2005 Jan;90(1):286-95. Epub 2004 Oct 13.

Braundmeier A G, Nowak R A. Cytokines regulate matrix metalloproteinases in human uterine endometrial fibroblast cells through a mechanism that does not involve increases in extracellular matrix metalloproteinase inducer. Am $\mathrm{J}$ of Reprod Immunol. 2006; 56:201-214.

Yamauchi N, Harada T, Taniguchi F, Yoshida S, Iwabe T, Terakawa N. Tumor necrosis factor-alpha induced the release of interleukin-6 from endometriotic stromal cells by the nuclear factor-kappaB and mitogen-activated protein kinase pathways. Fertil Steril. 2004; 82 Suppl 3:1023-8.

Khan KN, Masuzaki H, Fujishita A, Kitajima M, Hiraki K, Sekine I, Matsuyama T, Ishimaru T. Interleukin-6- and tumour necrosis factor alpha-mediated expression of hepatocyte growth factor by stromal cells and its involvement in the growth of endometriosis. Hum Reprod. 2005; 20(10):2715-23. 
Hirota Y, Osuga Y, Hirata T, Harada M, Morimoto C, Yoshino O, Koga K, Yano T, Tsutsumi O, Taketani Y. Activation of protease-activated receptor 2 stimulates proliferation and interleukin (IL)-6 and IL-8 secretion of endometriotic stromal cells. Hum Reprod. 2005; 20(12):3547-53.

Boutten A, Dehoux M, Edelman P, Seta N, Menard A, Madelenat P, Durand G. IL6 and acute phase plasma proteins in peritoneal fluid of women with endometriosis. Clin Chim Acta. 1992; 210(3):187-95.

Imaizumi E, Hirata J, Tode T, Kikuchi Y, Nagata I. Interleukin-6 production in endometriosis Nippon Sanka Fujinka Gakkai Zasshi. 1993 May;45(5):415-22

Keenan JA, Chen TT, Chadwell NL, Torry DS, Caudle MR. Interferon-gamma (IFN-gamma) and interleukin-6 (IL-6) in peritoneal fluid and macrophageconditioned media of women with endometriosis. Am J Reprod Immunol. 1994; 32(3):180-3.

Schroder W, Gaetje R, Baumann R. Interleukin-6 and soluble interleukin-6 receptor in peritoneal fluid and serum of patients with endometriosis. Clin Exp Obstet Gynecol. 1996; 23(1):10-4.

Tseng JF, Ryan IP, Milam TD, Murai JT, Schriock ED, Landers DV, Taylor RN. Interleukin-6 secretion in vitro is up-regulated in ectopic and eutopic endometrial stromal cells from women with endometriosis. J Clin Endocrinol Metab. 1996; 81(3):1118-22. 
Harada T, Yoshioka H, Yoshida S, Iwabe T, Onohara Y, Tanikawa M, Terakawa N. Increased interleukin-6 levels in peritoneal fluid of infertile patients with active endometriosis. Am J Obstet Gynecol. 1997; 176(3):593-7.

Khan KN, Masuzaki H, Fujishita A, Hamasaki T, Kitajima M, Hasuo A, Miyamura Y, Ishimaru T. Association of interleukin-6 and estradiol with hepatocyte growth factor in peritoneal fluid of women with endometriosis. Acta Obstet Gynecol Scand. 2002; 81(8):764-71 .

Rapkin A, Morgan M, Bonpane C, Martinez-Maza O. Peritoneal fluid interleukin-6 in women with chronic pelvic pain. Fertil Steril. 2000; 74(2):325-8.

Darai E, Detchev R, Hugol D, Quang NT. Serum and cyst fluid levels of interleukin (IL) -6 , IL-8 and tumour necrosis factor-alpha in women with endometriomas and benign and malignant cystic ovarian tumours. Hum Reprod. 2003;18(8):1681-5.

Iwabe T, Harada T, Sakamoto Y, Iba Y, Horie S, Mitsunari M, Terakawa N. Gonadotropin-releasing hormone agonist treatment reduced serum interleukin-6 concentrations in patients with ovarian endometriomas. Fertil Steril. 2003;80(2):300-4.

Malle E, De Beer F C. Human serum amyloid A (SAA) protein: a prominent acutephase reactant for clinical practice. Eur J Clin Invest. 1996; 26(6):427-435. 
Uhlar CM, Whitehead AS. Serum amyloid A, the major vertebrate acute-phase reactant. Eur J Biochem.1999;265(2):501-23.

Urieli-Shoval S, Linke RP, Matzner Y. Expression and function of serum amyloid A, a major acute-phase protein, in normal and disease states. Curr Opin Hematol. 2000;7(1):64-9.

Abrao MS, Neme RM, Carvalho FM, Aldrighi JM, Pinotti JA. Histological classification of endometriosis as a predictor of response to treatment. Int $\mathrm{J}$ Gynaecol Obstet. 2003; 82(1):31-40.

Buyalos RP, Watson JM, Martinez-Maza O. Detection of interleukin-6 in human follicular fluid. Fertil Steril. $1992 ; 57(6): 1230-4$.

Pellicer A, Albert C, Mercader A, Bonilla-Musoles F, Remohí J, Simón C. The follicular and endocrine environment in women with endometriosis: local and systemic cytokine production. Fertil Steril. 1998; 70(3):425-31.

Neme, RM. Avaliação do perfil epidemiológico e clínico de portadoras de endometriose pélvica e identificação dos principais fatores de riscorelacionados à doença obtidos através de questionário interativo.São Paulo: Faculdade demedicina da USP; 2005. 
Signorello LB, Harlow BL, Cramer DW, Spiegelman D, Hill JA. Epidemiologic determinants of endometriosis: a hospital-based case-control study. Ann Epidemiol. 1997; 7(4):267-741.

Arruda MS, Petta CA, Abrão MS, Benetti-Pinto CL. Time elapsed from onset of symptoms to diagnosis of endometriosis in a cohort study of Brazilian women. Hum Reprod. 2003; 18(4):756-9.

Simon C, Piquette GN, Frances A, Westphal LM, Heinrichs WL, Polan ML. Interleukin-1 type I receptor messenger ribonucleic acid expression in human endometrium throughout the menstrual cycle. Fertil Steril. 1993; 59(4):791-6.

Akoum A, Jolicoeur C, Boucher A. Estradiol amplifies interleukin-1-induced monocyte chemotactic protein-1 expression by ectopic endometrial cells of women with endometriosis. J Clin Endocrinol Metab. 2000; 85(2):896-904.

Akoum A, Jolicoeur C, Kharfi A, Aube M. Decreased expression of the decoy interleukin-1 receptor type II in human endometriosis. Am J Pathol. 2001; 158(2):481-9 .

Kharfi A, Boucher A, Akoum A. Abnormal interleukin-1 receptor type II gene expression in the endometrium of women with endometriosis. Biol Reprod. 2001; 66(2):401-6. 
Kharfi A, Akoum A. Soluble interleukin-1 receptor type II blocks monocyte chemotactic protein-1 secretion by U937 cells in response to peripheral blood serum of women with endometriosis. Fertil Steril. 2002; 78(4):836-42.

Akoum A, Lawson C, Herrmann-Lavoie C, Maheux R. Imbalance in the expression of the activating type I and the inhibitory type II interleukin 1 receptors in endometriosis. Hum Reprod. 2007; 22(5):1464-73.

Sahakian V, Anners J, Haskill S, Halme J. Selective localization of interleukin-1 receptor antagonist in eutopic endometrium and endometriotic implants. Fertil Steril. 1993; 60(2):276-9.

Zhang X, Wen J, Deng L, Lin J. Decreased levels of peritoneal interleukin-1 receptor antagonist in patients with endometriosis and disease-related dysmenorrhea. Fertil Steril. 2007 Feb 9; [Epub ahead of print] 


\section{Anexo A}

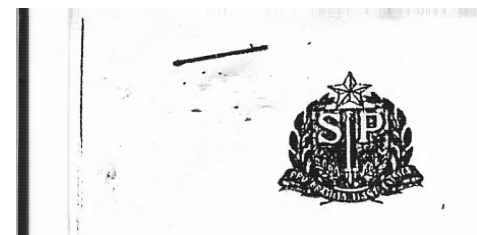

HOSPITAL DAS ClíNICAS

da FACULDADE DE MEDICINA DA UNIVERSIDAdE DE SÁO PAULO

CAIXA POSTAL, 8091 - SIO PAULO - BRASIL

\section{DIRETORIA CLÍNICA}

\section{Comissão de Ética para Análise de Projetos de Pesquisa}

\section{APROVACAO}

A. Comissaio de Ética para Amólise de Projetos de Pesquisa - CAppesq da Diretorio Clinica do Hornitol dos climicas e da Faculdade de Medicina da Universidade de Säo Poulo, en sessdo de 09.10.02, ARROVOU o Protocolo de Pesquisa n 769102, intitulado: "Avalocedo do THFalla, hGF.

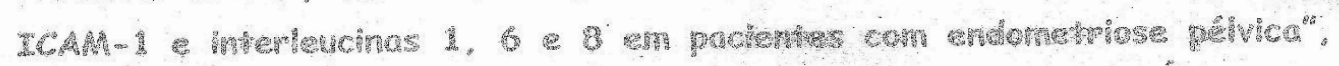
apresentado pelo Departamento de ORSTETRLCHA E GNECOLOCLA, bem como - Termo de Consentmento Livre Esclarecido.

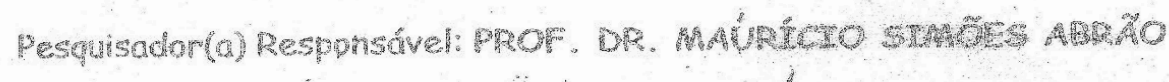

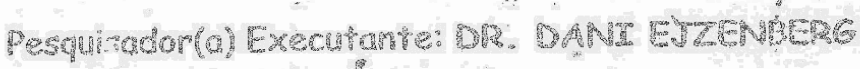

CAPpesq, 09 de Outubro de 2002.

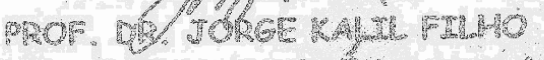

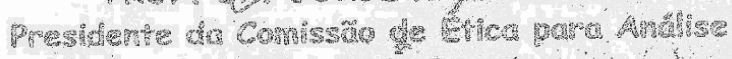

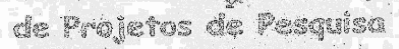




\section{ANEXO-B}

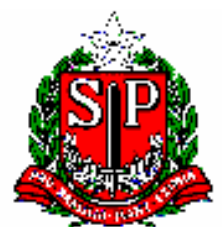

HOSPITAL DAS CLÍNICAS

DA

FACULDADE DE MEDICINA DA UNIVERSIDADE DE SÃO PAULO

\section{TERMO DE CONSENTIMENTO PÓS -INFORMAÇÃO}

(Instruções para preenchimento no verso)

\section{I - DADOS DE IDENTIFICAÇÃO DO SUJEITO DA PESQUISA OU RESPONSÁVEL LEGAL}

1. NOME DO PACIENTE :

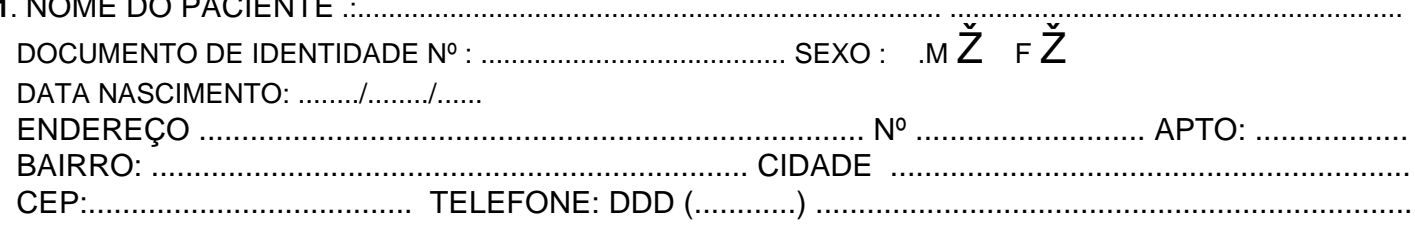

2.RESPONSÁVEL LEGAL

NATUREZA (grau de parentesco, tutor, curador etc.) DOCUMENTO DE IDENTIDADE : SEXO: $M \breve{Z}$ F Z̆ DATA NASCIMENTO.: ..................... ENDEREÇO № APTO: BAIRRO: CEP: TELEFONE: DDD CIDADE: ..).

\section{II - DADOS SOBRE A PESQUISA CIENTÍFICA}

1.TÍTULO DO PROTOCOLO DE PESQUISA: "Avaliação das concentrações das interleucinas 1-ß e 6 e da proteína amilóide A, no líquido peritoneal e no soro de pacientes com endometriose pélvica"

\section{CARGO/FUNÇÃO: chefe do setor de Endometriose} INSCRIÇÃO CONSELHO REGIONAL № 52842 UNIDADE DO HCFMUSP: Departamento de Obstetrícia e Ginecologia 3. AVALIAÇÃO DO RISCO DA PESQUISA:

$\begin{array}{lllll}\text { SEM RISCO } & \check{Z} & \text { RISCO MíNIMO } & \mathbf{X} & \text { RISCO MÉDIO } \\ \text { RISCO BAIXO } & \check{Z} & \text { RISCO MAIOR } & \check{Z} & \end{array}$

(probabilidade de que o indivíduo sofra algum dano como consequência imediata ou tardia do estudo) 4.DURAÇÃO DA PESQUISA : 36 meses 


\section{III - REGISTRO DAS EXPLICAÇÕES DO PESQUISADOR AO PACIENTE OU SEU REPRESENTANTE LEGAL SOBRE A PESQUISA, CONSIGNANDO:}

1. justificativa e os objetivos da pesquisa ; 2. procedimentos que serão utilizados e propósitos, incluind identificação dos procedimentos que são experimentais; 3 . desconfortos e riscos esperados; 4 . benefícios $c$ poderão ser obtidos; $\mathbf{5}$. procedimentos alternativos que possam ser vantajosos para o indivíduo.

1. Você está convidada a participar de um estudo que mede substâncias que fazem parte da inflamação e 1 deverá ajudar no futuro a entender melhor a endometriose, permitindo novos tratamentos e formas diagnóstico.

2. A medição das substâncias que levam a inflamação são feitas através de retirada de pequena quantidade sangue e de um líquido de dentro da barriga sem nenhum prejuízo para sua saúde, quando você tiver que operada, sempre com anestesia, e que será encaminhada para o laboratório para a medição. Depoi! tratamento da senhora seguirá o caminho normal, sendo feito o que precisar para curá-la ou melhorar : problema.

3. Os riscos são os mesmos que a senhora teria se fosse feito só o tratamento do problema da senhora, pois I haverá aumento do tempo de cirurgia, nem quaisquer outros procedimentos que não os normais para : tratamento.

\section{IV - ESCLARECIMENTOS DADOS PELO PESQUISADOR SOBRE GARANTIAS DO SUJEITO DA PESQUIS،}

1. acesso, a qualquer tempo, às informações sobre procedimentos, riscos e benefícios relacionados à pesqui inclusive para dirimir eventuais dúvidas.

2. liberdade de retirar seu consentimento a qualquer momento e de deixar de participar do estudo, sem que i traga prejuízo à continuidade da assistência.

3. salvaguarda da confidencialidade, sigilo e privacidade.

4. disponibilidade de assistência no HCFMUSP, por eventuais danos à saúde, decorrentes da pesquisa.

5. viabilidade de indenização por eventuais danos à saúde decorrentes da pesquisa.

\section{INFORMAÇÕES DE NOMES, ENDEREÇOS E TELEFONES DOS RESPONSÁVEIS PELO ACOMPANHAMENTO DA PESQUISA, PARA CONTATO EM CASO DE INTERCORRÊNCIAS CLÍNICAS I REAÇÕES ADVERSAS.}

Prof. Dr. Maurício Simões Abrão

Av. Dr. Enéas de Carvalho Aguiar, 255 10ª andar ICHC tel 30696248

COMPLEMENTARES:

\section{OBSERVAÇÕES}

\section{VII - CONSENTIMENTO PÓS-ESCLARECIDO}

Declaro que, após convenientemente esclarecido pelo pesquisador e ter entendido o que me foi explica consinto em participar do presente Protocolo de Pesquisa

São Paulo, de de 200 . 
Anexo C

Tabela 1: Valores de média, desvio-padrão, mediana, limites mínimo e máximo dos marcadores no líquido peritoneal (LP), nos dois grupos estudados (A: com sintoma e com endometriose, B: com sintoma e sem endometriose) segundo a presença de dismenorréia severa/incapacitante

\begin{tabular}{ccccccccc}
\hline & GRUPO & N & MÉDIA & DP & MEDIANA & MÍNIMO & MÁXIMO & P* $^{*}$ \\
\hline \multirow{6}{*}{ IL-1 } & A SEM & 20 & 10,55 & 2,62 & 10,12 & 7,80 & 18,86 & \\
& A COM & 37 & 24,99 & 29,56 & 12,63 & 8,61 & 144,90 & \\
& B SEM & 24 & 18,72 & 15,78 & 14,84 & 8,01 & 67,11 & 0,01 \\
& B COM & 3 & 43,86 & 21,55 & 49,42 & 20,07 & 62,08 & \\
& & & & & & & & \\
& IL-6 SEM & 20 & 24,26 & 55,84 & 6,05 & 2,80 & 233,80 & \\
& A COM & 37 & 21,09 & 41,45 & 6,90 & 1,90 & 221,80 & \\
& $B$ SEM & 24 & 10,35 & 9,27 & 7,80 & 1,90 & 35,18 & 0,97 \\
& $B$ COM & 3 & 11,44 & 7,83 & 10,90 & 3,30 & 21,00 & \\
& & & & & & & & \\
& SAA SEM & 20 & 304,50 & 98,64 & 306,20 & 140,80 & 460,90 & \\
& A COM & 37 & 311,60 & 98,96 & 310,30 & 95,08 & 466,30 & \\
& $B$ SEM & 24 & 292,90 & 94,32 & 310,30 & 105,80 & 404,40 & 0,96 \\
& $B$ COM & 3 & 303,10 & 69,38 & 283,40 & 245,70 & 380,20 & \\
\hline
\end{tabular}

$\left.{ }^{*}\right)$ nível descritivo de probabilidade do teste não-paramétrico de Kruskal-Wallis IL-1ß e IL-6 pg/ml, SAA ng/ml

TABELA 2: Valores de média, desvio-padrão, mediana, limites mínimo e máximo dos marcadores no sangue, nos dois grupos estudados (A: com sintoma e com endometriose, B: com sintoma e sem endometriose) segundo a presença de dismenorréia severa/incapacitante

\begin{tabular}{|c|c|c|c|c|c|c|c|c|}
\hline & GRUPO & $\mathbf{N}$ & MÉDIA & DP & MEDIANA & MÍNIMO & MÁXIMO & $\mathbf{P}^{*}$ \\
\hline & A SEM & 20 & 3,63 & 4,95 & 1,94 & 0,61 & 20,62 & \\
\hline & $A C O M$ & 37 & 2,31 & 2,84 & 1,83 & 0,00 & 16,62 & \\
\hline \multirow[t]{4}{*}{ IL-1 } & $B$ SEM & 24 & 1,76 & 1,38 & 1,28 & 0,39 & 5,28 & 0,68 \\
\hline & $B C O M$ & 3 & 2,94 & 4,06 & 1,05 & 0,70 & 10,17 & \\
\hline & A SEM & 20 & 4,04 & 1,61 & 3,80 & 1,90 & 8,10 & \\
\hline & $A C O M$ & 37 & 4,04 & 1,76 & 3,45 & 1,90 & 8,90 & \\
\hline \multirow[t]{3}{*}{ IL-6 } & $B$ SEM & 24 & 3,58 & 1,09 & 3,40 & 1,80 & 5,30 & 0,08 \\
\hline & $B C O M$ & 3 & 5,58 & 1,33 & 5,45 & 3,90 & 7,20 & \\
\hline & A SEM & 20 & 26,29 & 34,79 & 13,65 & 4,60 & 153,10 & \\
\hline \multirow[t]{3}{*}{ SAA } & A COM & 37 & 19,75 & 31,26 & 14,01 & 1,70 & 195,80 & \\
\hline & $B$ SEM & 24 & 13,94 & 7,78 & 12,20 & 0,98 & 28,50 & 0,57 \\
\hline & $B C O M$ & 3 & 14,01 & 13,05 & 9,67 & 6,05 & 37,19 & \\
\hline
\end{tabular}

$\left(^{\star}\right)$ nível descritivo de probabilidade do teste não-paramétrico de Kruskal-Wallis 
TABELA 3: Valores de média, desvio-padrão, mediana, limites mínimo e máximo dos marcadores no líquido peritoneal, nos dois grupos estudados (A: com sintoma e com endometriose, $B$ : com sintoma e sem endometriose) segundo a presença de infertilidade

\begin{tabular}{ccccccccc}
\hline & GRUPO & N & MÉDIA & DP & MEDIANA & MÍNIMO & MÁXIMO & P $^{*}$ \\
\hline \multirow{6}{*}{ IL-1 } & A SEM & 38 & 20,44 & 28,39 & 11,22 & 7,80 & 144,90 & \\
& A COM & 19 & 20,61 & 17,81 & 12,83 & 8,61 & 70,12 & \\
& B SEM & 17 & 23,19 & 17,43 & 16,45 & 8,61 & 62,08 & 0,47 \\
& B COM & 10 & 23,97 & 24,57 & 14,84 & 8,01 & 67,11 & \\
& & & & & & & & \\
& A SEM & 38 & 19,37 & 41,64 & 5,55 & 1,90 & 221,80 & \\
& IL-6 COM & 19 & 28,09 & 55,89 & 10,50 & 2,80 & 233,80 & \\
& $B$ SEM & 17 & 11,10 & 9,16 & 9,40 & 1,90 & 35,18 & 0,31 \\
& $B$ COM & 10 & 9,18 & 8,11 & 5,20 & 1,90 & 21,00 & \\
& & & & & & & & \\
& SAA SEM & 38 & 299,30 & 108,50 & 296,80 & 95,08 & 466,30 & \\
& A COM & 19 & 331,60 & 66,61 & 331,80 & 189,20 & 439,40 & \\
& $B$ SEM & 17 & 310,80 & 99,68 & 350,60 & 105,80 & 404,40 & 0,38 \\
& $B$ COM & 10 & 259,70 & 45,55 & 245,70 & 202,70 & 310,30 & \\
\hline
\end{tabular}

(*) nível descritivo de probabilidade do teste não-paramétrico de Kruskal-Wallis IL-1ß e IL-6 pg/ml, SAA $\mathrm{ng} / \mathrm{ml}$

TABELA 4: Valores de média, desvio-padrão, mediana, limites mínimo e máximo dos marcadores no sangue, nos dois grupos estudados (A: com sintoma e com endometriose, B: com sintoma e sem endometriose) segundo a presença de infertilidade.

\begin{tabular}{|c|c|c|c|c|c|c|c|c|}
\hline & GRUPO & $\mathbf{N}$ & MÉDIA & DP & MEDIANA & MÍNIMO & MÁXIMO & $\mathbf{P}^{*}$ \\
\hline \multirow{4}{*}{ IL-1 } & A SEM & 38 & 2,94 & 4,14 & 1,94 & 0,00 & 20,62 & \multirow{4}{*}{0,64} \\
\hline & A COM & 19 & 2,40 & 2,70 & 1,28 & 0,16 & 10,84 & \\
\hline & B SEM & 17 & 2,03 & 2,27 & 1,16 & 0,39 & 10,17 & \\
\hline & B COM & 10 & 1,84 & 1,54 & 1,32 & 0,70 & 4,61 & \\
\hline \multirow{4}{*}{ IL-6 } & A SEM & 38 & 4,18 & 1,94 & 3,50 & 1,90 & 8,90 & \multirow{4}{*}{0,70} \\
\hline & $A C O M$ & 19 & 3,79 & 1,14 & 3,80 & 1,90 & 6,90 & \\
\hline & $B$ SEM & 17 & 3,89 & 1,41 & 3,90 & 1,80 & 7,20 & \\
\hline & $B C O M$ & 10 & 4,53 & 1,41 & 4,20 & 3,40 & 6,90 & \\
\hline \multirow{4}{*}{ SAA } & A SEM & 38 & 18,94 & 32,14 & 11,84 & 1,70 & 195,80 & \multirow{4}{*}{0,03} \\
\hline & $A C O M$ & 19 & 27,43 & 32,73 & 18,36 & 7,49 & 153,10 & \\
\hline & $B$ SEM & 17 & 14,89 & 9,33 & 12,57 & 0,98 & 37,19 & \\
\hline & B COM & 10 & 11,00 & 6,22 & 9,67 & 3,87 & 22,71 & \\
\hline
\end{tabular}

$\left.{ }^{*}\right)$ nível descritivo de probabilidade do teste não-paramétrico de Kruskal-Wallis IL-1ß e IL-6 pg/ml, SAA $\mathrm{ng} / \mathrm{ml}$ 
TABELA 5: Valores de média, desvio-padrão, mediana, limites mínimo e máximo dos marcadores no líquido peritoneal (LP), nos dois grupos estudados ( $A$ : com sintoma e com endometriose, B: com sintoma e sem endometriose) segundo a presença de dismenorréia leve/moderada.

\begin{tabular}{|c|c|c|c|c|c|c|c|c|}
\hline & GRUPO & $\mathbf{N}$ & MÉDIA & DP & MEDIANA & MÍNIMO & MÁXIMO & $\mathbf{P}^{*}$ \\
\hline \multirow{4}{*}{ IL-1 } & A SEM & 40 & 24,02 & 28,88 & 11,83 & 7,80 & 144,90 & \multirow{4}{*}{0,13} \\
\hline & $A C O M$ & 17 & 10,82 & 2,70 & 10,22 & 8,41 & 18,86 & \\
\hline & $B$ SEM & 17 & 21,78 & 16,47 & 16,45 & 8,01 & 62,08 & \\
\hline & $B$ COM & 10 & 30,59 & 31,73 & 14,84 & 9,82 & 67,11 & \\
\hline \multirow{4}{*}{ IL-6 } & A SEM & 40 & 20,02 & 39,91 & 7,25 & 1,90 & 221,80 & \multirow{4}{*}{0,99} \\
\hline & $A C O M$ & 17 & 27,61 & 60,93 & 5,50 & 2,80 & 233,80 & \\
\hline & $B$ SEM & 17 & 11,09 & 9,59 & 9,35 & 1,90 & 35,18 & \\
\hline & $B$ COM & 10 & 8,75 & 4,30 & 8,60 & 3,70 & 14,10 & \\
\hline \multirow{4}{*}{ SAA } & A SEM & 40 & 303,70 & 101,40 & 304,90 & 95,08 & 466,30 & \multirow{4}{*}{0,91} \\
\hline & $A C O M$ & 17 & 325,10 & 89,31 & 318,30 & 175,80 & 460,90 & \\
\hline & $B$ SEM & 17 & 292,90 & 89,45 & 310,30 & 105,80 & 382,90 & \\
\hline & $B C O M$ & 10 & 303,10 & 100,90 & 302,20 & 202,70 & 404,40 & \\
\hline
\end{tabular}

$\left(^{*}\right)$ nível descritivo de probabilidade do teste não-paramétrico de Kruskal-Wallis

IL-1ß e IL-6 pg/ml, SAA $\mathrm{ng} / \mathrm{ml}$

TABELA 6: Valores de média, desvio-padrão, mediana, limites mínimo e máximo dos marcadores no sangue (S), nos dois grupos estudados (A: com sintoma e com endometriose, $\mathrm{B}$ : com sintoma e sem endometriose) segundo a presença de dismenorréia leve/moderada.

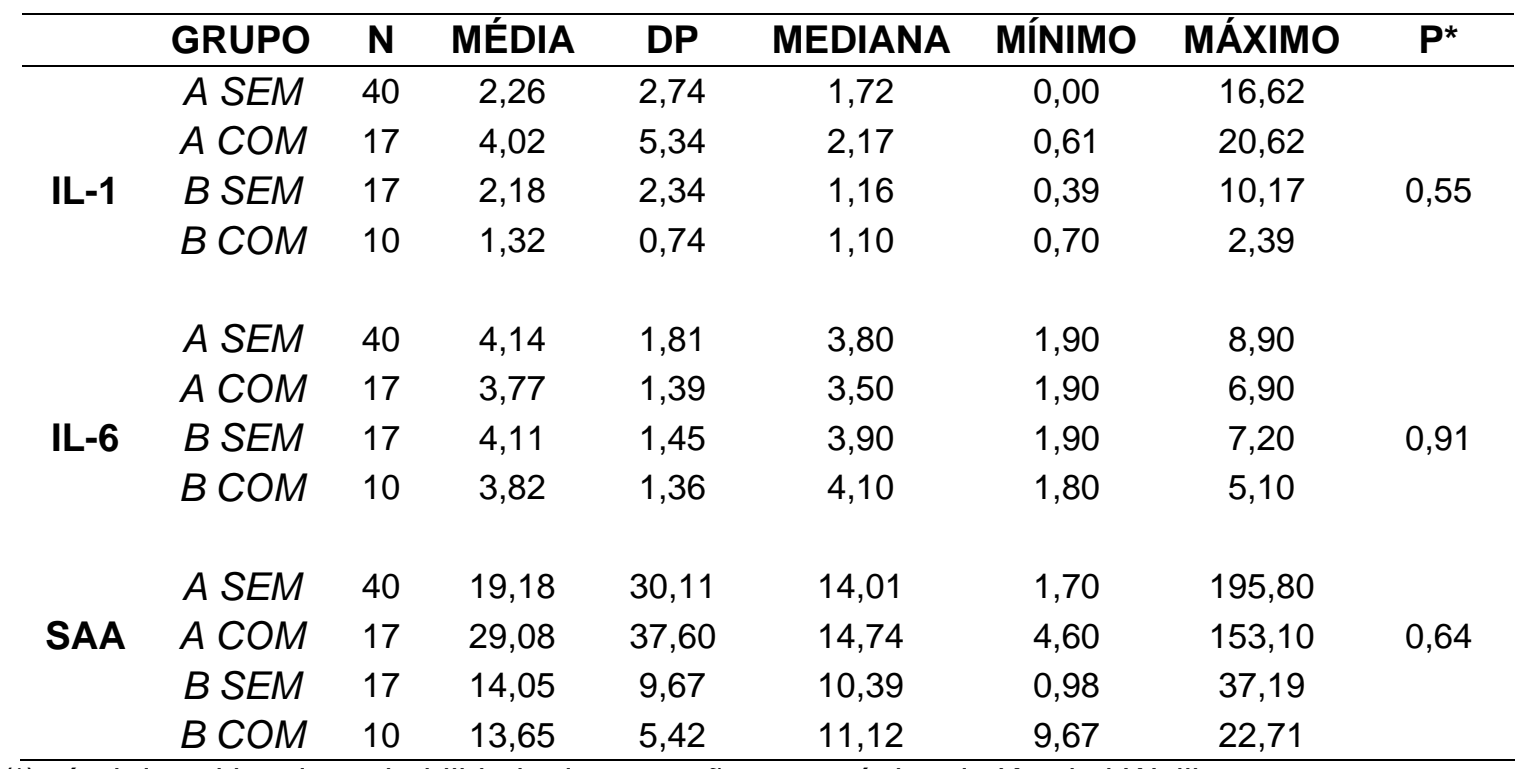

$\left.{ }^{*}\right)$ nível descritivo de probabilidade do teste não-paramétrico de Kruskal-Wallis IL-1ß e IL-6 pg/ml, SAA $\mathrm{ng} / \mathrm{ml}$ 
TABELA 7: Valores de média, desvio-padrão, mediana, limites mínimo e máximo dos marcadores no líquido peritoneal (LP), nos dois grupos estudados ( $A$ : com sintoma e com endometriose, B: com sintoma e sem endometriose) segundo a presença de dispareunia

\begin{tabular}{ccccccccc}
\hline & GRUPO & N & MÉDIA & DP & MEDIANA & MíNIMO & MÁXIMO & P $^{*}$ \\
\hline \multirow{6}{*}{ IL-1 } & A SEM & 26 & 17,58 & 18,13 & 11,02 & 8,41 & 70,12 & \\
& A COM & 31 & 23,05 & 30,50 & 11,62 & 7,80 & 144,90 & \\
& B SEM & 20 & 18,91 & 16,46 & 14,64 & 8,01 & 67,11 & 0,10 \\
& B COM & 7 & 37,00 & 22,30 & 34,74 & 16,45 & 62,08 & \\
& & & & & & & & \\
& A SEM & 26 & 11,66 & 14,61 & 6,60 & 1,90 & 64,80 & \\
& IL-6 COM & 31 & 31,55 & 61,22 & 7,20 & 2,30 & 233,80 & 0,52 \\
& B SEM & 20 & 10,26 & 9,61 & 7,80 & 1,90 & 35,18 & \\
& B COM & 7 & 11,45 & 7,01 & 11,20 & 3,30 & 21,00 & \\
& & & & & & & & \\
SAA & A SEM & 26 & 303,10 & 100,30 & 300,90 & 95,08 & 458,20 & \\
& A COM & 31 & 314,40 & 97,50 & 321,00 & 127,40 & 466,30 & \\
& B SEM & 20 & 288,30 & 96,98 & 306,20 & 105,80 & 404,40 & 0,92 \\
& B COM & 7 & 314,30 & 60,92 & 315,60 & 245,70 & 380,20 & \\
\hline
\end{tabular}

$\left.{ }^{\star}{ }^{\star}\right)$ nível descritivo de probabilidade do teste não-paramétrico de Kruskal-Wallis IL-1ß e IL-6 pg/ml, SAA $\mathrm{ng} / \mathrm{ml}$

TABELA 8: Valores de média, desvio-padrão, mediana, limites mínimo e máximo dos marcadores no sangue, nos dois grupos estudados (A: com sintoma e com endometriose, B: com sintoma e sem endometriose) segundo a presença de dispareunia

\begin{tabular}{ccccccccc}
\hline & GRUPO & N & MÉDIA & DP & MEDIANA & MÍNIMO & MÁXIMO & P $^{*}$ \\
\hline \multirow{6}{*}{ IL-1 } & A SEM & 26 & 3,32 & 4,77 & 1,94 & 0,00 & 20,62 & \\
& A COM & 31 & 2,21 & 2,22 & 1,50 & 0,16 & 10,84 & 0,67 \\
& $B$ SEM & 20 & 1,80 & 1,49 & 1,14 & 0,39 & 5,28 & \\
& $B$ COM & 7 & 2,40 & 3,17 & 1,28 & 0,70 & 10,17 & \\
& & & & & & & & \\
& IL SEM & 26 & 3,82 & 1,67 & 3,40 & 1,90 & 8,90 & \\
& $A$ COM & 31 & 4,24 & 1,73 & 3,80 & 1,90 & 8,10 & \\
& $B$ SEM & 20 & 3,56 & 1,10 & 3,40 & 1,80 & 5,30 & 0,13 \\
& $B$ COM & 7 & 5,11 & 1,50 & 4,75 & 2,80 & 7,20 & \\
& & & & & & & & \\
& SAA $S E M$ & 26 & 14,91 & 12,93 & 11,84 & 1,70 & 60,37 & \\
& $A$ COM & 31 & 28,45 & 42,44 & 16,55 & 6,77 & 195,80 & \\
& $B$ SEM & 20 & 13,97 & 7,59 & 11,84 & 0,98 & 28,50 & 0,11 \\
& $B$ COM & 7 & 13,92 & 11,40 & 9,67 & 1,70 & 37,19 & \\
\hline
\end{tabular}

$\left.{ }^{*}\right)$ nível descritivo de probabilidade do teste não-paramétrico de Kruskal-Wallis IL-1ß e IL-6 pg/ml, SAA $\mathrm{ng} / \mathrm{ml}$ 
TABELA 9: Valores de média, desvio-padrão, mediana, limites mínimo e máximo dos marcadores no líquido peritoneal (LP), nos dois grupos estudados ( $A$ : com sintoma e com endometriose, B: com sintoma e sem endometriose) segundo a presença de dor acíclica.

\begin{tabular}{ccccccccc}
\hline & GRUPO & N & MÉDIA & DP & MEDIANA & MÍNIMO & MÁXIMO & P $^{*}$ \\
\hline \multirow{6}{*}{ IL-1 } & A SEM & 25 & 27,81 & 35,56 & 11,62 & 7,80 & 144,90 & \\
& A COM & 32 & 15,62 & 14,15 & 11,02 & 8,41 & 81,18 & \\
& B SEM & 19 & 26,70 & 20,82 & 17,35 & 9,82 & 67,11 & 0,13 \\
& B COM & 8 & 17,99 & 15,93 & 11,72 & 8,01 & 49,42 & \\
& & & & & & & & \\
& IL SEM & 25 & 28,29 & 49,04 & 11,50 & 1,90 & 221,80 & \\
& A COM & 32 & 18,14 & 44,77 & 5,55 & 1,90 & 233,80 & \\
& B SEM & 19 & 10,04 & 9,32 & 7,80 & 1,90 & 35,18 & 0,08 \\
& B COM & 8 & 11,70 & 8,13 & 10,90 & 1,90 & 26,10 & \\
& & & & & & & & \\
& SAA SEM & 25 & 297,70 & 99,62 & 310,30 & 95,08 & 450,10 & \\
& A COM & 32 & 317,90 & 97,49 & 313,00 & 135,40 & 466,30 & 0,86 \\
& B SEM & 19 & 284,30 & 89,87 & 302,20 & 105,80 & 404,40 & \\
& B COM & 8 & 308,30 & 91,04 & 350,60 & 146,20 & 382,90 & \\
\hline
\end{tabular}

$\left.{ }^{*}\right)$ nível descritivo de probabilidade do teste não-paramétrico de Kruskal-Wallis IL-1ß e IL-6 pg/ml, SAA $\mathrm{ng} / \mathrm{ml}$

TABELA 10: Valores de média, desvio-padrão, mediana, limites mínimo e máximo dos marcadores no sangue, nos dois grupos estudados (A: com sintoma e com endometriose, B: com sintoma e sem endometriose) segundo a presença de dor acíclica.

\begin{tabular}{ccccccccc}
\hline & GRUPO & N & MÉDIA & DP & MEDIANA & MÍNIMO & MÁXIMO & P $^{*}$ \\
\hline \multirow{6}{*}{ IL-1 } & A SEM & 25 & 1,94 & 1,74 & 1,28 & 0,00 & 6,17 & \\
& A COM & 32 & 3,35 & 4,57 & 2,17 & 0,16 & 20,62 & \\
& B SEM & 19 & 1,88 & 2,27 & 1,05 & 0,61 & 10,17 & 0,37 \\
& $B$ COM & 8 & 2,18 & 1,84 & 1,28 & 0,39 & 5,28 & \\
& & & & & & & & \\
& IL SEM & 25 & 3,54 & 1,56 & 3,40 & 1,90 & 8,10 & \\
& $A$ COM & 32 & 4,37 & 1,73 & 3,85 & 1,90 & 8,90 & \\
& $B$ SEM & 19 & 3,88 & 1,33 & 3,90 & 1,80 & 6,90 & 0,30 \\
& $B$ COM & 8 & 4,34 & 1,59 & 4,00 & 2,60 & 7,20 & \\
& & & & & & & & \\
& SAA $S E M$ & 25 & 17,73 & 12,94 & 14,74 & 3,15 & 60,37 & \\
& $A$ COM & 32 & 25,04 & 41,19 & 13,29 & 1,70 & 195,80 & \\
& $B$ SEM & 19 & 15,10 & 8,84 & 11,12 & 6,05 & 37,19 & 0,76 \\
& $B$ COM & 8 & 11,92 & 8,67 & 9,67 & 0,98 & 23,43 & \\
\hline
\end{tabular}

${ }^{*}$ ) nível descritivo de probabilidade do teste não-paramétrico de Kruskal-Wallis IL-1ß e IL-6 pg/ml, SAA $\mathrm{ng} / \mathrm{ml}$ 


\section{Anexo D}

Avaliação peritoneal e sérica da IL-1B, IL-6 e proteína amilóide A em pacientes com endometriose pélvica

Resumo

Objetivo: determinar as concentrações séricas e peritoneais das interleucinas 1 (IL-1ß) e 6 (IL-6) e da proteína amilóide $\mathrm{A}$ (SAA) em pacientes com endometriose pélvica. Métodos: foram avaliadas 84 pacientes submetidas à videolaparoscopia, 57 com endometriose (A), e 13 sem sintomas e doenças (B). Foram coletados no ato cirúrgico líquido peritoneal e sangue. As concentrações dos mediadores foram determinadas em $\mathrm{pg} / \mathrm{ml}$ (IL-1 e 6) e $\mathrm{ng} / \mathrm{ml}$ (SAA) por método imunoenzimático e leitura óptica. Resultados: no líquido peritoneal e sangue as medianas foram IL-1B: A- 11,22 e 1,83; B- 1,92 and 0,80; IL-6: A- 6,80 e 3,70; B- 3,40 and 2,0; SAA- A- 310,30 e 14,01; B- 53,4 e 9,5. Conclusão: as concentrações dos mediadores de inflamação avaliados estão elevadas no líquido peritoneal e no soro das mulheres com endometriose frente a paciente sem doença ou sintomas sugestivos. A fase do ciclo menstrual, o tipo histológico envolvido e o local de acometimento da doença não influíram de forma significante nas concentrações séricas ou peritoneais de IL-1ß, IL-6 e SAA.

\section{Introdução}

O padrão-ouro para o diagnóstico da endometriose pélvica é o exame anatomopatológico das lesões obtidas através de procedimento cirúrgico, preferencialmente por laparoscopia ${ }^{1}$. Como partes dos casos de endometriose são iniciais e poderiam ser tratados através de medicação hormonal, os autores têm buscado encontrar exames não invasivos para o diagnóstico desta doença. Entre os exames hoje utilizados estão os métodos de imagem - ultrassonografia e ressonância magnética, assim como os marcadores séricos da doença, como o $\mathrm{CA}-125^{2}$. Porém, a sensibilidade dos métodos de imagem é limitada para casos iniciais, e o CA125 apresenta sensibilidade de 25 a $40 \%{ }^{3}$. Estes limites hoje 
existentes para o diagnóstico não-invasivo, e a constatação da natureza inflamatória da endometriose, levaram diversos autores a avaliar a concentração de mediadores de inflamação no sangue e no líquido peritoneal, como exames diagnósticos para a doença. As interleucinas 1 e 6 têm sido avaliadas com resultados diversos. A IL-1 começou a ser investigada na endometriose através do estudo de Fakih et al de 1987 que encontraram níveis elevados de IL-1 no líquido peritoneal obtido através de punção de fórnice vaginal posterior em 10 de 11 pacientes com endometriose, frente a 7 outras que foram submetidas a laqueadura tubárea ${ }^{4}$. O papel da IL-6 na endometriose tem sido estudado desde 1992, quando Boutten et al verificaram em cultura de células que os macrófagos do líquido peritoneal das pacientes com endometriose produziam maiores concentrações de IL-6 frente a pacientes sem a doença ${ }^{5}$. Estudo de Bedaiwy et al em 2002 envolvendo 130 pacientes e um painel de citocinas mostrou elevadas sensibilidade e especificidade apenas para a interleucina (IL)-6 sérica (90\% e $67 \%$ ) e para o fator de necrose tumoral alfa (TNF-a) peritoneal (100\% e $85 \%$ ) adotando como nível de corte $2 \mathrm{pg} / \mathrm{ml}$ e $15 \mathrm{pg} / \mathrm{ml}$, respectivamente ${ }^{6}$. Como a proteína C reativa, a proteína amilóide A constitui um marcador de atividade de fase aguda de doença, e é o melhor destes para indicar rejeição em casos de transplante heterólogo. Estudo da SAA em relação à endometriose de Abrão et al.(1997) encontraram níveis séricos elevados em pacientes nos estádios III/IV .

Neste cenário, os autores do presente estudo se propuseram a avaliar 0 papel da concentração de IL1, IL6 e SAA no diagnóstico da endometriose, em comparação com o padrão ouro - a análise histológica das lesões intrabdominais. 


\section{Casuística e métodos}

Foi desenvolvido um estudo prospectivo na Clínica Ginecológica do Hospital das Clínicas da Faculdade de Medicina da Universidade de São Paulo, de Janeiro de 2004 a Abril de 2007. O estudo foi aprovado pelo Comitê de Ética e Pesquisa do Hospital das Clínicas da Faculdade de Medicina da Universidade de São Paulo (Protocolo 601/2003). Todas as pacientes foram informadas sobre 0 estudo, leram e assinaram o termo de consentimento pós-informação. A Fundação de Amparo à Pesquisa do Estado de São Paulo patrocinou a realização do estudo, através do processo 05/01218-3.

\section{Casuística}

A partir de abril de 2004 foram triadas 84 pacientes com suspeita clínica de endometriose e indicação de avaliação cirúrgica. A suspeita clínica de endometriose foi estabelecida através de anamnese, exame físico e exames complementares. O quadro clínico foi considerado sugestivo na presença de algum dos seis sintomas mais prevalentes nesta doença: dismenorréia, dispareunia de profundidade, dor pélvica crônica, infertilidade, alterações intestinais e urinárias cíclicas ${ }^{8}$. Quanto à dismenorréia, foram selecionados os casos de intensidade severa e incapacitante ${ }^{8}$. O exame físico foi considerado sugestivo de endometriose quando havia nódulos em fundo de saco vaginal, útero em retroversão fixa, espessamento de ligamentos utero-sacros ou aumento de volume anexial. Outros critérios seletivos desta amostra foram: idade entre 18 e 40 anos, ausência de doenças auto-imunes e neoplasias malignas, e não utilização 
de terapêutica hormonal nos três meses precedentes ao estudo. A ultrassonografia pélvica transvaginal foi realizada em todos os casos e quando necessário também a ressonância nuclear magnética para exclusão de doenças não-ginecológicas e/ou para o planejamento cirúrgico. Foram critérios de exclusão os casos com doenças auto-imunes e neoplásicas (anamnese, exames radiológicos e laboratoriais) e os casos onde não havia líquido peritoneal $(n=5)$.

As pacientes triadas foram convidadas a participar da pesquisa, e assinaram o termo de consentimento pós-informação. A videolaparoscopia confirmou o diagnóstico de endometriose em 57 casos, através de biópsia cirúrgica e exame histológico de todas as lesões cavitárias suspeitas de endometriose ou de outra doença, e que constituíram a amostra do estudo, o grupo A. O grupo controle B foi composto por 13 pacientes que foram submetidas à laqueadura tubárea eletiva por videolaparoscopia, com idade entre 18 e 40 anos, e que concordaram em participar da pesquisa. Neste grupo foram observados como critérios de exclusão a presença de dismenorréia severa ou incapacitante, dispareunia de profundidade, infertilidade, dor pélvica acíclica ou alterações intestinais e urinárias cíclicas, doenças auto-imunes e neoplasias malignas, utilização de terapêutica hormonal no mês precedente à inclusão no estudo, e ausência de líquido peritoneal $(n=2)$.

As pacientes com endometriose do (grupo A) tinham idade média de 32,7士5,2 anos e mediana de 33 anos, semelhante ao grupo controle (B)- 33,8 $\pm 2,2(p=0,28)$. As demais características das pacientes com endometriose estão na Tabela 1estadiamento pelos critérios da American Society for Reproductive Medicine 
(1996), local de acometimento e tipo histológico das lesões ${ }^{9}$. Observa-se que os estádios mais avançados III e IV predominaram sobre os estádios I/II. Na maior parte dos casos havia mais de um local de doença na cavidade abdominal (94 focos, média de 1,6 sítios/caso) e o padrão histológico era composto por mais de um subtipo em $91 \%$ das pacientes ${ }^{10}$.Quanto à fase do ciclo menstrual das pacientes no momento da realização da videolaparoscopia para comprovação diagnóstica, a maior parte das pacientes estava na fase folicular - $47(82,8 \%)$, enquanto no grupo controle eram 6 pacientes $(46,2 \%)$ nesta fase.

\section{Coleta de exames e procedimento cirúrgico}

Antes da anestesia para a videolaparoscopia, foram coletados $5 \mathrm{ml}$ de sangue periférico de membro superior em tubo seco. Na passagem da agulha de Veress não foi realizada injeção de soro fisiológico na cavidade abdominal, pela punção secundária foi feita a coleta de todo o líquido peritoneal depositado em fundo-de-saco vaginal anterior e/ou posterior, que foi armazenado em tubo seco. O material foi imediatamente colocado sob refrigeração, centrifugado, separado em alíquotas e congelado a $-20^{\circ} \mathrm{C}$. O procedimento cirúrgico, e a inspeção de toda a cavidade abdominal e pélvica (peritôneo, ovário, regiões retro-cervical, paracervical, septo reto-vaginal, reto-sigmóide, ureteres e bexiga) foram realizados por um dos autores, e todas as lesões suspeitas de endometriose ou de outras moléstias foram biopsiadas. Os casos também foram classificados pelos critérios da American Society for Reproductive Medicine (1996), em estádios de I a IV 9 . 
A avaliação histológica das lesões retiradas seguiu a classificação proposta por Abrão et al (2003) em padrões estromal, glandular bem diferenciado, glandular indiferenciado e glandular misto de diferenciação ${ }^{10}$.

\section{Métodos laboratoriais}

As amostras de sangue e líquido peritoneal estocadas foram descongeladas simultaneamente para realização das dosagens da IL-1-ß, da IL-6 e do SAA. O método laboratorial utilizado para as dosagens das interleucinas 1-ß e 6 e do SAA foi o ELISA, ténica de ensaio imunoenzimático quantitativo tipo sanduíche: anticorpo-antígeno-anticorpo conjugado ${ }^{3,6}$. Anticorpos monoclonais específicos para as interleucinas foram pré-fixados em uma placa de ELISA. Nesta foram colocadas seis soluções padrões de IL-1-B, IL-6 e SAA, e as amostras clínicas, e a seguir os conjugados de anticorpos policlonais contra IL-1 e contra IL6 ligados à peroxidase. Após a lavagem para remover substâncias não ligadas, uma solução contendo tetrametilbenzidina e peróxido de hidrogênio era adicionada, observando-se o aparecimento de cor. A reação era interrompida através da adição de solução de ácido sulfúrico $2 \mathrm{~N}$, e a intensidade da cor medida por um leitor de densidade óptica. Os resultados de cada mediador foram calculados em relação à curva-padrão, estabelecida na leitura óptica de seis concentrações de padrões pré-estabelecidos. Foram utilizados os kits Human 1L-ß ELISA Kit (BD Biosciences ${ }^{\circledR}$, EUA) e Human IL-6 e SAA (Biosource ${ }^{\circledR}$, Bélgica).

$\mathrm{Na}$ análise estatística dos resultados referentes aos grupos e subgrupos do estudo foram utilizados os testes do Chi-quadrado e Fisher para a comparação de 
proporções. A comparação dos resultados de cada variável contínua foi precedida da verificação da distribuição normal dos dados. Para as distribuições não-normais foram utilizados os testes não-paramétricos de Mann-Whitney e o teste de Dunn, para comparação das medianas. Foi utilizado o teste de Spearman para correlações entre variáveis. Foi utilizada a curva ROC para verificação de sensibilidade e especificidade de diferentes variáveis. Os cálculos estatísticos foram realizados com o software INSTAT 3 (SPSS ${ }^{\circledR}$ inc., USA), adotando-se 0 nível de significância de 5\%.

\section{Resultados}

Os resultados referentes às concentrações de IL-1ß, IL-6 e SAA no líquido peritoneal e no sangue se encontram na Tabela 2. No líquido peritoneal as concentrações de IL-1ß, IL-6 e SAA foram maiores no grupo A em relação ao controle. No sangue as concentrações das interleucinas 1 e 6 também foram significativamente maiores no grupo $A$, porém não alcançaram significância na avaliação do SAA .

\section{AQUI TABELA 2}

As concentrações dos mediadores no líquido peritoneal e no sangue das pacientes com endometriose (grupo A) foram distribuídas segundo o estádio inicial (I/II) e avançado (III/IV), os resultados estão contidos na tabela 3. As concentrações de IL-1ß, IL-6 e SAA entre os subgrupos A I-II, A III-IV não diferiram no líquido peritoneal assim como no soro.

\section{AQUI TABELA 3}


$\mathrm{Na}$ tabela 4 estão contidos os resultados das concentrações dos marcadores no líquido peritoneal e no sangue segundo a fase do ciclo menstrual das pacientes com endometriose (grupo A). Não foram observadas diferenças nas concentrações dos três mediadores inflamatórios tanto no sangue como no líquido peritoneal.

\section{AQUI TABELA 4}

$\mathrm{Na}$ tabela 5 estão contidos os resultados das concentrações dos marcadores no líquido peritoneal e no sangue segundo o tipo histológico das lesões endometrióticas. Foram agrupados os casos do grupo A com aspecto histológico diferenciado, classificados como bem definido ou estromal, e comparados com os restantes, de aspecto indiferenciado isolado ou misto ${ }^{10}$. Não foram observadas diferenças nas concentrações dos três mediadores inflamatórios tanto no sangue como no líquido peritoneal.

\section{AQUI TABELA 5}

Foi utilizado o teste de correlação de Spearman para avaliar a possibilidade de predição das concentrações peritoneais dos marcadores a partir dos valores séricos. O teste não mostrou correlação significante $(p>0,05)$. Entretanto, foi constatado que as pacientes do grupo A que apresentam níveis mais elevados de IL-1 no peritônio também apresentam níveis mais elevados de IL-6 $(p<0,05)$. Não foi constatada correlação entre estas interleucinas e o SAA.

Com os resultados das dosagens dos mediadores IL-1 e IL-6 no soro e líquido peritoneal foi construída uma curva ROC, para se estabelecer qual seria o melhor 
preditor de endometriose. A maior área sob a curva ROC foi da IL-6 sérica $(0,668)$, seguida da IL-1 sérica $(0,627)$, da IL-1 peritoneal 0,621 , e da IL-6 peritoneal $(0,427)$. Portanto, a IL-6 sérica foi o melhor preditor dentre os mediadores estudados para a endometriose no grupo A.

\section{AQUI FIGURA 1}

\section{Discussão}

\section{Concentrações peritoneais dos mediadores inflamatórios}

Quanto às concentrações dos mediadores encontrados nas pacientes do grupo endometriose (grupo A), o valor de mediana para IL-1ß no líquido peritoneal foi semelhante ao verificado por Sokolov et al (2005) que encontraram 24,3 pg/ml em um grupo de 27 pacientes, avaliadas com metodologia semelhante, e ao de Ishimaru em 1994, com mediana cerca de 20 pg/ml em 34 casos de endometriose ${ }^{11,12}$. Alguns outros autores verificaram concentrações menores que as apresentadas, como Ho em 1996, mas este incluiu na sua casuística pacientes já medicadas, e Calhaz em 2003 que teve um valor máximo de 8,7 pg/ml, mas

este avaliou uma casuística heterogênea que englobou pacientes com endometriose e outros sem doença aparente ${ }^{13,14}$.

No presente estudo, as concentrações da IL-6 no líquido peritoneal no grupo A resultaram em mediana de $6,8 \mathrm{pg} / \mathrm{ml} \pm 46,31$. Estes valores são inferiores ao encontrado por Khan em 2002 - 82,1 113,0 para todos os estádios da doença,

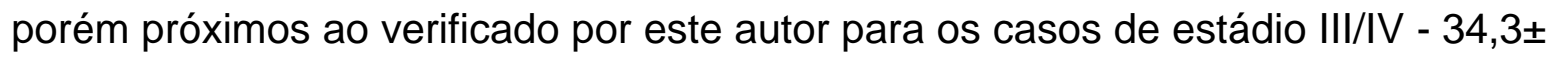
$4,8 \mathrm{pg} / \mathrm{ml}^{15}$. O resultado que observamos é compatível com o encontrado por Rapkin em 2000 de 15,34 $\pm 50,56$ pg/ml, que também mostra extensa dispersão 
dos valores encontrados, assim como Skrzypczak em 2005, quando as medianas de grupos de pacientes com endometriose situaram-se entre 0 a $110 \mathrm{pg} / \mathrm{ml}$ e 0 desvio padrão de 49 a 290,3 $3^{16,17}$. Para este autor; as maiores concentrações da IL6 foram verificadas nas pacientes férteis com endometriose.

No líquido peritoneal verificaram-se para a SAA uma concentração média e um valor da mediana semelhantes, respectivamente $309,40 \pm 97,79 \mathrm{ng} / \mathrm{ml}$ e 310,30 $\mathrm{ng} / \mathrm{ml}$, ambas superiores ao grupo controle. Não foram encontrados outros trabalhos na literatura que tenham avaliado este mediador de fase aguda no líquido peritoneal em casos de endometriose, apesar da SAA ter sido descoberta desde 1973 nos casos de amiloidose, e ter sido avaliada posteriormente em outras doenças inflamatórias ${ }^{7}$. É reconhecido que a SAA é produzida, entre outros estímulos, em resposta à ação das citocinas IL-1 e IL-6, mas isto não foi verificado no estudo - não houve associação entre as concentrações destas interleucinas e da SAA.

As concentrações peritoneais dos mediadores inflamatórios IL-1 $\beta$, IL-6 e SAA nas pacientes com endometriose mostraram-se elevadas em relação ao grupo controle (tabela 2), como também foi verificada a associação entre as concentrações da IL-1ß e da IL-6 no líquido peritoneal destas pacientes. Estas constatações indicam que há na endometriose pélvica uma inflamação local, como observado por outros autores ${ }^{6,11}$. Porém, alguns aspectos dos resultados como a extensa faixa de variação das concentrações das interleucinas e da SAA no líquido peritonial e as concentrações similares nos estádios mais avançados (estádios III e IV) aos estádios iniciais limita a utilização destes mediadores como 
marcadores de atividade da doença.Além das concentrações dos mediadores deve-se avaliar também sua interação com os receptores específicos como na IL1. Desta forma pode-se explicar a intensidade variável dos sintomas apresentados com iguais concentrações de mediadores inflamatórios peritoneais. Outros reconhecem frente a estes achados, haver indícios de que além da inflamação na endometriose possam ocorrer outros mecanismos fisiopatogênicos, associados.

\section{As concentrações séricas dos mediadores inflamatórios}

A IL-1ß no soro (Tabela 2) teve mediana de $1,83 \mathrm{pg} / \mathrm{ml}$, média de 2,75 $\mathrm{pg} / \mathrm{ml} \pm 3,68$, e uma faixa de valores entre 0 e 20,62. Estes resultados são similares aos encontrados por Koumantakis et al em 1994, 2,97 $\pm 2,83 \mathrm{pg} / \mathrm{ml}^{18}$.

As concentrações séricas de IL-6 para o grupo A tiveram mediana de 3,70 $\mathrm{pg} / \mathrm{ml}$, média de 4,04 e um desvio padrão de 1,70 pg/ml, proporcionalmente menor que o da IL-1 (Tabela 2). As concentrações são superiores às encontradas por Somigliana em 2004 (valor máximo de 1,4 pg/ml), e inferiores às verificadas por Bedaiwy em $2002-21,58 \mathrm{pg} / \mathrm{ml}(8,22-60,36)$, que também utilizou a técnica de ELISA, e à observada por Darai em 2003 que encontrou mediana de 18,4 pg/ml $\pm 13,5$ através de radioimunoensaio ${ }^{19}$.

A concentração de SAA sérica média (tabela 2) encontrada foi 21,93 \pm $32,30 \mathrm{ng} / \mathrm{ml}$ com mediana de $14,01 \mathrm{ng} / \mathrm{ml}$, semelhante ao verificado nas pacientes do grupo controle. Abrão et al em 1997 avaliaram a possível correlação da SAA sérica com a endometriose. Neste estudo da proteína de fase aguda, 
encontraram uma concentração média de 4,1 \pm 0,8 (estádio I/II) a 38,8 \pm 17 (estádio III/IV), resultado semelhante ao do grupo $\mathrm{A}^{7}$.

A elevação dos níveis séricos dos marcadores nos casos de endometriose, frente ao grupo controle, indica que parte das interleucinas séricas pode refletir a inflamação gerada pelo foco pélvico de endometriose,passando de uma inflamação local a um quadro sistêmico. Porém a dispersão dos valores encontrados para cada interleucina foi elevada. A verificação de alteração na concentração sérica destas interleucinas e a grande dispersão dos valores nos casos de endometriose, haviam sido previamente observadas por Kharfi 2001 e Bedaiwy $2002^{20}$.

As concentrações séricas e peritoneais dos mediadores inflamatórios segundo as características da endometriose

Ao subdividirmos os resultados séricos do grupo A segundo o estádio da doença ou a fase do ciclo menstrual, observa-se que não há diferença significante das concentrações (tabelas 3 e 4). No líquido peritoneal, as concentrações dos mediadores mostram semelhança para a IL-1ß nos 4 estádios, para IL-6 houve uma tendência para níveis mais elevados nos estádios III/IV, não significante, e para a SAA os níveis tenderam a serem maiores nos estádios I/II. Na literatura, a IL-1ß não apresenta diferença nas concentrações entre os estádios, e, eventualmente seria discretamente superior nos estádios iniciais $(I / I I)^{11,21}$. Para a IL-6 nossos resultados são semelhantes aos de Schroder (1996), com aumento discreto nos estádios avançados ${ }^{22}$. Por outro lado, Keenan em 1994 encontrou níveis quatro vezes maiores nos estádios avançados frente aos iniciais ${ }^{23}$. Em 
conjunto, estas observações não indicam de forma absoluta reação inflamatória inespecífica mais intensa nos estádios avançados.

As concentrações dos mediadores séricos e peritoneais no grupo A não diferiram nas fases folicular e secretora do ciclo menstrual. Parte dos autores observaram valores superiores para a IL-1 na fase lútea, e não encontraram diferença entre as concentrações de IL-6 nas duas fases do ciclo; a SAA não foi avaliada previamente frente à fase do ciclo ${ }^{3,24}$.

Quanto ao tipo histológico envolvido, ao avaliarmos o grau de diferenciação do tecido endometriótico (tabela 5) não houve associação significante com as concentrações séricas ou peritoniais dos três mediadores avaliados com a presença de tecido indiferenciado de forma isolada ou mista.

Correlação entre o nível sérico e peritoneal dos mediadores IL-1 $\beta$, IL-6 e SAA nas pacientes com endometriose

As medianas das concentrações dos mediadores tiveram valores superiores no peritônio frente aos níveis séricos, de forma semelhante nos dois grupos. Nos casos de endometriose as concentrações peritoniais foram 22,14 vezes maiores para a SAA, 6,13 vezes para a IL-1 e 1,83 vez para a IL-6; enquanto no grupo $B$ eram 5,62 vezes maiores para a SAA, 2,38 vezes para a IL-1 e 1,70 vez para a IL-6. Foram avaliadas as correlações entre os níveis séricos e peritoneais do mesmo marcador, pela possibilidade das concentrações séricas refletirem as concentrações peritoneais. O teste de correlação de Spearman não encontrou uma relação direta significativa entre os níveis séricos e peritoneais para os mediadores estudados em cada paciente. O único autor que comprovou 
uma correlação direta foi Harada em 1997, para a IL-6 ${ }^{24}$. No presente estudo, o melhor marcador para o diagnóstico da endometriose foi a IL-6 sérica, como descrito previamente por Bedaiwy 2002. Este autor obteve melhores índices de sensibilidade e especificidade com nível de corte acima de $2 \mathrm{pg} / \mathrm{ml}$. No presente estudo, acima do ponto de corte $3,45 \mathrm{pg} / \mathrm{ml}$ a IL-6 apresentou sensibilidade de $52,6 \%$ e especificidade de $61,5 \%$ no diagnóstico da endometriose, tendo perfil superior ao $\mathrm{CA}-125^{3,25}$. O reconhecimento da natureza inflamatória da endometriose pélvica e de sua repercussão sérica auxilia na compreensão da etiopatogenia da doença, e indica que a busca por marcadores inflamatórios séricos pode ser um caminho promissor para o diagnóstico não-invasivo.

Ao analisar-se as relações entre as concentrações dos três mediadores no sangue e no líquido peritoneal, através do teste de Spearman, foi verificada a correlação positiva entre a IL-1ß e a IL-6 no líquido peritoneal para os grupos A e B, conforme classicamente é descrito nas reações de imunidade inata. Esta correlação direta entre IL-1 e IL-6 não foi observada no sangue. A contraprova desta associação é verificada após a remoção dos focos endometrióticos, que constatam a diminuição dos níveis de IL-1 e IL-6, acompanhadas muitas vezes de melhora dos sintomas ${ }^{24}$.

\section{Características da amostra e a implicação no perfil dos mediadores}

O estudo avaliou 84 pacientes com queixas compatíveis com endometriose pélvica (grupos A) e 13 pacientes sem doença alguma. A mediana de idade do grupo A, 33 anos, é semelhante a verificada habitualmente nos serviços 
especializados, com início na menacme e declínio de incidência após os 44 anos de idade, o que afasta alguma possível interferência do fator etário ${ }^{25}$. Os grupos A e $B$ não apresentaram diferenças em relação à média de idade. $O$ grupo $A$ foi operado predominantemente na primeira fase do ciclo, como analisado previamente, mas a fase do ciclo não teve correlação com as concentrações dos mediadores. O grupo $\mathrm{C}$ foi operado nas duas fases, uniformemente, conforme seria previsível para pacientes sem doença.

Com relação às queixas clínicas das pacientes predominou a dismenorréia, habitualmente o sintoma mais frequente da doença ${ }^{25}$. Na literatura o percentual de prevalência da endometriose varia segundo o perfil das pacientes - cerca de $70 \%$ entre as que apresentam algia pévica crônica, 50 a 68\% naquelas com infertilidade e apenas $5 \%$ em pacientes assintomáticas. No grupo A também houve maior incidência de infertilidade, dispareunia, dor acíclica e sintomas intestinais em comparação com população da mesma faixa etária ${ }^{25}$. O número de queixas por paciente foi elevado - 173 sintomas para 57 casos, com média de 2,9 sintomas/caso. Em nosso meio desde o início dos sintomas até o diagnóstico da doença transcorrem em média sete anos.(Arruda et al, 2003). Isto pode explicar o predomínio dos casos dos estádios avançados (III e IV-58,6\%) frente aos estádios iniciais (I/II- 41,4\%) na presente amostra. $O$ fato deste estudo ter sido realizado em hospital de refência aumenta a probabilidade de selecionar os casos mais avançados.

O grupo controle B foi reduzido, com apenas 13 pacientes hígidas submetidas à laqueadura tubárea eletiva, sem queixas clínicas e sem alterações à videolaparoscopia, e que se dispuseram a participar do estudo. É difícil a obtenção 
de controles com este perfil, por este motivo muitos autores constituem grupos controles inadequados, principalmente recrutados entre casos sem endometriose porém com sintomatologia ${ }^{6}$. O tamanho da amostra foi adequado à avaliação dos mediadores $^{3}$.

Quanto à característica do tecido endometrial encontrado, em $60,3 \%$ dos casos o tecido era indiferenciado, de forma isolada ou associada a outros tipos histológicos. Esta predominância de tecido pouco diferenciado ocorre nos estádios III e IV freqüentes na amostra, como já descrito por Abrão ${ }^{10}$.

Em conclusão, foram observados dados que reforçam a teoria inflamatória na fisiopatogenia da endometriose, sem desconsiderar que alterações imunológicas locais e sistêmicas também têm sido observadas ${ }^{15-17}$. A especificidade diagnóstica dos mediadores séricos IL-1 $\beta$, IL-6 e SAA para a endometriose deverá ser cotejada ainda, com os achados em outras doenças. Há relatos de aumento nas concentrações de mediadores em pacientes com outras afecções ginecológicas benignas ${ }^{14-16}$. . Fica portanto ressalvada uma possível inespecificidade das alterações verificadas nas concentrações dos mediadores frente a outras doenças com componente inflamatório .

Os marcadores peritoniais e séricos de IL-1B, IL6 e SAA apresentam limitada sensibilidade e especificidade para o diagnóstico da endometriose. O melhor parâmetro foi a concentração de IL-6 sérica que acima do ponto de corte 3,45 $\mathrm{pg} / \mathrm{ml}$ teve sensibilidade de $52,6 \%$ e especificidade de $61,5 \%$, superiores ao que é descrito para o CA-125, o marcador sérico mais empregado atualmente. 


\section{BIBLIOGRAFIA}

1. Abbott JA, Hawe J, Clayton RD, Garry R. The effects and effectiveness of laparoscopic excision of endometriosis: a prospective study with 2-5 year follow-up. Hum Reprod. 2003; 18(9):1922-27.

2. Abrão MS, Gonçalves MOC, Dias JA, Podgaec S, Chamie LP, Blasbalg R. Comparison between clinical examination, transvaginal sonography and magnetic resonance imaging for the diagnosis of deep endometriosis Human Reprod 2007 in press.

3. Somigliana E, Vigano P, Tirelli AS, Felicetta I, Torresani E, Vignali M, Di Blasio AM. Use of the concomitant serum dosage of CA 125, CA 19-9 and interleukin-6 to detect the presence of endometriosis- results from a series of reproductive age women undergoing laparoscopic surgery for benign gynaecological conditions. Hum Reprod. 2004; 19(8):1871-6.

4. Fakih H, Baggett B, Holtz G, Tsang KY, Lee JC, Williamson HO. Interleukin-1: a possible role in the infertility associated with endometriosis. Fertil Steril. 1987;47(2):213-7.

5. Boutten A, Dehoux M, Edelman P, Seta N, Menard A, Madelenat P, Durand G. IL6 and acute phase plasma proteins in peritoneal fluid of women with endometriosis. Clin Chim Acta. 1992; 210(3):187-95.

6. Bedaiwy MA, Falcone T, Sharma RK, Goldberg JM, Attaran M, Nelson DR, Agarwal A. Prediction of endometriosis with serum and peritoneal fluid markers: a prospective controlled trial. Hum Reprod. 2002; 17(2):426-31. 
7. Abrao MS, Podgaec S, Filho BM, Ramos LO, Pinotti JA, de Oliveira RM. The use of biochemical markers in the diagnosis of pelvic endometriosis. Hum Reprod. 1997; 12(11):2523-7.

8. Eskenazi B, Warner M, Bonsignore L, Olive D, Samuels S, Vercellini P. Validation study of nonsurgical diagnosis of endometriosis. Fertil Steril. $2001 ; 76(5): 929-35$.

9. Revised American Society for Reproductive Medicine classification of endometriosis: 1996. Fertil Steril. 1997;67:817-21.

10. Abrao MS, Neme RM, Carvalho FM, Aldrighi JM, Pinotti JA. Histological classification of endometriosis as a predictor of response to treatment. Int $\mathrm{J}$ Gynaecol Obstet. 2003; 82:31-40.

11. Sokolov DI, Solodovnikova NG, Pavlov OV, Niauri DA, Volkov NN, Sel'kov SA. Study of cytokine profile and angiogenic potential of peritoneal fluid inpatients with external genital endometriosis. Bull Exp Biol Med. 2005; 140(5):541-4.

12. Ishimaru T. Interleukin-6- and tumour necrosis factor alpha-mediated expression of hepatocyte growth factor by stromal cells and its involvement in the growth of endometriosis. Hum Reprod. 2005; 20(10):2715-23.

13. Ho HN, Wu M, Chao K, Chen C, Chen, S, Chen H, Yang, Y. Decrease in interferon gamma production and impairment of T-lymphocyte proliferation in peritoneal fluid of women with endometriosis. Am J Obstet \& Gynecol. $1996 ; 175(5): 1236-1241$. 
14. Calhaz CJ, Costa AP, Santos MC, Palma MLC. Soluble intercellular adhesion molecule 1 in the peritoneal fluid of patients with endometriosis correlates with the extension of peritoneal implants. Eur J Obstet Gynecol Reprod Biol. 2003; 106 170-4.

15. Khan KN, Masuzaki H, Fujishita A, Hamasaki T, Kitajima M, Hasuo A, Miyamura Y, Ishimaru T. Association of interleukin-6 and estradiol with hepatocyte growth factor in peritoneal fluid of women with endometriosis. Acta Obstet Gynecol Scand. 2002; 81(8):764-71.

16. Rapkin A, Morgan M, Bonpane C, Martinez-Maza O. Peritoneal fluid interleukin-6 in women with chronic pelvic pain. Fertil Steril. 2000; 74(2):325-8.

17. Skrzypczak J, Szczepanska M, Puk E, Kamieniczna M, Kurpisz M. Peritoneal fluid cytokines and SICAM-1 in minimal endometriosis: search for discriminating factors between infertility and/or endometriosis. Eur J Obstet Gynecol Reprod Biol. 2005; 122(1):95-103.

18. Koumantakis E., Matalliotakis I., Neonaki M., Froudarakis G., Georgoulias V. Soluble serum interleukin-2 receptor,interleukin-6 and interleukin-1a in patients with endometriosis and controls. Arch Gynecol Obstet. 1994; 255:107-12.

19. Darai E, Detchev R, Hugol D, Quang NT. Serum and cyst fluid levels of interleukin (IL) -6, IL-8 and tumour necrosis factor-alpha in women with endometriomas and benign and malignant cystic ovarian tumours. Hum Reprod. 2003;18(8):1681-5. 
20. Kharfi A, Akoum A. Correlation between decreased type-II interleukin-1 receptor and increased monocyte chemotactic protein-1 expression in the endometrium of women with endometriosis. Am J Reprod Immunol. 2001; 45(4):193-9.

21. Mori H, Sawairi M, Nakagawa M, Itoh N, Wada K, Tamaya T. Peritoneal fluid interleukin-1 beta and tumor necrosis factor in patients with benign gynecologic disease. Am J Reprod Immunol. 1991; 26(2):62-7.

22. Schroder W, Gaetje R, Baumann R. Interleukin-6 and soluble interleukin-6 receptor in peritoneal fluid and serum of patients with endometriosis. Clin Exp Obstet Gynecol. 1996; 23(1):10-4.

23. Keenan JA, Chen TT, Chadwell NL, Torry DS, Caudle MR. Interferongamma (IFN-gamma) and interleukin-6 (IL-6) in peritoneal fluid and macrophage-conditioned media of women with endometriosis. Am J Reprod Immunol. 1994; 32(3):180-3.

24. Harada T, Yoshioka H, Yoshida S, Iwabe T, Onohara Y, Tanikawa M, Terakawa N. Increased interleukin-6 levels in peritoneal fluid of infertile patients with active endometriosis. Am J Obstet Gynecol. 1997; 176(3):5937.

25. Signorello LB, Harlow BL, Cramer DW, Spiegelman D, Hill JA. EPIDEMIOLOGIC DETERMINANTS OF ENDOMETRIOSIS: A HOSPITALBASED CASE-CONTROL STUDY. ANN EPIDEMIOL. 1997; 7(4):267-741. 
Tabela 1- Características das mulheres com endometriose quanto à localização, estadiamento e tipo histológico das lesões

\begin{tabular}{|c|c|c|}
\hline CARACTERÍSTICA & $\mathbf{N}$ & $\%$ \\
\hline \multicolumn{3}{|l|}{ SINTOMAS } \\
\hline Dismenorréia leve/moderada & 17 & 29,3 \\
\hline Dismenorréia severa/incapacitante & 38 & 65,5 \\
\hline Dispareunia de profundidade & 31 & 53,5 \\
\hline Dor acíclica & 34 & 58,6 \\
\hline Infertilidade & 21 & 36,2 \\
\hline Alteração Intestinal & 30 & 51,7 \\
\hline Alteração urinária & 2 & 3,5 \\
\hline \multirow[t]{4}{*}{ ESTÁDIO } & 8 & 13,8 \\
\hline & 16 & 27,6 \\
\hline & 4 & 6,9 \\
\hline & 30 & 51,7 \\
\hline \multirow[t]{3}{*}{ LOCALIZAÇÃO } & 27 & 46,6 \\
\hline & 36 & 62,1 \\
\hline & 31 & 53,4 \\
\hline TIPO & 1 & 1,7 \\
\hline \multirow[t]{4}{*}{ HISTOLÓGICO* } & 4 & 6,9 \\
\hline & 18 & 31,1 \\
\hline & 3 & 5,2 \\
\hline & 32 & 55,1 \\
\hline
\end{tabular}


Tabela 2- Concentrações séricas e peritoniais das interleucinas 1, 6 e da SAA no líquido peritoneal e no sangue em crianças com endometriose e no grupo controle

\begin{tabular}{|c|c|c|c|c|c|c|c|c|}
\hline & \multicolumn{5}{|c|}{ LÍQUIDO PERITONEAL } & \multicolumn{3}{|c|}{ SANGUE } \\
\hline & GRUPO & $\mathbf{N}$ & MEDIANA & DP & $\mathbf{P}^{*}$ & MEDIANA & DP & $\mathbf{P}^{*}$ \\
\hline \multirow[t]{2}{*}{ IL-1 } & $A$ & 57 & 11,22 & 25,36 & \multirow{2}{*}{$<0,01$} & 1,83 & 3,68 & \multirow{2}{*}{0,02} \\
\hline & $B$ & 13 & 1,91 & 2,49 & & 0,80 & 0,23 & \\
\hline \multirow[t]{2}{*}{ IL-6 } & $A$ & 57 & 6,80 & 46,31 & \multirow{2}{*}{0,02} & 3,70 & 1,70 & \multirow{2}{*}{$<0,01$} \\
\hline & $B$ & 13 & 3,40 & 1,90 & & 2,00 & 0,80 & \\
\hline \multirow[t]{2}{*}{ SAA $^{\&}$} & $A$ & 57 & 310,30 & 97,79 & \multirow{2}{*}{0,01} & 14,01 & 32,30 & \multirow{2}{*}{0,35} \\
\hline & $B$ & 13 & 53,4 & 58,16 & & 9,5 & 15,90 & \\
\hline
\end{tabular}

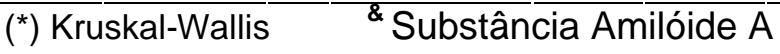


Tabela 3- Concentrações séricas e peritoniais das interleucinas 1, 6 e da SAA no líquido peritoneal e no sangue de pacientes com endometriose conforme 0

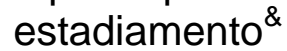

\begin{tabular}{|c|c|c|c|c|c|c|c|c|}
\hline & \multicolumn{2}{|l|}{ GRUPO } & \multicolumn{3}{|c|}{ LÍQUIDO PERITONEAL } & \multicolumn{3}{|c|}{ SANGUE } \\
\hline MEDIADOR & ESTÁDIO \& & $\mathbf{N}$ & MEDIANA & DP & $\mathbf{P}^{*}$ & MEDIANA & DP & $\mathbf{P}^{*}$ \\
\hline \multirow{3}{*}{ IL-1 } & $A I-I I$ & 22 & 11,02 & 34,67 & \multirow{3}{*}{0,80} & 1,72 & 1,41 & \multirow{3}{*}{0,48} \\
\hline & $A I I I-I V$ & 35 & 11,22 & 18,22 & & 1,94 & 4,64 & \\
\hline & $B$ & 13 & 1,91 & 2,49 & & 0,80 & 0,23 & \\
\hline \multirow{3}{*}{ IL-6 } & A I-II & 22 & 5,05 & 48,48 & \multirow{3}{*}{0,24} & 3,10 & 1,65 & \multirow{3}{*}{0,33} \\
\hline & $A / I I-I V$ & 35 & 7,60 & 45,48 & & 3,90 & 1,69 & \\
\hline & $B$ & 13 & 3,40 & 1,90 & & 2,00 & 0,00 & \\
\hline \multirow{3}{*}{ SAA } & A I-II & 22 & 323,70 & 91,29 & \multirow{3}{*}{0,54} & 14,74 & 13,73 & \multirow{3}{*}{0,47} \\
\hline & $A I I I-I V$ & 35 & 294,10 & 97,40 & & 13,29 & 41,19 & \\
\hline & $B$ & 13 & 53,4 & 58,16 & & 9,5 & 15,90 & \\
\hline
\end{tabular}


Tabela 4- Concentrações dos marcadores no líquido peritoneal e no sangue segundo a fase do ciclo menstrual das pacientes com endometriose (grupo A)

\begin{tabular}{|c|c|c|c|c|c|c|c|c|}
\hline & \multicolumn{2}{|l|}{ GRUPO A } & \multicolumn{3}{|c|}{ LÍQUIDO PERITONEAL } & \multicolumn{3}{|c|}{ SANGUE } \\
\hline MEDIADOR & FASE & $\mathbf{N}$ & MEDIANA & DP & $\mathbf{P}^{*}$ & MEDIANA & DP & $\mathbf{P}^{*}$ \\
\hline \multirow{2}{*}{ IL-1 } & FOLICULAR & 45 & 11,02 & 27,04 & \multirow{2}{*}{0,62} & 1,72 & 2,04 & \multirow{2}{*}{0,43} \\
\hline & LÚTEA & 12 & 12,13 & 7,75 & & 2,17 & 7,50 & \\
\hline \multirow{2}{*}{ IL-6 } & FOLICULAR & 45 & 6,90 & 49,86 & \multirow{2}{*}{0,69} & 3,75 & 1,69 & \multirow{2}{*}{0,29} \\
\hline & LÚTEA & 12 & 5,55 & 8,93 & & 3,00 & 1,69 & \\
\hline \multirow{2}{*}{ SAA } & FOLICULAR & 45 & 314,30 & 94,36 & \multirow{2}{*}{0,33} & 14,74 & 34,89 & \multirow{2}{*}{0,57} \\
\hline & LÚTEA & 12 & 278,00 & 124,90 & & 12,57 & 12,45 & \\
\hline
\end{tabular}


Tabela 5 - Concentrações dos marcadores no líquido peritoneal e no sangue segundo a diferenciação histológica das lesões endometrióticas

\begin{tabular}{|c|c|c|c|c|c|c|c|}
\hline \multirow[b]{2}{*}{ MEDIADORES } & \multirow[b]{2}{*}{$\begin{array}{c}\text { DIFERENCIAÇÃO } \\
\text { HISTOLÓGICA }\end{array}$} & \multicolumn{3}{|c|}{ LÍQUIDO PERITONEAL } & \multicolumn{3}{|c|}{ SANGUE } \\
\hline & & MEDIANA & DP & $\mathbf{P}^{*}$ & MEDIANA & DP & $\mathbf{P}^{*}$ \\
\hline \multirow{2}{*}{ IL-1 } & $B D E / O U E^{\&}$ & 11,62 & 36,81 & \multirow{2}{*}{0,56} & 1,94 & 3,26 & \multirow{2}{*}{0,82} \\
\hline & I E/OU $M^{\#}$ & 11,12 & 9,00 & & 1,83 & 4,08 & \\
\hline \multirow{2}{*}{ IL-6 } & $B D E / O U E^{\&}$ & 5,40 & 49,11 & \multirow{2}{*}{0,27} & 3,40 & 1,72 & \multirow{2}{*}{0,26} \\
\hline & I E/OU $M^{\#}$ & 7,25 & 44,53 & & 3,85 & 1,69 & \\
\hline \multirow{2}{*}{ SAA } & $B D E / O U E^{\&}$ & 314,30 & 91,11 & \multirow{2}{*}{0,24} & 14,01 & 13,72 & \multirow{2}{*}{0,89} \\
\hline & I E/OU $M^{\#}$ & 296,80 & 101,70 & & 24,01 & 42,90 & \\
\hline
\end{tabular}

$\approx$ diferenciados BD: Bem diferenciada; E:Estromal,

\# indiferenciados I:Indiferenciada, M:Mista

* teste de Mann-Whitney 


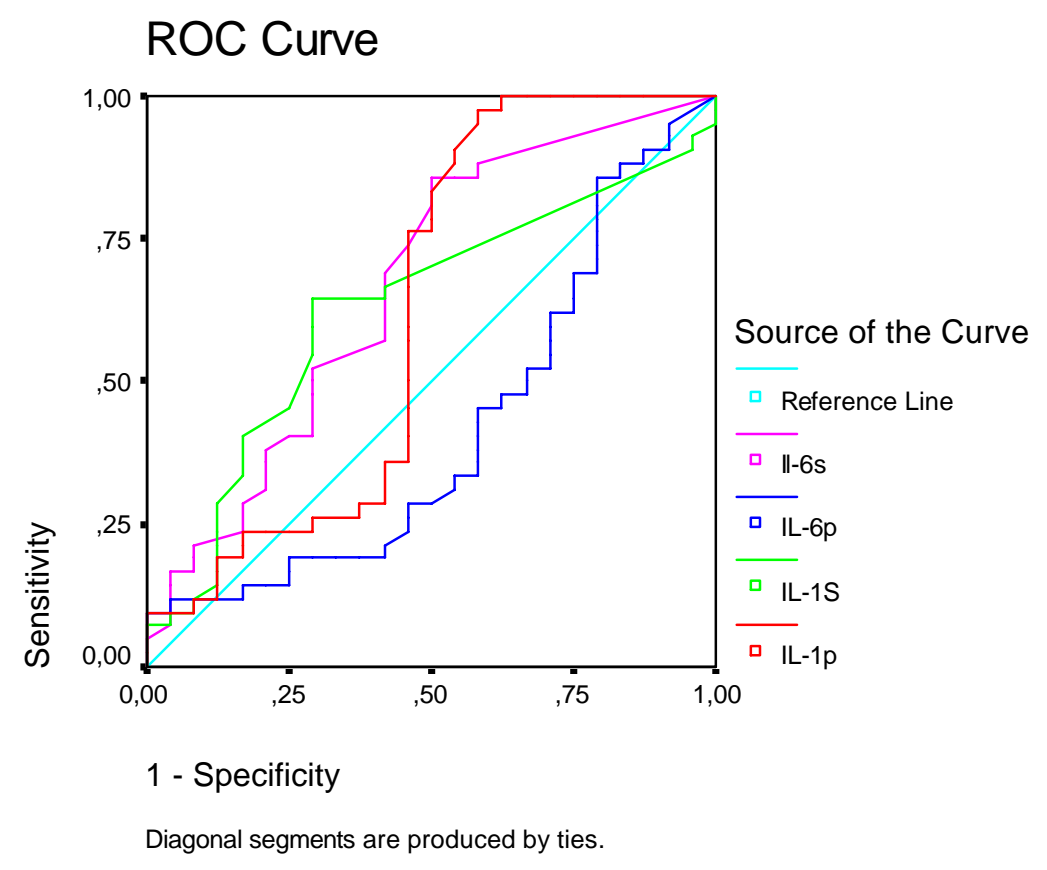

Figura 1 - Curva ROC com a sensibilidade e especificidade das diferentes concentrações séricas e peritoneais dos mediadores IL-1 e IL-6 no diagnóstico da endometriose 